WSRC-TR-91-617

\title{
Scoping Heat Transfer Analysis of a Completely-Blocked Type-Q Septifoil (U)
}

\author{
G. P. Flach
}

December 1991

Hyi: 11414

Westinghouse Savannah River Company Savannah River Laboratory Aiken, SC 29808

Prepared for the U.S. D partment of Energy under Contract DE-AC09-8\$SR 18035 


\section{DISCLAIMER}

This report was prepared by Westinghouse Savannah River Company (WSRC) for the United States Department of Energy under Contract No. DE-AC09-89SR 18035 and is an account of work performed under that contract. Neither the United States Department of Energy, nor WSRC, nor any of their employees makes any warranty, expressed or implied, or assumes any legal liability or responsibility for accuracy, completeness, or usefulness, of any information, apparatus, or product or process disclosed herein or represents that its use will not infringe privately owned rights. Reference herein to any specific commercial product, process, or service by trademark, name, manufacturer or otherwise does not necessarily constitute or imply endorsement, recommendation, or favoring of same by WSRC or by the United States Government or any agency thereof. The views and opinions of the authors expressed herein do not necessarily state or reflect those of the United States Government or any agency thereof. 
NRTSC

NUCLEAR REACTOR TECHNOLOGY

AND SCIENTIFIC COMPUTATIONS

KEYWORDS: SEPTIFOILS

SAFETY

ANALYSIS

BLOCKAGE

RETENTION: PERMANENT

\section{Scoping Heat Transfer Analysis of a Completely-Blocked Type-Q Septifoil (U)}

by

G. P. Flach

ISSUED: December 1991

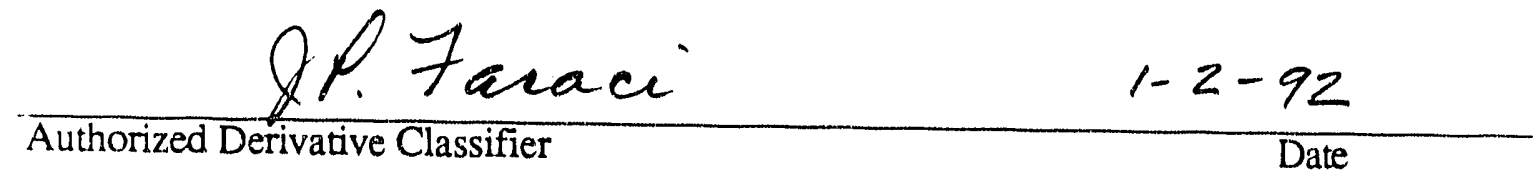

Westinghouse Savannah River Company

Savannah River Laboratory

Aiken, SC 29808 
PROJECT: 91-061-1

DOCUMENT: WSRC-TR-91-617 TITLE: Scoping Heat Transfer Analysis of a Completely-Blocked Type-Q Septifoil (U)
REVISION NUMBER: 0

T.K. Janaen / INEL 1219191

T. K. LARSON, TECHNICAL REVIEWER DATE

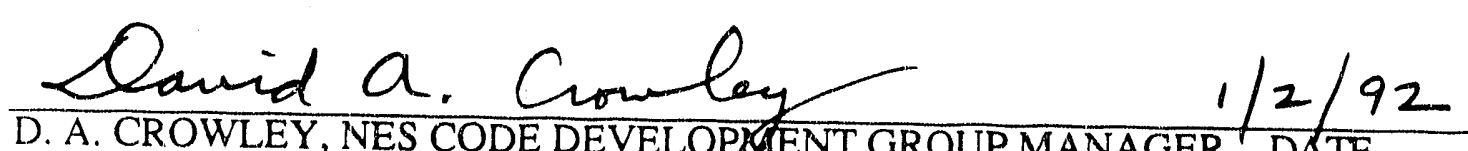
D. A. CROWLEY, NES CODE DEVELOP\&IENT GROUP MANAGER DATE

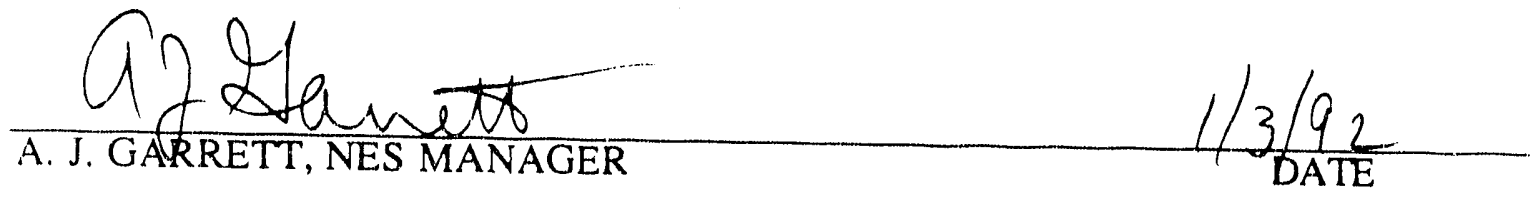




\section{Table of Contents}

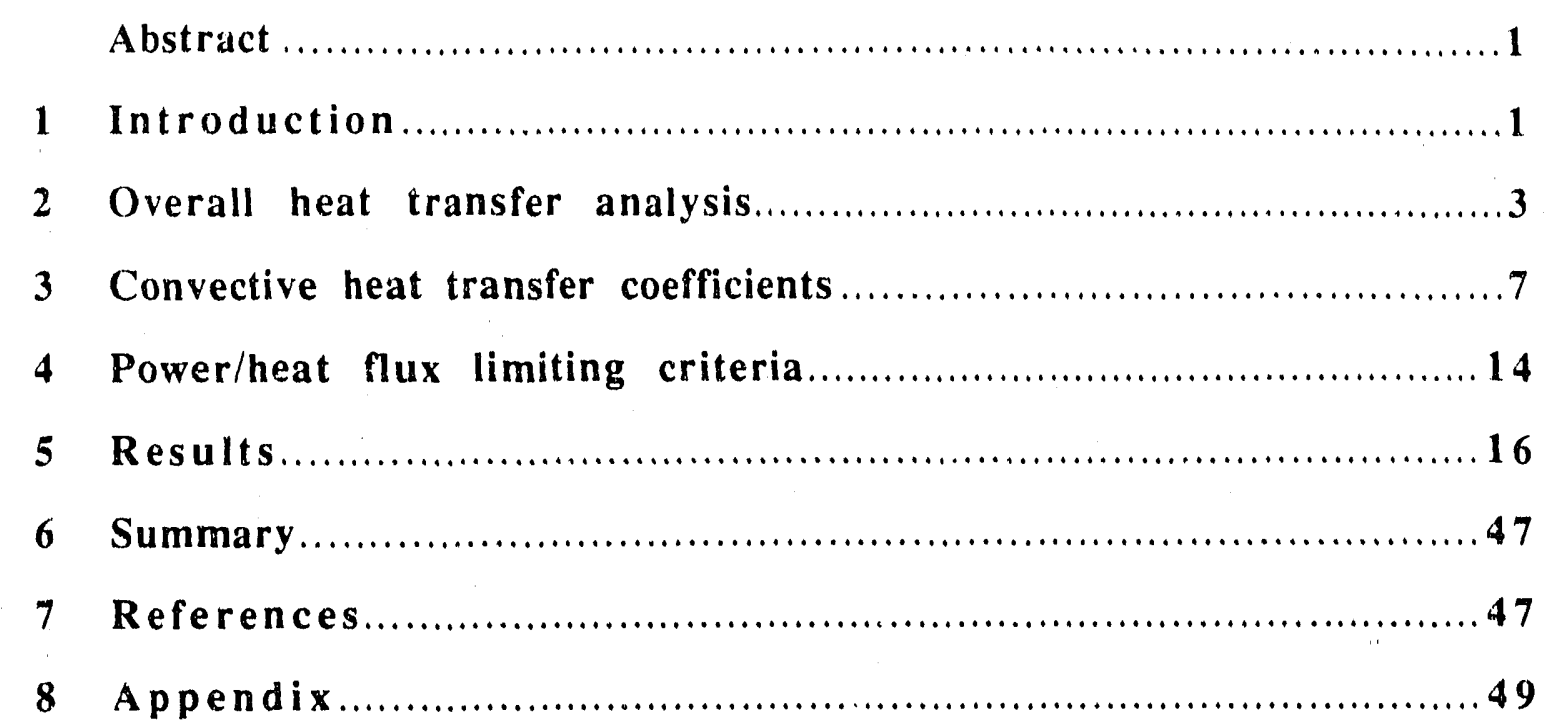




\begin{abstract}
Heat removal mechanisms for a completely-blocked Type-Q (new design) septifoil situated in an otherwise normally operating $\mathrm{K}$-reactor are investigated in this report. The bestestimate maximum septifoil heat generation rate for a $26.2{ }^{\circ} \mathrm{C}$ cooling water inlet temperature is 119 to $141 \mathrm{~kW}$ depending on the counter-current flow limitation correlation chosen. The corresponding reactor powers are 648 and $768 \mathrm{MW}$ or 27 and $32 \%$ of 2400 MW (historical annual averaged full power). These estimates are based on a steady-state scoping analysis and have a large uncertainty.
\end{abstract}

\title{
1 Introduction
}

The newly designed Type-Q septifoil is scheduled to be in $\mathrm{K}$-Reactor when restarted. The Type-Q septifoil housing has 12 slots and holes at the poison plate level in contrast to the preceding Type-J housing which has perforations over the entire length (Drwg. ST-MDX5-10072). The new design is intended to enhance septifoil cooling under drained tank conditions. The Type-J septifoil subjected to a complete inlet flow (bottom) blockage in a full reactor tank can dissipate control rod heat generation relatively effectively through natural circulation cooling iy the moderator. The Type- $Q$ septifoil precludes natural circulation since the housing is perforated only at the top. This report examines the heat removal mechanisms which are available for cooling a Type-Q septifoil in the event of a complete inlet flow blockage and provides estimates of maximum septifoil heat generation rate.

Figure 1 is an approximate full-scale drawing of a septifoil cross-section. Five rods are shown in place since this is the maximum number which can be present under normal reactor operation. Some rods are full length; the remainder are partial length rods. The web separating the seven subchannels is slotted over its entire length such that roughly half the surface area separating subchannels is open. Figure 2 is a schematic longitudinal view of a Type-Q septifoil in the vicinity of a peripheral contro: rod and adjacent housing. The control rod actuator system above the reactor plenum contains an approximately $16^{\prime}$ long guide tube for each septifoil which guides the actuator gripping mechanism onto the control rod tips. Some of the control rods are drawn up into the guide tube during reactor operation. Hydraulically, the guide tube serves as a standpipe vented to the atmosphere at the top extending several feet above the septifoil housing slots/holes.

Since the slots/holes at the top of the housing are below the liquid level in the tank, liquid boiled off within the housing can be replaced with liquid entering through the slots/holes. Therefore some control rod power can be dissipated through boiling within the housing. The power is directly proportional to the liquid flowrate incoming through the housing slots/holes and draining down the interior of the septifoil. The liquid flowrate is limited by the interfacial shear exerted on the liquid by the rising vapor counter-current flow. This phenomenon is known as a counter-current flow limitation (CCFL). Vapor may escape out the top of the septifoil through the standpipe and/or through the housing slots/holes. Most of vapor will probably escape out the standpipe. Nevertheless, it is prudent to consider the case of all vapor leaving through the slots/holes. In this case, the CCFL may occur below the slots/holes within the septifoil cross-section or at the slots/holes depending on which geometry is more limiting. The septifoil cross-sectional area with 5 rods in place is $0.00278 \mathrm{~m}^{2}$ and the slot/hole area is $0.00396 \mathrm{~m}^{2}$. 
Additional energy can be dissipated from the hot internal fluid (single-phase liquid or steam and liquid) directly through the housing to the colder moderator (full tank). The difference between rod generation and losses to the moderator gives the energy available to vaporize liquid.

Provided the critical heat flux (CHF) is not exceeded anywhere locally, the maximum heat removal capability is the sum of the energies dissipated through boiling at the CCFL condition and convective heat transfer through the housing. Otherwise, the maximum heat removal is limited by critical heat flux. Whether the heat generation rate is limited by CCFL or $\mathrm{CHF}$, the rod temperatures are expected to be sufficiently low (pre-CHF temperatures) that radiation is not an important heat removal mechanism.

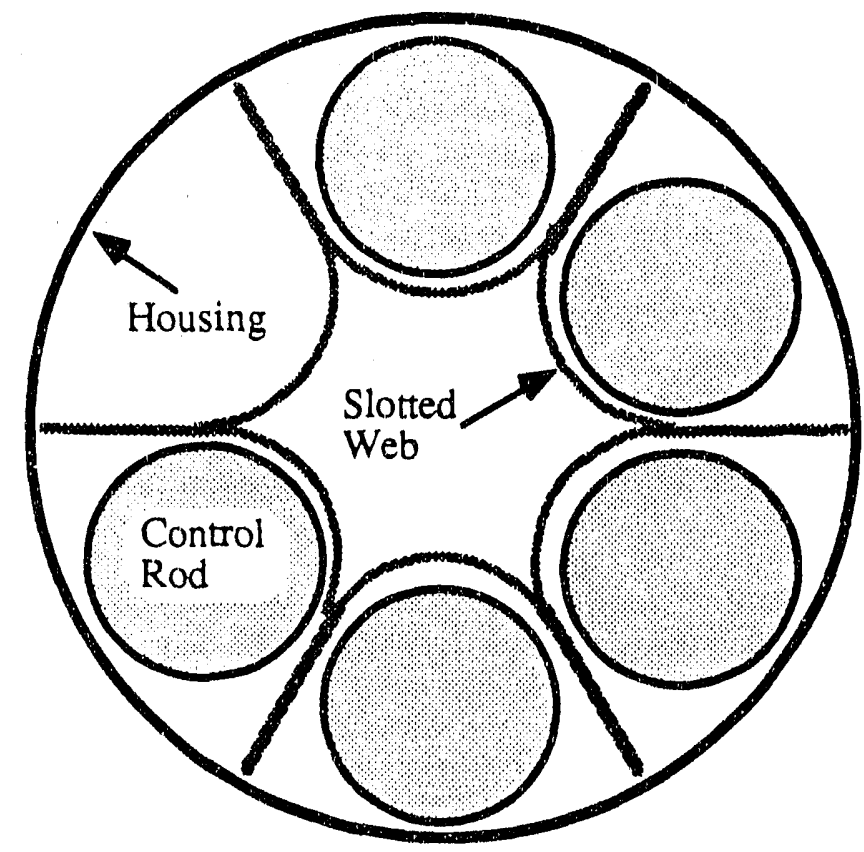

Figure 1 Full-scale cross-sectional view of septifoil (approximately to scale). 


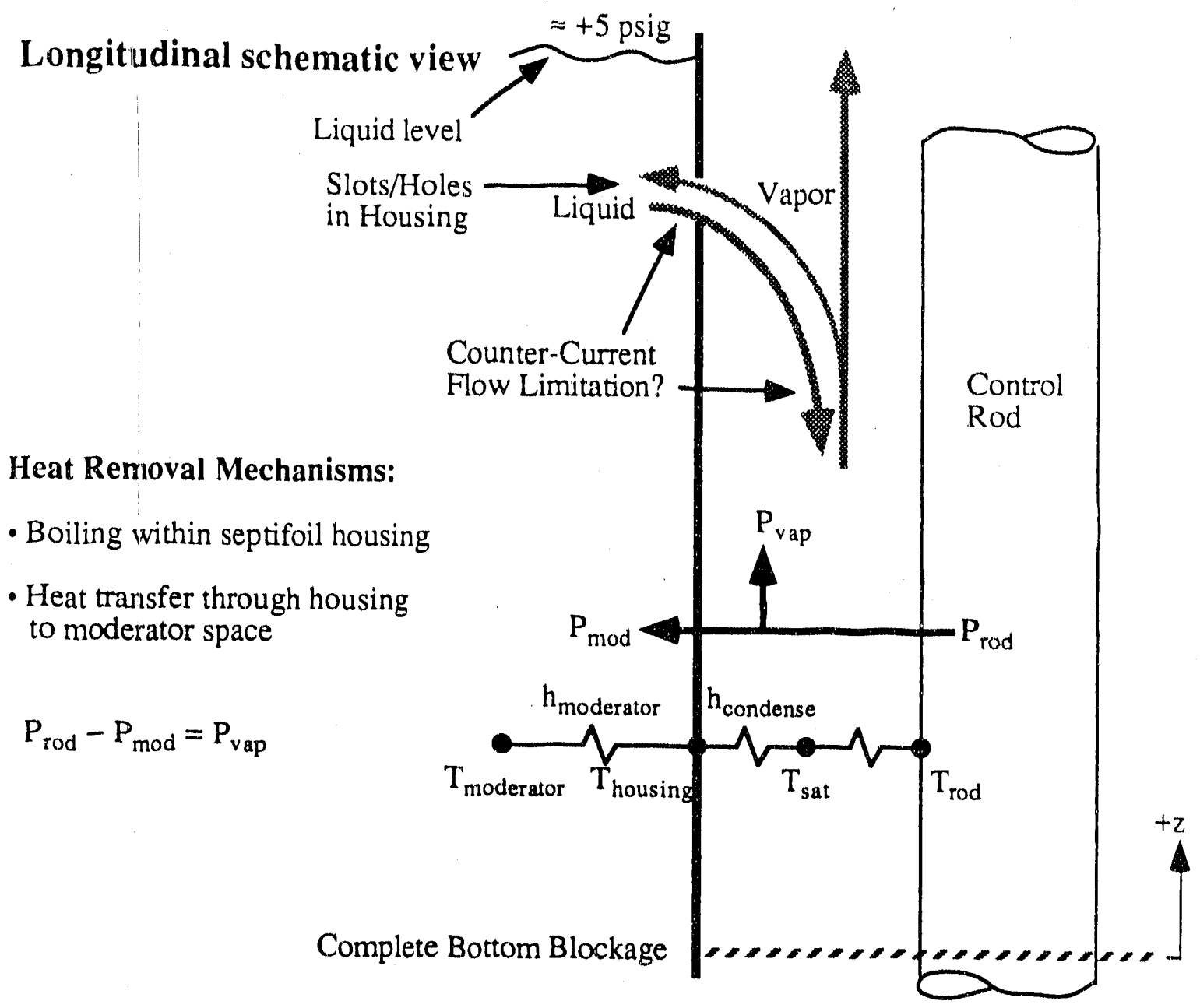

Figure 2 Schematic illustration of longitudinal geometry and heat removal mechanisms for a completely-blocked, type-Q septifoil.

\section{Overall heat transfer analysis}

Strong axial power shapes are possible in a septifoil due to the presence of partial length rods (Brown, 1991). A detailed axial heat transfer analysis is necessary to capture the correct heat transfer behavior of a blocked septifoil. Figure 3 illustrates the onedimensional computational mesh chosen for a steady-state analysis. The septifoil is divided into nz cells which are generally nonuniform although uniform length cells are shown in Figure 3. All state variables (temperature, void fraction, ...) are defined at the cell centers while superficial velocities are defined at the cell faces or junctions (staggered mesh approach).

Also shown in Figure 3 are the energy inputs to an individual cell. Because the septifoil bottom (face number 0 ) is completely blocked, the steady-state total mass flowrate across all cell faces is zero. That is, there can be no net mass transfer into a cell and the mass balance for face $\mathrm{j}$ is 


$$
\left(\rho_{\mathrm{g}} \mathrm{j}_{\mathrm{g}}\right)_{\mathrm{j}}=\left(\rho_{\mathrm{f}} \mathrm{j}_{\mathrm{f}}\right)_{\mathrm{j}}
$$

where

$$
\begin{aligned}
\rho_{k} & \equiv \text { phasic density, } k=g \text { or } f \\
j_{g} & \equiv \text { magnitude of upward vapor superficial velocity } \\
j_{f} & \equiv \text { magnitude of downward liquid superficial velocity }
\end{aligned}
$$

The steady-state energy analysis for the jth cell is

$$
P_{\text {rod }, j}+\left(A_{c} \rho_{g} \hat{j}_{g} \hat{h}_{g s}\right)_{j-1}-\left(A_{c} \rho_{f} j_{j} \hat{h}_{f}\right)_{j-1}=P_{\text {mod }, j}+\left(A_{c} \rho_{g} j_{g} \hat{h}_{g s}\right)_{j}-\left(A_{c} \rho_{f j} \hat{h}_{f}\right)_{j}
$$

where

$$
\begin{aligned}
\mathrm{P}_{\text {rod }, \mathrm{j}} & \equiv \text { cumulative control rod power } \\
\mathrm{P}_{\text {mod, }} & \equiv \text { power loss to the moderator through the housing } \\
\hat{h}_{\mathrm{gs}} & \equiv \text { enthalpy of saturated steam at cell face } \\
\hat{h}_{\mathrm{f}} & \equiv \text { enthalpy of liquid at cell face }
\end{aligned}
$$

A cell face enthalpy is defined to be the upstream cell ceiter enthalpy (donored property). Constant saturation properties are assumed. Taking into account flow directions, the cell face properties become

$$
\begin{gathered}
\hat{h}_{g s, j}=h_{g s, j}=h_{g s} \\
\hat{h_{f, j}}=h_{f, j+1}=\left[h_{f s}-c_{p f s}\left(T_{s a t}-T_{f}\right)\right]_{j+1}=h_{f s}-c_{p f s}\left(T_{s a t}-T_{f, j+1}\right)
\end{gathered}
$$

where

$$
\begin{aligned}
& \mathrm{h}_{\mathrm{gs}} \equiv \text { saturated gas enthalpy (assumed constant) } \\
& \mathrm{h}_{\mathrm{fs}} \equiv \text { saturated liquid enthalpy (assumed constant) } \\
& \mathrm{c}_{\mathrm{pfs}} \equiv \text { specific heat capacity at saturation (assumed constant) }
\end{aligned}
$$

The moderator power loss is given in terms of 'he overall '.eat transfer coefficient, $U$, by

$$
P_{\text {mod,j }}=U_{j} A_{w, j}\left(T_{i, j}-\Gamma_{\text {mod }}\right)
$$

where $A_{w}$ is the septifoil housing surface area and $T_{\text {mod }}$ is the moderator temperature. Models for $U_{j}$ in terms of cell temperatures and flowrates are given below. The energy
balance given by equation (2) becomes 


$$
\begin{aligned}
P_{\text {rod, }, j}-U_{j} A_{w, j}\left(T_{f, j}-T_{\text {mod }}\right) & =\left(A_{c} \rho_{g} j_{g}\right)_{j} \quad\left[h_{f g}+c_{p f s}\left(T_{s a t}-T_{f, j+1}\right)\right] \\
& -\left(A_{c} \rho_{g} j_{g}\right)_{j-1}\left[h_{f g}+c_{p f s}\left(T_{s a t}-T_{f, j}\right)\right]
\end{aligned}
$$

The unknowns associated with equation (6), which is for the jth cell, are $\mathrm{j}_{\mathrm{g}, \mathrm{j}}$ and $\mathrm{T}_{\mathrm{r}, \mathrm{j}}$. Two solutions are possible corresponding to subcooled liquid and saturated gas-licquid within the jth cell, respectively:

1) set $j_{g, j}=0$ and solve for $T_{f, j}$

2) set $T_{f, j}=T_{\text {sat }}$ and solve for $j_{g, j}$

Solution 1) is the valid one if $T_{f, j} \leq T_{s a t}$ otherwise, solution 2) is valid and $j_{g, j}>0$. Solution 1) is given by

$$
T_{f, j}=\frac{P_{\text {rod, }, j}+U_{j} A_{w, j} T_{\text {mod }}+\left(A_{c} \rho_{g} j_{g}\right)_{j-1}\left(h_{f g}+c_{p f s} T_{s a t}\right)}{U_{j} A_{w, j}+\left(A_{c} \rho_{g} j_{g}\right)_{j-1} c_{p f s}}
$$

and solution 2) by

$$
j_{g, j}=\frac{P_{\text {rod }, j}-U_{j} A_{w, j}\left(T_{s a t}-T_{\text {mod }}\right)+\left(A_{c} \rho_{g} j_{g}\right)_{j-1} h_{f g}}{\left(A_{c} \rho_{g}\right)_{j}\left[h_{f g}+c_{p f s}\left(T_{s a t}-T_{f, j+1}\right)\right]}
$$

Equations (7-8) are solved iteratively using the Gauss-Seidel technique.

Cell rod power, $\mathrm{P}_{\mathrm{kod}, \mathrm{j}}, \mathrm{is}$ defined through specification of total septifoil power and the relative axial power shape. The overall heat transfer coefficient, $U$, is defined in terms of an internal heat transfer coefficient, $h_{\text {cond }}$, and an external coefficient, $h_{\text {mod }}$, by

$$
\mathrm{U}=\frac{1}{\frac{1}{\mathrm{~h}_{\text {cond }}}+\frac{1}{\mathrm{~h}_{\bmod }}}
$$

where resistance through the thin aluminum housing has been neglected. Models and correlations for $h_{c o n d}$ and $h_{\text {mod }}$ are given in the next section. The septifoil housing temperature $T_{w}$ is defined by

$$
h_{\text {cond }}\left(T_{f}-T_{w}\right)=h_{\text {mod }}\left(T_{w}-T_{\text {mod }}\right)
$$

The moderator temperature $T_{\text {mod }}$ is related to the septifoil power through total reactor power. Reactor power is related to septifoil power through the simple proportionality

$$
P_{\text {reactor }}=R_{\text {power }} P_{\text {septifoil }}
$$

where $\mathrm{R}_{\text {power }}$ is a constant. Knowing total reactor power and the cold side heat exchanger temperature, $T_{c}$, the moderator can be estimated from a heat exchanger analysis (Shadday, 1989). The result is 


$$
T_{\text {mod }}=T_{c}+\frac{P_{\text {reactor }}}{\varepsilon\left(\dot{m} c_{p}\right)_{c}}
$$

where

$$
\begin{aligned}
\varepsilon & \equiv \text { effectiveness } \\
\left(\mathrm{mc}_{\mathrm{p}}\right)_{\mathrm{c}} & \equiv \text { cold side heat capacity rate }
\end{aligned}
$$

The appropriate values for K-reactor are $\varepsilon=0.705 \pm 0.024$ and $\left(\mathrm{mc}_{\mathrm{p}}\right)_{\mathrm{c}}=44.11 \pm 0.24$
$\mathrm{MW} /{ }^{\circ} \mathrm{C}(1.96$ standard deviations or $95 \%$. moderator temperature may be estimated from confidence). Given the total septifoil power, moderator temperature may be estimated from equations (11) and (12).

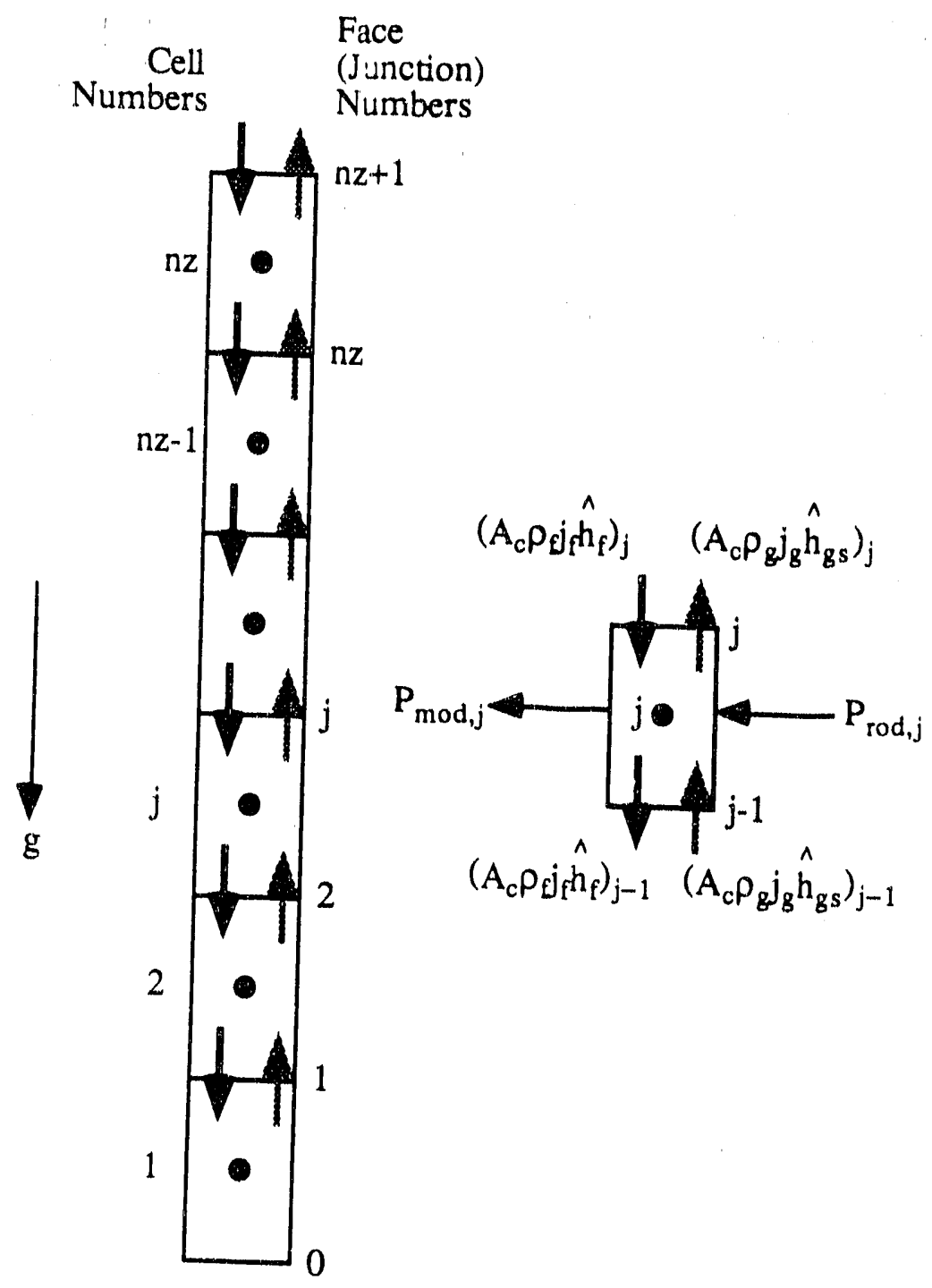

Figure 3 Computational mesh for steady-state heat transfer analysis. 


\section{Convective heat transfer coefficients}

As shown in Figure 2 the resistance to heat transfer through the septifoil housing is assumed to be negligible leaving internal and external convection coefficients to be estimated. The Mark-22 hydraulics manual DPSTM-22(H) states that the expected heat transfer coefficient between an USH and the moderator is $1050 \mathrm{BTU} / \mathrm{hr}-\mathrm{ft}^{2}{ }^{\circ} \mathrm{F}$ based on reactor operating experience (Boswell, 1974). A rigorous basis for this value is not given or referenced. Therefore, the external heat transfer coefficient will be estimated from handbook correlations/models. The external heat transfer process is assumed to be best modeled as single-phase forced convection through tube banks. Both longitudinal and cross flows are prese it in the tank moderator space and two corresponding correlations are presented in the following subsection for estimating the average extcrnal heat transfer coefficient.

The internal heat transfer process between the saturated gas-liquid mixture and the housing is assumed to occur typically at a zero net mixture mass flowrate comprised of a relatively small downward liquid mass flowrate balanced with an equal upward vapor mass flowrate. The appropriate heat transfer correlation for this flow situation is not clear. Since vigorous bulk boiling is occurring, engineering judgement suggests the internal heat transfer may be large relative to the external convection coefficient. In this case, the resistance is dominated by the external surface and the internal heat transfer coefficient could be assumed to be infinite without appreciable error. This assumption is clearly non-conservative so it is prudent to compute a finite internal heat transfer coefficient instead.

For lack of a better alternative, the internal heat transfer is assumed to be best modeled as a condensation process. The logic for this choice is as follows. When a pure vapor condenses onto a cold vertical surface, a liquid film forms and drains down the surface. Although thin, the condensate film provides a significant heat transfer resistance. Larger heat transfer coefficients are obtained if a significant vapor flow is present such that interfacial shear between the vapor and film is large. In the present blocked septifoil application, the vapor-liquid mixture at saturation temperature is presumably also separated from the relatively cold housing by a thin subcooled liquid layer. Assuming this layer is similar to those encountered in conventional condensing flows motivates estimating the heat transfer coefficient from conventional condensation correlations. Two such correlations are presented in the second subsection.

External heat transfer coefficient (forced flow through tube bank): Figure 4 illustrates the basic flow field in the tank under normal operating conditions. While these data are not for the exact K-Reactor restart charge and are not qualified, they are sufficient for providing qualitative understanding and rough velocity estimates. Observe that individual septifoils may experience a variety of flow patterns from longitudinal flow to crossflow. Of the flow fields for which heat transfer correlations are readily available, flow through tule banks most closely resembles the actual tank flow patterns. Correlations for longitudinal and cross flow through a triangular array of equal-sized tubes are presented below. For the purpose of evaluating these correlations, the USH diameter is chosen as shown in Figure 5 since the majority of the tubes in the reactor tank are USH's.

A series of correlations for crossflow in staggered tube bundles is given in the Handbook of Single-Phase Convective Heat Transfer (Kakac et al., 1987, Chap. 6) as 


$$
\begin{aligned}
& \mathrm{Nu}=1.04 \operatorname{Re}^{0.4} \operatorname{Pr}^{0.36}\left(\operatorname{Pr} / \operatorname{Pr}_{w}\right)^{0.25} \quad 1<\operatorname{Re}<5 \times 10^{2} \\
& \mathrm{Nu}=0.71 \operatorname{Re}^{0.5} \operatorname{Pr}^{0.36}\left(\operatorname{Pr} / \operatorname{Pr}_{w}\right)^{0.25} \quad 5 \times 10^{2}<\operatorname{Re}<10^{3} \\
& \mathrm{Nu}=0.35\left(\mathrm{X}_{\mathrm{t}}^{*} / \mathrm{X}_{l}^{*}\right)^{0.2} \operatorname{Re}^{0.6} \operatorname{Pr}^{0.36}\left(\operatorname{Pr} / \operatorname{Pr}_{\mathrm{w}}\right)^{0.25} \quad 10^{3}<\operatorname{Re}<2 \times 10^{5} \\
& \mathrm{Nu}=0.031\left(\mathrm{X}_{\mathrm{t}}^{*} / \mathrm{X}_{l}^{*}\right)^{0.2} \operatorname{Re}^{0.8} \operatorname{Pr}^{0.36}\left(\operatorname{Pr}_{\mathrm{Pr}} \mathrm{Pr}_{\mathrm{w}}\right)^{0.25} \quad 2 \times 10^{5}<\operatorname{Re}<2 \times 10^{6}
\end{aligned}
$$

where

$$
\begin{aligned}
\mathrm{Nu} & \equiv \text { Nusselt number based on tube diameter, } h \mathrm{D} / \mathrm{k} \\
\mathrm{Re} & \equiv \text { Reynolds number based on tube diameter, } \rho \mathrm{uD} / \mu \\
\mathrm{Pr} & \equiv \text { Prandtl number } \\
\mathrm{Pr}_{\mathrm{w}} & \equiv \text { Prandtl number based on properties cvaluated at wall temperature } \\
\mathrm{X}_{\mathrm{t}}^{*} & \equiv \text { nondimensional transverse distance, } \mathrm{X}_{\sqrt{\mathrm{D}}} \\
\mathrm{X}_{l}^{*} & \equiv \text { nondimensional longitudinal distance, } \mathrm{X}_{/} / \mathrm{D}
\end{aligned}
$$

All properties are evaluated at the bulk fluid temperature except $\mathrm{Pr}_{\mathrm{w}}$.

For longitudinal flow through a triangular-array tube bundle the Handbook of Single-Phase Convective Heat Transfer (Kakac et al., 1987, Chap. 7) indicates the data can be mainly fit with the following circular tube correlation

$$
\mathrm{Nu}_{\mathrm{t}}=\frac{\mathrm{f} / 2 \operatorname{Re} \operatorname{Pr}}{\mathrm{h}_{1}+12.7(\mathrm{f} / 2)^{1 / 2}\left(\operatorname{Pr}^{2 / 3}-1\right)}
$$

where

$$
\begin{aligned}
& h_{1}=1.07+\frac{900}{\operatorname{Re}}-\frac{0.63}{1+10 \mathrm{Pr}} \\
& f=\left(3.64 \log _{10} \operatorname{Re}-3.28\right)^{-2}
\end{aligned}
$$

and the Nusselt and Reynolds numbers are based on the infinite triangular-array hydraulic
diameter defined by

$$
\frac{D_{h, \infty}}{D}=\frac{2 \sqrt{3}}{\pi}\left(\frac{P}{D}\right)^{2}-1
$$

In the above expressions 


$$
\begin{aligned}
N u_{t} & \equiv \text { circular tube Nusselt number, } h_{t} D_{h, \infty} / k \\
R e & \equiv \text { circular tube Reynolds number, } \rho u D_{h, o d} / \mu \\
\operatorname{Pr} & \equiv \text { Prandtl number } \\
f & \equiv \text { friction factor of a circular pipe } \\
D & \equiv \text { tube diameter } \\
P & \equiv \text { pitch }
\end{aligned}
$$

All properties are evaluated at the film temperature. The circular tube correlation is valid for $4 \times 10^{3} \leq \operatorname{Re} \leq 6 \times 10^{5}$ and $0.7 \leq \operatorname{Pr} \leq 5 \times 10^{5}$. The pitch to diameter ratio from Figure 5 is 1.70. Figure 7.19 of the Handbook of Single-Phase Convective Heat Transfer indicates the Nusselt number data is 10 to $20 \%$ higher than the circular tube correlation for $P / D=$ 1.70. The Handbook presents an equivalent-annulus correction formula which largely captures the increase in Nu over the above circular tube correlation, but, a simple 1.15 multipli $v_{i}$ is sufficient considering the scatter in the data:

$$
\mathrm{Nu}=1.15 \mathrm{Nu}_{\mathrm{t}}
$$

In equation (18) both Nusselt numbers are defined in terms of the infinite triangular-array hydraulic diameter $\mathrm{D}_{\mathrm{h}, \infty}$.

Equations (13) or (18) cr a combination actually applies to individual septifoils depending on the core location. For simplicity, the average septifoil heat transfer coefficient is assumed to be the average of the longitudinal and cross flow values

$$
h_{\text {mod }}=\frac{1}{2}\left(h_{\text {long }}+h_{\text {cross }}\right)
$$

where

$$
\begin{aligned}
h_{\text {mod }} \equiv & \text { external heat transfer coefficient between septifoil housing and moderator } \\
h_{\text {long }} \equiv & \text { heat transfer coefficient based on longitudinal flow through a tube bundle } \\
& \text { defined by equation (18) }
\end{aligned}
$$

Table I lists values of $h_{\text {long }}$ and $h_{\text {cross }}$ for the approximate fluid and wall temperatures expected for the present application and various fluid velocities. For the same velocity the cross flow correlation yields a significantly larger value than the longitudinal correlation. However, Figure 4 indicates the average cross flow velocities are lower than the longitudinal velocities so roughly the same heat transfer coefficient is expected throughout the reactor core. The model given by equation (19) and accompanying relations yields a moderator heat transfer coefficient of about $4100 \mathrm{~W} / \mathrm{m}^{2}{ }^{\circ} \mathrm{C}$ or $725 \mathrm{BTU} / \mathrm{hr}-\mathrm{ft}^{2}{ }^{\circ}{ }^{\circ} \mathrm{F}$ for the case subsequently considered in the Results section. This is significantly lower than the $1050 \mathrm{BTU} / \mathrm{hr}-\mathrm{ft}^{2}{ }^{\circ} \mathrm{F}$ value given in the Mark 22 hydraulics manual (DPSTM-22(H)). The reason for the discrepancy is unknown. 
This observation at least suggests that the calculated moderator heat transfer coefficient is conservative. Incidently, while the moderator heat transfer coefficient is critical to this analysis, it typically need not be precisely known. Under normal reactor operating conditions for example, heat transfer to/from the materator space is only about $1 \%$ the size of the assembly heat generation. Forced convection cooling within the assembly is a two orders of magnitude larger effect. This probably explains the lack of emphasis on moderator heat transfer coefficient in the Mark-22 hydraulics manual (Boswell, 1974).

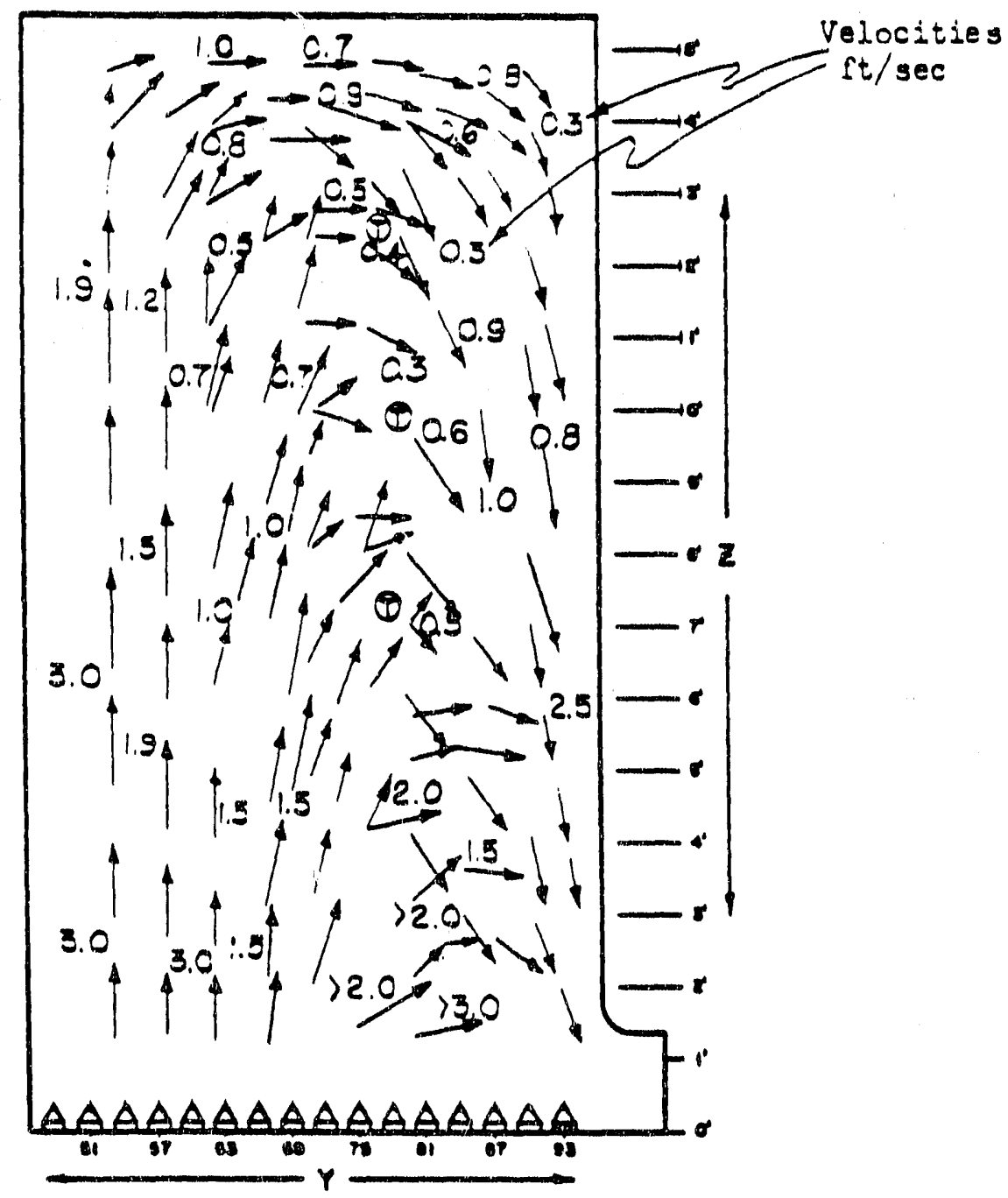

Figure 4 Basic flow pattern in reactor tank moderator space (Carleton, 1959, Figure 7). 


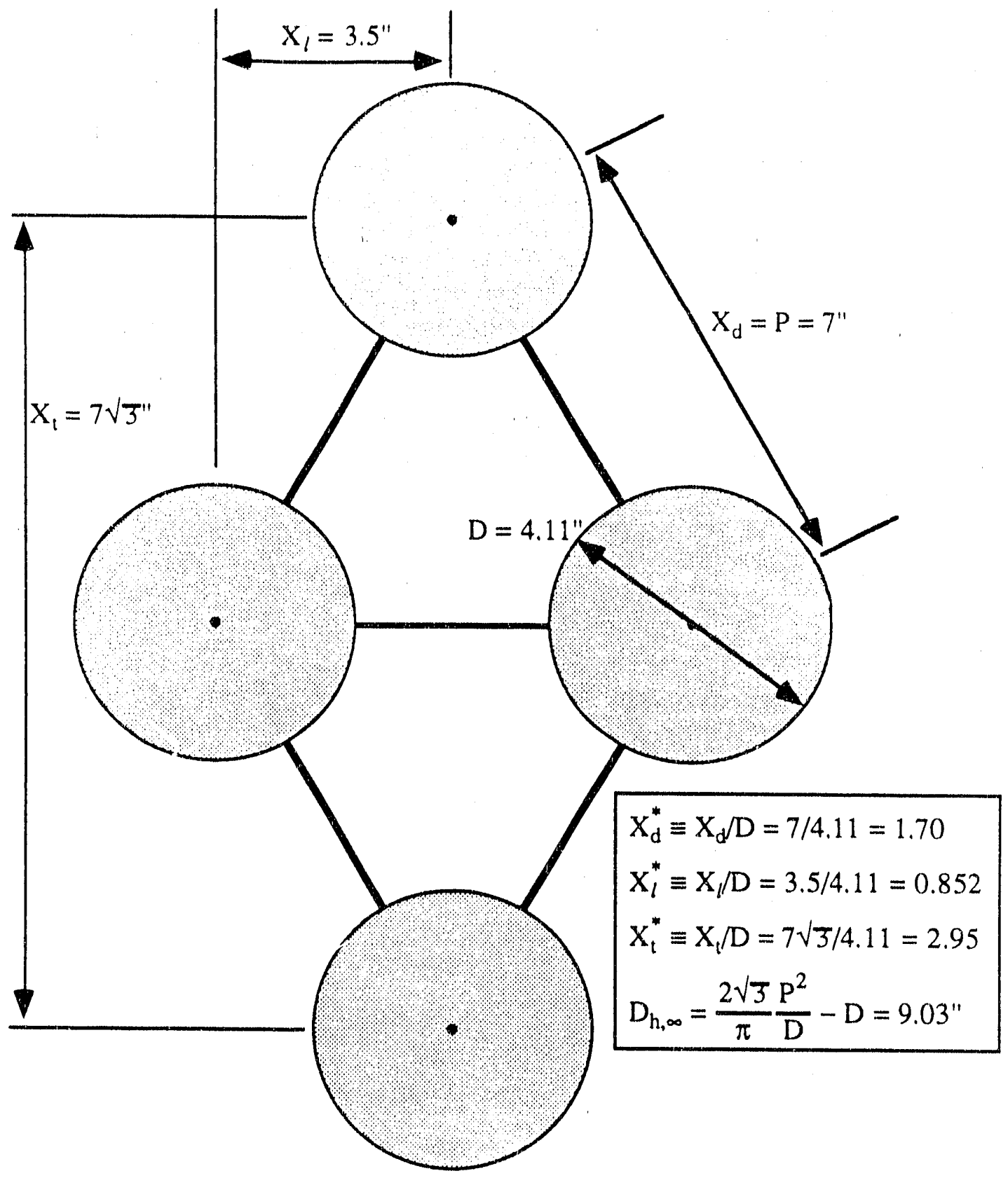

Figure 5 Assumed tube bundle geometry for moderator heat transfer coefficient correlations. 
Table I Comparison of longitudinal and cross flow heat transfer correlations $\mathrm{D} 2 \mathrm{O}, \mathrm{T}_{\text {mod }}=50^{\circ} \mathrm{C}, \mathrm{T}_{\text {wall }}=\mathrm{T}_{\text {sal }} @ 1 \mathrm{~atm}+5 \mathrm{psig}=110^{\circ} \mathrm{C}$.

\begin{tabular}{|c|c|c|c|}
\cline { 2 - 4 } & $\begin{array}{c}\mathbf{u}_{\operatorname{long}} \\
(\mathrm{m} / \mathrm{s})\end{array}$ & $\begin{array}{c}\mathbf{u}_{\text {cross }} \\
(\mathrm{W} / \mathrm{s})\end{array}$ & $\begin{array}{c}\mathbf{h}_{\operatorname{cross}} \\
\left(\mathrm{W} / \mathrm{m}^{2}-\mathrm{C}\right)\end{array}$ \\
\hline 0.25 & 1588 & 0.25 & 3401 \\
\hline 0.50 & 2846 & 0.50 & 5155 \\
\hline 0.75 & 4014 & 0.75 & 6575 \\
\hline 1.00 & 5128 & 1.00 & 7813 \\
\hline
\end{tabular}

Internal heat transfer coefficient (condensation): The Nusselt equation for the average heat transfer coefficient of a laminar condensate film draining down a vertical plate is (Collier, 1972, pp. 314-317)

$$
h_{\text {cond }, 1}=0.943\left[\frac{\rho_{\mathrm{f}} \Delta \rho \mathrm{gh}_{\mathrm{fg}} \mathrm{k}_{\mathrm{f}}^{3}}{\mu_{\mathrm{f}} \mathrm{L}\left(\mathrm{T}_{\text {sat }}-\mathrm{T}_{\mathrm{w}}\right)}\right]^{1 / 4}
$$

where

$$
\begin{aligned}
h_{\text {cond, } 1} & \equiv \text { average heat transfer coefficient } \\
\rho_{\mathrm{f}} & \equiv \text { liquid density } \\
\Delta \rho & \equiv \text { density difference, } \rho_{\mathrm{f}}-\rho_{\mathrm{g}} \\
\mathrm{h}_{\mathrm{fg}} & \equiv \text { latent heat of vaporization } \\
\mathrm{k}_{\mathrm{f}} & \equiv \text { liquid thermal conductivity } \\
\mu_{\mathrm{f}} & \equiv \text { liquid viscosity } \\
\mathrm{T}_{\mathrm{sat}} & \equiv \text { saturation temperature } \\
\mathrm{T}_{\mathrm{w}} & \equiv \text { wall temperature } \\
\mathrm{L} & \equiv \text { vertical length of condensing surface }
\end{aligned}
$$

Properties are evaluated at saturation conditions. The choice of $\mathrm{L}$ is not clear for the present application but since it appears to the $1 / 4$ power in equation (20) the heat transfer coefficient is not very sensitive to $\mathrm{L}$. The septifoil length is chosen for $\mathrm{L}$ for lack of a better choice. Equation (20) was developed assuming wall shear balances with the gravitational force.

If the vapor flowrate is high enough, interfacial shear (neglected above) dominates over gravitational and momentum terms. Carpenter and Colburn developed the following model for condensation in a tube with large interfacial shear (Collier, 1972, pp. 323-325): 


$$
h_{\text {corid }, 2}=0.065 \frac{k_{f}}{\mu_{f}}\left(\rho_{f} \operatorname{Pr}_{f} \tau_{i}\right)^{1 / 2}
$$

Here

$$
\begin{aligned}
h_{\text {cond }, 2} & \equiv \text { average heat transfer coefficient } \\
k_{f} & \equiv \text { liquid thermal conductivity } \\
\mu_{f} & \equiv \text { liquid viscosity } \\
\rho_{f} & \equiv \text { liquid density } \\
\operatorname{Pr}_{\mathrm{f}} & \equiv \text { liquid Prandtl number } \\
\tau_{\mathrm{i}} & \equiv \text { interfacial shear stress }
\end{aligned}
$$

The interfacial shear stress is modeled as

$$
\tau_{i}=f_{i}\left[\frac{\rho_{g} j_{g}^{2}}{2}\right]
$$

where

$$
\begin{aligned}
f_{i} & \equiv \text { interfacial friction factor } \\
\rho_{g} & \equiv \text { gas density } \\
j_{g} & \equiv \text { gas superficial velocity }
\end{aligned}
$$

For annular flow the interfacial friction factor can be estimated from (Collier, 1972, p. 78)

$$
f_{i}=f_{g}[1+75(1-\alpha)]
$$

where $f_{g}$ is the single-phase wall friction factor which can be estimated from the Blasius expression

$$
f_{g}=0.079 \operatorname{Re}_{g}^{-1 / 4}
$$

The various symbols in equations (23) and (24) are defined as

$$
\alpha \equiv \text { void fraction (gas volume fraction) }
$$

$R e_{\mathrm{g}} \equiv$ gas-phase Reynolds number based on superficial velocity, $\rho_{\mathrm{g}} \mathrm{j}_{\mathrm{g}} \mathrm{D}_{\mathrm{h}} / \mu_{\mathrm{g}}$

Equation (23) is valid within the approximate range of $0.75<\alpha<1$ (annular flow regime). For void fractions less than about 0.75 a dispus su regime is expected. The interfacial shear in a dispersed regime (bubbly, slug, churn-turbulent, ...) is typically much larger than that of separated (annular) flow. A conser ative and convenient modification of equation (23) is 


$$
\mathrm{f}_{\mathrm{i}}=\mathrm{f}_{\mathrm{g}}\{1+75[1-\max (0.75, \alpha)]\}
$$

and will be used in place of equation (23).

Equations (20) and (21) are valid for low and high vapor flowrates, respectively. As is done in RELAP5, equation (20) is treated as a lower bound (Ransom et al., 1985, p. 114) and the final condensation heat transfer coefficient is chosen as the maximum of these correlations:

$$
h_{\text {cond }}=\max \left(h_{\text {cond, },}, h_{\text {cond }, 2}\right)
$$

\section{Power/heat flux limiting criteria}

Two phenomena are candidates for limiting the septifoil power. The control rods are assumed to receive insufficient cooling if the local critical heat flux is exceeded on any surface. Secondly, septifoil power is restricted by the counter-current flow limit which must not be exceeded locally in the coolant channel between the rods and housing. Specific criteria for these phenomena are discussed below.

Critical heat flux: Based on an analysis of Taylor and Kevin-Helmholtz instabilities associated with vapor escaping from a heated surface, Zuber (1959) (Lienhard, 1988) derived the following critical heat flux expression for an upward-facing, horizontal surface freely communicating with a pool of saturated liquid:

$$
q_{\text {Zuber }}^{\prime \prime}=0.13 \rho_{g} h_{f g}\left(\frac{\sigma g \Delta \rho}{\rho_{g}^{2}}\right)^{1 / 4}
$$

Various other values for the leading coefficient have been proposed by others to better reflect the data, including 0.16 and 0.18 (Rohsenow et al., 1985). For vertical surfaces, Lienhard and Dhir observed about a $15 \%$ reduction in the maximum heat flux given by equation (27) which was geometry insensitive (Lahey et al., 1977; Lienhard et al., 1972):

$$
\frac{\mathrm{q}_{\mathrm{CHF}}^{\prime \prime}}{\mathrm{q}_{\text {Zuber }}^{\prime \prime}}=0.85
$$

The critical heat flux is significantly reduced when a heated surface is in contact with a pool having a significant bulk void fraction. Griffith proposed the following simple approximation to the data (Griffith et al., 1977; Lahey et al., 1977; Walkush et al, 1975)

$$
\frac{q_{C H F}^{\prime \prime}}{q_{\text {Zuber }}^{\prime \prime}}=(1-\alpha)
$$

where void fraction is defined to be the fraction of channel volume occupied by gas: 


$$
\alpha=\frac{V_{g}}{V_{g}+V_{f}}
$$

Note that for solid liquid $(\alpha=0)$, correlation (29) does not reduce to equation (28). The data can be correlated more precisely, incorporating equation (28) as a limit, but the exercise is unwarranted since $\mathrm{CHF}$ is not expected to be the limiting phenomenon. A CHF limit is not anticipated because the system is under low pressure (large volumetric vapor generation) and the channel dimensions are small; these conditions suggest CCFL will be reached before CHF, Consequently, equation (29) is taken as an upper limit on the locial heat flux allowed on iny heated surface.

In order to make use of equation (29) the local void fraction $\alpha(z)$ is needed. Since both the gas and liquid superficial velocities are available from the preceding mass and energy balances, a drift-flux model can be used to estimate $\alpha$. The model is (Zuber and Findlay, 1965)

$$
u_{g}=C_{0 j}+u_{g j}
$$

where

$$
\begin{aligned}
u_{g} & \equiv \text { gas phasic velocity } \\
j & \equiv \text { mixture superficial velocity, } \mathrm{j}_{\mathrm{g}}+\mathrm{j}_{\mathrm{f}} \\
\mathrm{C}_{0} & \equiv \text { distribution coefficient } \\
\mathrm{u}_{\mathrm{gj}} & \equiv \text { drift velocity }
\end{aligned}
$$

and $j_{k}, k=g$ or $f$, represents the magnitude of the superficial velocity as in the previous section. Solving equation (31) for void fraction yields

$$
\alpha(z)=\frac{j_{g}(z)}{C_{0 j_{g}}(z)\left(1-\frac{\rho_{g}}{\rho_{f}}\right)+u_{g j}}
$$

For bubbly/churn-turbulent flow in vertical tubes, Ishii (1977) proposed the following expressions for the drift-flux parameters $C_{0}$ and $u_{\mathrm{gj}}$ :

$$
\begin{gathered}
C_{0}=1.2-0.2\left(\frac{\rho_{g}}{\rho_{f}}\right)^{1 / 2} \\
u_{g j}=\sqrt{2}\left(\frac{\sigma g \Delta \rho}{\rho_{f}^{2}}\right)^{1 / 4}
\end{gathered}
$$

Equivalent expressions for annular flow will yield higher drift velocities than those from equation (34). Holding superficial gas velocity constant, inspection of equation (32) indicates a lower void fraction is obtained with a higher drift velocity. Equation (34) can therefore be used regardless of flow regime to obtain a conservative critical heat flux 
estimate from equation (32). This conservative approach is taken again in anticipation that critical heat flux will not be the limiting phenomenon.

Counter-current flow limitation: The counter-current flow limit (CCFL) is usually estimated from an empirical data correlation. For small pipes, the following Wallis form has proved successful (Whalley, 1987, Chap. 11)

$$
\left|j_{g}^{*}\right| 1 / 2+m\left|j_{f}^{*}\right| 1 / 2=C
$$

where

$$
j_{k}^{*} \equiv j_{k}\left(\frac{\rho_{k}}{\Delta \rho g D_{c}}\right)^{1 / 2}
$$

and

$$
\begin{aligned}
j_{k} & \equiv \text { superficial velocity of } k \text {-phase } \\
\mathrm{m}, \mathrm{C} & \equiv \text { empirical constants } \\
\rho_{k} & \equiv \text { density of } k \text {-phase } \\
\Delta \rho & \equiv \text { density difference, } \rho_{\mathrm{f}}-\rho_{\mathrm{g}} \\
D_{c} & \equiv \text { characteristic dimension }
\end{aligned}
$$

The values of the CCFL parameters depend strongly on geometry. For a circular tube of diameter $\mathrm{D}, \mathrm{D}_{\mathrm{c}}=\mathrm{D}, \mathrm{m}=1$ and $\mathrm{C}$ is about 0.8 (Whalley, 1987, p. 110). These values are also frequently used as generic values for an arbitrary geometry. For an annular channel, Osakabe and Kawasaki (1989) suggest $D_{c}=\pi D_{a v g}, m=0.8$ and $C=0.38$. This latter correlation may be more appropriate for channels between the rods and web.

\section{Results}

The above steady-state heat transfer model has been implemented in the FOR'TRAN code listed in the Appendix. The worst rod configuration is assumed to be the one with the most rods in place, the highest septifoil to reactor power ratio, and the peak power generation near the top of the septifoil. From the available rod configurations given in Calc-Note SRL-SAG-91-9051, case \#8 appears to be the worst. Case \#8 is 3 full rods and 2 partial rods at $700 \mathrm{vu}$. Two sets of computed results are given corresponding to using the Wallis and Osakabe \& Kawasaki CCFL correlations, respectively, as the limiting CCFL criterion. The input information is the same for both cases except for septifoil total power. A detailed discussion of the input and computed results is given for the Wallis CCFL correlation case followed by a more brief discussion of the results using the Osakabe and Kawasaki correlation. Finally, two sensitivity runs with respect to the overall heat transfer coefficient are presented.

Results based on Wallis CCFL correlation: The first set of results is based on using the Wallis CCFL correlation with $\mathrm{C}=0.8$ as the limiting criterion. Table II is the code output for the limiting septifoil power of $141 \mathrm{~kW}$. The number of cells, cell lengths, 
and total length were chosen for convenience to be compatible with the power shape information given in Calc-Note SRL-SAG-91-9051 (Brown, 1991). The control rod diameter specified is $0.94^{\prime \prime}$ while the septifoil housing diameter is set to 3.30" (Drwg. ST-MDX5-10072). The power generation values in SRL-SAG-91-905 1 are for $1324 \mathrm{MW}$ reactor power. The total septifoil power for Case \#8 is $243 \mathrm{~kW}$. The reactor total power to septifoil power ratio is therefore $1324 \mathrm{MW} / 243 \mathrm{~kW}=5449.0$. The power shape and related information given in Table II are based on Figure 2 and the table given on Sheet 24 of SRL-SAG-91-9051. Note the strong 1.85 peak to average axial power shape present. The hydraulic parameters are based on Calc-Note SRL-SAG-910120 (Bornt, 1991). The cooling water temperature was chosen as $26.2^{\circ} \mathrm{C}$ which is the maximum temperature recorded from 1985 to 1988 (Mertz, 1990). The system pressure is defined to be $+5 \mathrm{psig}$ $=34475 \mathrm{~Pa}$ which corresponds to the blanket gas pressure. The septifoil average pressure is expected to be higher so this input is conservative. The longitudinal and cross moderator velocities outside the septifoil housing are assumed to be 3.0 and $1.0 \mathrm{ft} / \mathrm{s}$, respectively (see Figure 4 of this report or Figure 7 of DPST-59-13-6).

The computed results are given in the remainder of Table II and in Figures 6 through 10. The limiting power of $141 \mathrm{~kW}$ corresponds to a reactor power of $758 \mathrm{MW}$ or $32 \%$ of historical annual-averaged full power $(2400 \mathrm{MW})$. The power is CCFL limited in the septifoil cross-section where the gas superficial velocity is at the threshold of exceeding the limit imposed by equation (35) as shown in Figure 10. Note that the limiting condition does not occur at the exit as one might guess initially. In fact, relatively little net vapor escapes the septifoil housing. Only $4.1 \mathrm{~kW}$ out of a total of $141 \mathrm{~kW}$ is dissipated through net boiling. Figure 7 indicates the lower portion of septifoil contains subcooled bulk liquid. In the middle portion, the rod power exceeds that which can be dissipated through the housing and boiling occurs. In the top portion where the relative axial power drops sharply, the moderator heat loss exceeds the rod heat generation and nearly all of the vapor rising from the middle section condenses. Figure 8 confirms that critical heat flux is not limiting. Fluid and housing temperatures are shown in Figure 9.

Table II Computed results for septifoil power limited by the Wallis CCFL correlation.

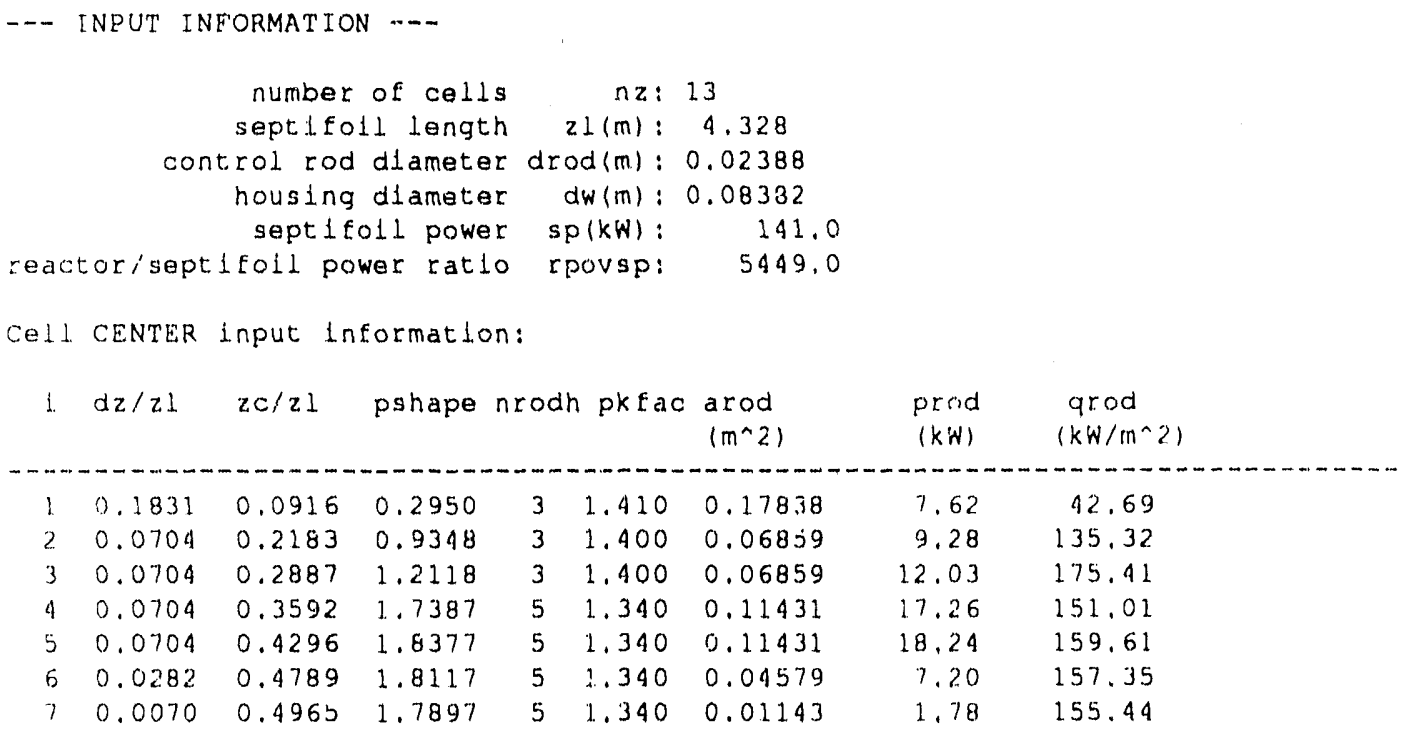




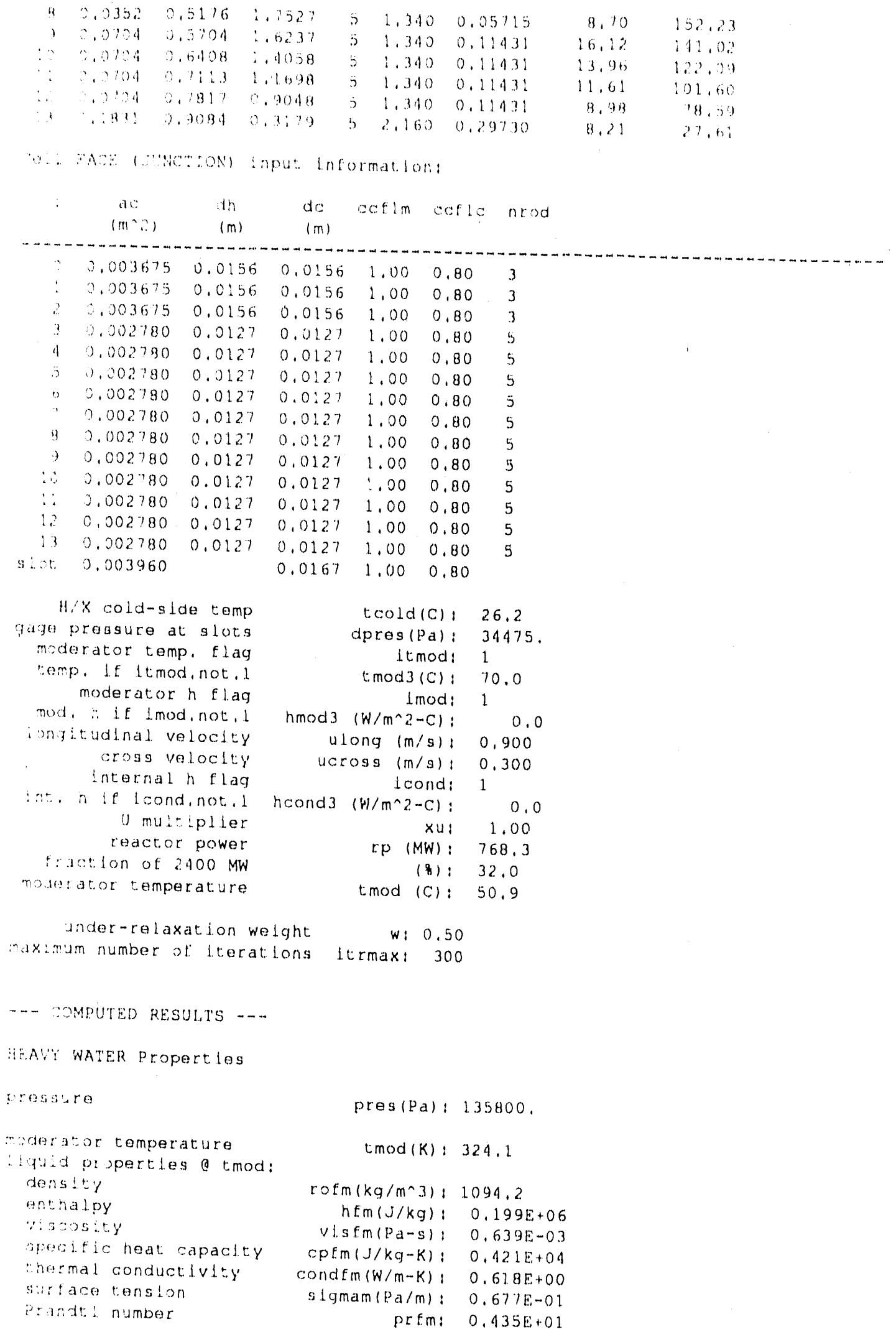




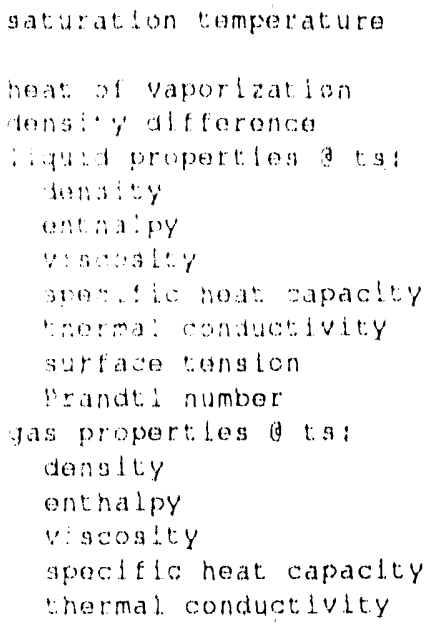

Cell CENTER computed results

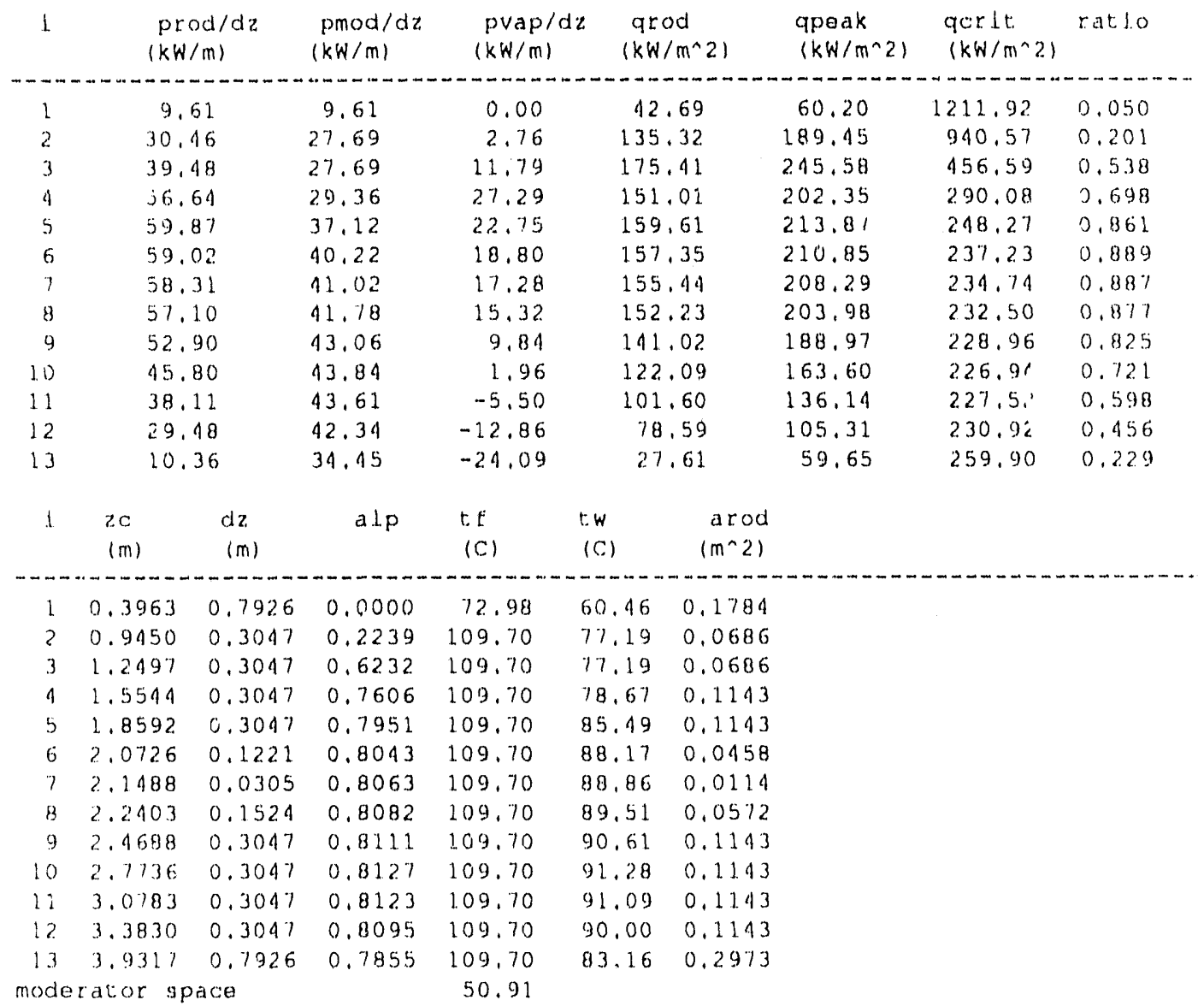




\begin{tabular}{|c|c|c|c|c|c|c|c|c|}
\hline$!$ & $\begin{array}{l}n \text { cond } \\
m \cdot 2-c)\end{array}$ & $\begin{array}{l}\text { inmod } \\
\left(W / m^{n} 2-(.)\right)\end{array}$ & $\left(w / m^{\wedge} a-c\right)$ & $\begin{array}{c}a w \\
(m \cdot 2)\end{array}$ & $\begin{array}{l}\text { ncond } \\
\left(\mathrm{W} / \mathrm{m}^{\wedge} 2-\mathrm{C}\right)\end{array}$ & $\begin{array}{l}\text { hoond2 } \\
\left\langle w / m^{\prime} 2-c\right)\end{array}$ & $\begin{array}{l}\text { hmodl } \\
\left(w / m^{\wedge} 2-C\right)\end{array}$ & $\begin{array}{l}\text { hmodz } \\
\left(W / m^{*} 2-O\right)\end{array}$ \\
\hline \multicolumn{9}{|c|}{. } \\
\hline$\therefore$ & $\therefore: \div .6$ & $39: 8,6$ & 1653.3 & 0.2087 & $29: 5.6$ & 0.0 & 9400.5 & 3236.8 \\
\hline 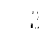 & 3274,5 & 1000,8 & 1788.5 & 0.0802 & 3234.5 & 200.1 & 4530.7 & 3450.9 \\
\hline$!$ & 1.34 .3 & 1000,9 & 1788.5 & 0.0802 & 3234.5 & 1243,9 & 1550.7 & 3450.9 \\
\hline i & 3003,3 & 1014.9 & 1996.1 & $0.090 \%$ & 3272.5 & 3593.0 & 4561.3 & 3468.6 \\
\hline$\because$ & $302 \%$ & $4276 .:$ & $\therefore 37.3$ & 0.2902 & 3481.7 & 5820.5 & 4605.1 & 3547. \\
\hline$\therefore$ & 121,3 & 4098.6 & 2597.7 & 0.0321 & 3585.5 & 7093.5 & 4620.3 & 3576.9 \\
\hline$\because$ & 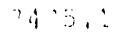 & 4104.2 & 2049.5 & 0.0080 & $36: 9.9$ & 7475.1 & 9624.0 & 3584.4 \\
\hline 3 & 13353,9 & 4109.5 & 2698.4 & .0 .0401 & 3643.7 & 7858.9 & 4627.5 & 3591.5 \\
\hline 9 & 3566.4 & $4: 18.3$ & 2781.2 & 0.0802 & 3695.0 & 8566.4 & 4633.1 & 3603.4 \\
\hline$\therefore$ & 9038.2 & 4123.6 & 2831.7 & 0.0802 & 3728.1 & $9038 . ?$ & 1636.5 & 3610.6 \\
\hline$\because:$ & 3895.6 & 1122.0 & 2816.9 & 0.0802 & 3718.3 & 8896.6 & 4635.5 & 3608.5 \\
\hline$\therefore$ & 3158,2 & $41: 3,4$ & 2731.6 & 0.0802 & 3665.7 & 8158,2 & 4630.0 & 3596.7 \\
\hline$: 3$ & 4929,9 & 4055.9 & 2225.2 & 0.2087 & 3402,9 & 4929.9 & 4591.0 & 3520.8 \\
\hline
\end{tabular}

at: FACE (JUNCTION) computed results:

\begin{tabular}{|c|c|c|c|c|}
\hline : & $\begin{array}{l}a t \\
(m)\end{array}$ & $\begin{array}{l}j g \\
(\mathrm{n} / \mathrm{s})\end{array}$ & $\begin{array}{l}f(g c c t) \\
(\mathrm{m} / \mathrm{s})\end{array}$ & rat: 10 \\
\hline & & & & \\
\hline 3 & 2.0000 & 0.000 & 6.440 & 0.000 \\
\hline : & 0.7926 & 0.000 & 6.440 & 0.000 \\
\hline 3 & 1.0973 & 0.131 & 6.440 & 0.020 \\
\hline 3 & 1.4021 & 0.912 & 5.811 & 0.157 \\
\hline 4 & 1.7068 & 2.622 & 5.811 & 0.451 \\
\hline 5 & $2.01: 5$ & 4.048 & 5.811 & 0.697 \\
\hline 6 & 2.1336 & 4.520 & 5,811 & 0.778 \\
\hline 7 & 2.1641 & 4.628 & 5.811 & 0.796 \\
\hline 8 & 2.3165 & 5.108 & 5.811 & 0.879 \\
\hline 9 & 2.6212 & 5.725 & 5.811 & 0.985 \\
\hline 20 & 2.9259 & 5.847 & 5.811 & 1.006 \\
\hline 11 & 3.2307 & 5.502 & 5.811 & 0.947 \\
\hline 12 & 3.5354 & 4.696 & 5.811 & 0.808 \\
\hline 13 & 4.3280 & 0.687 & 5.811 & 0.118 \\
\hline $3.0 t$ & 4.3280 & 0.482 & 6.663 & 0.072 \\
\hline
\end{tabular}




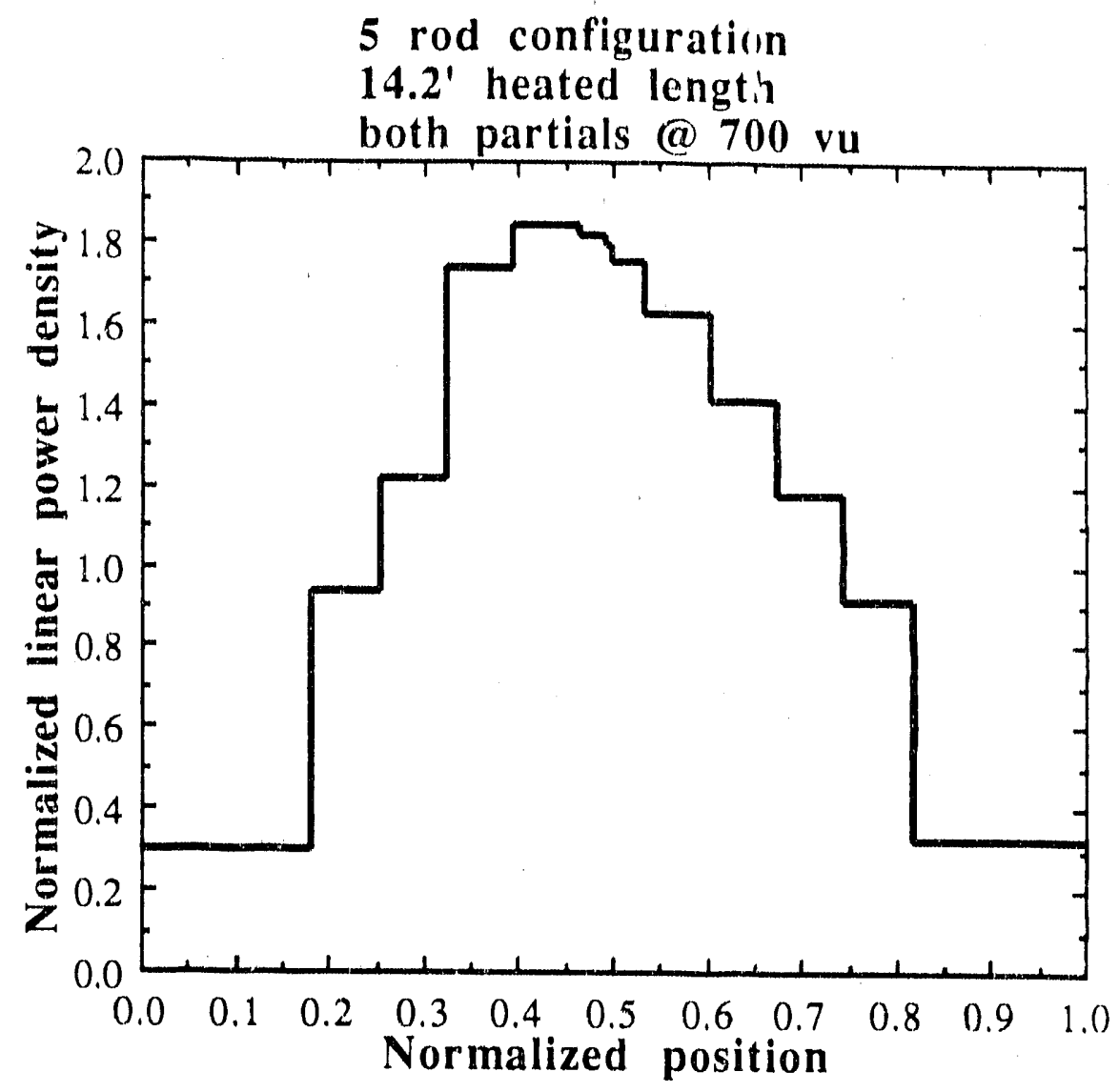

Figure 6 Relative linear power density axial profile as a function of relative position. 


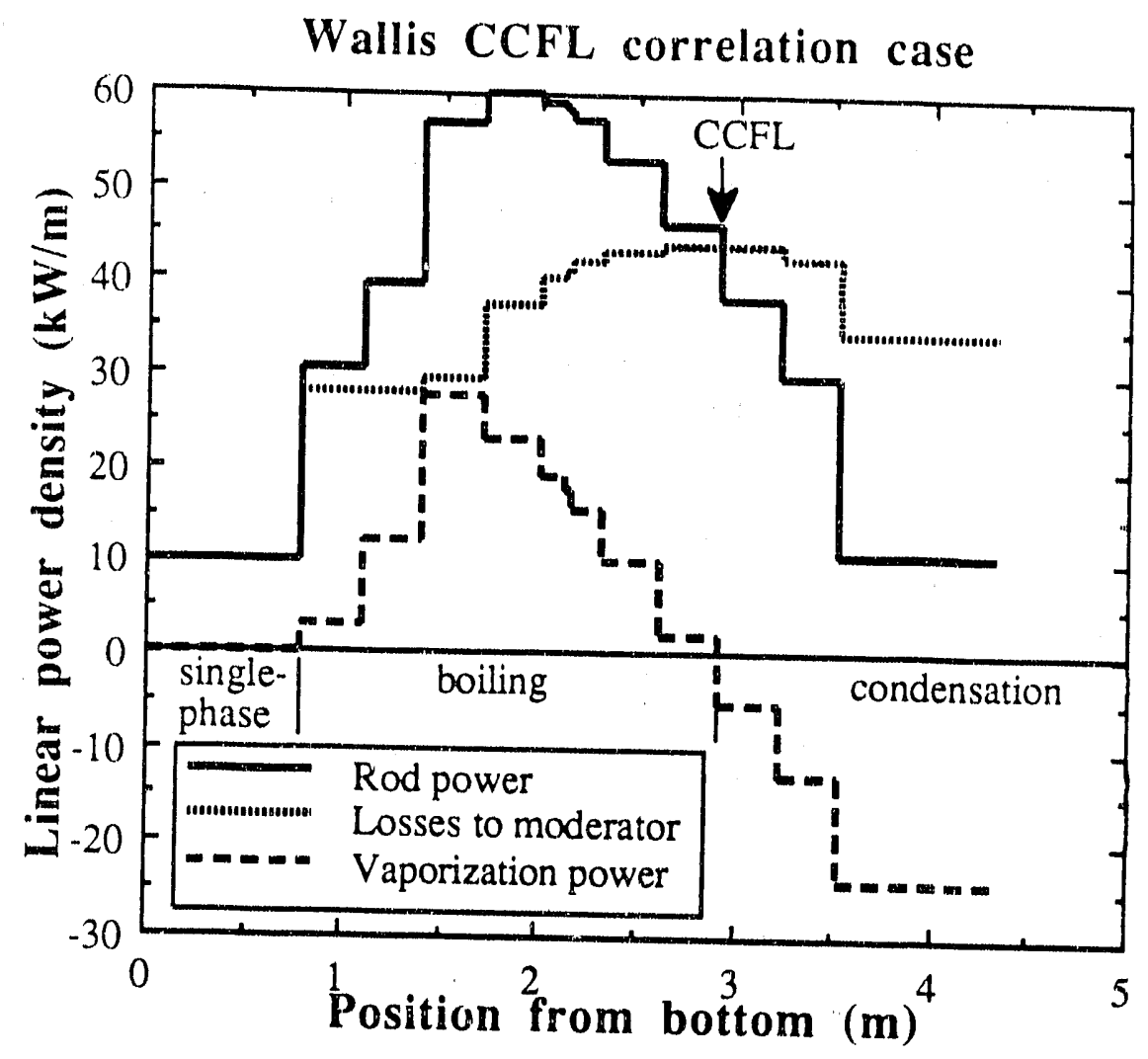

Figure 7 Linear power generation and dissipation as a function of axial position. 


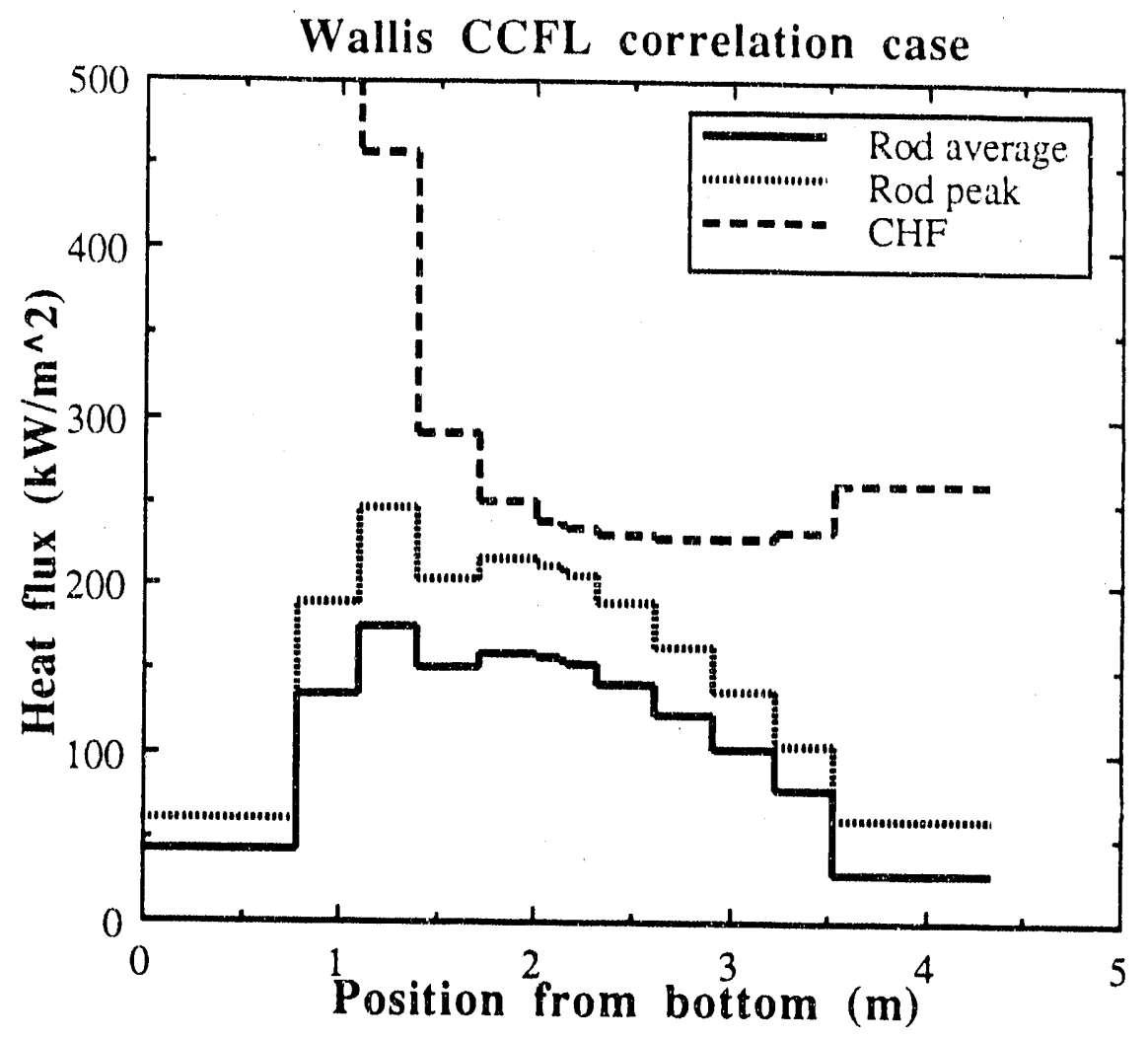

Figure 8 Heat fluxes as a function of axial position. 


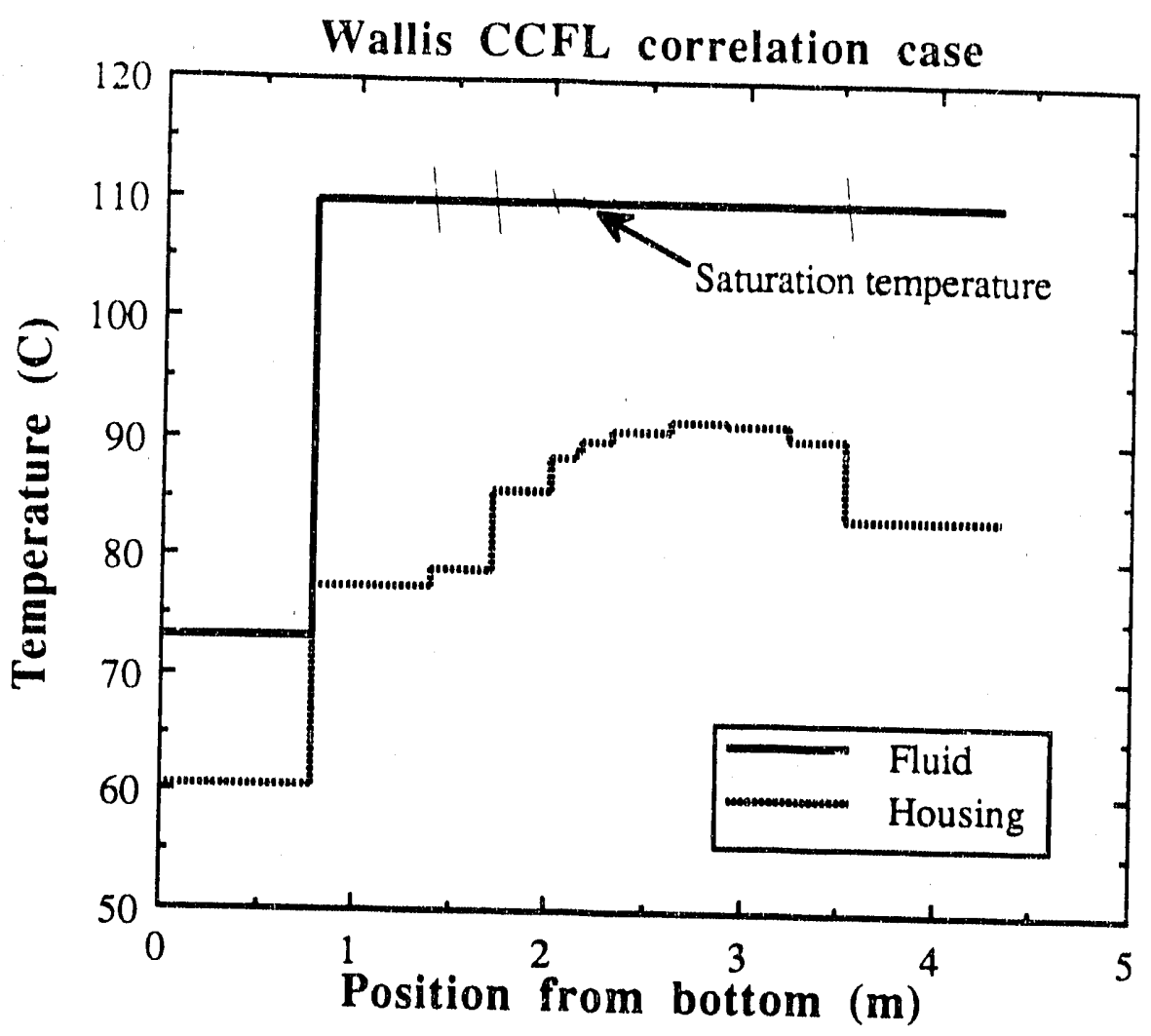

Figure 9 Internal fluid and housing temperature as a function of axial position. 


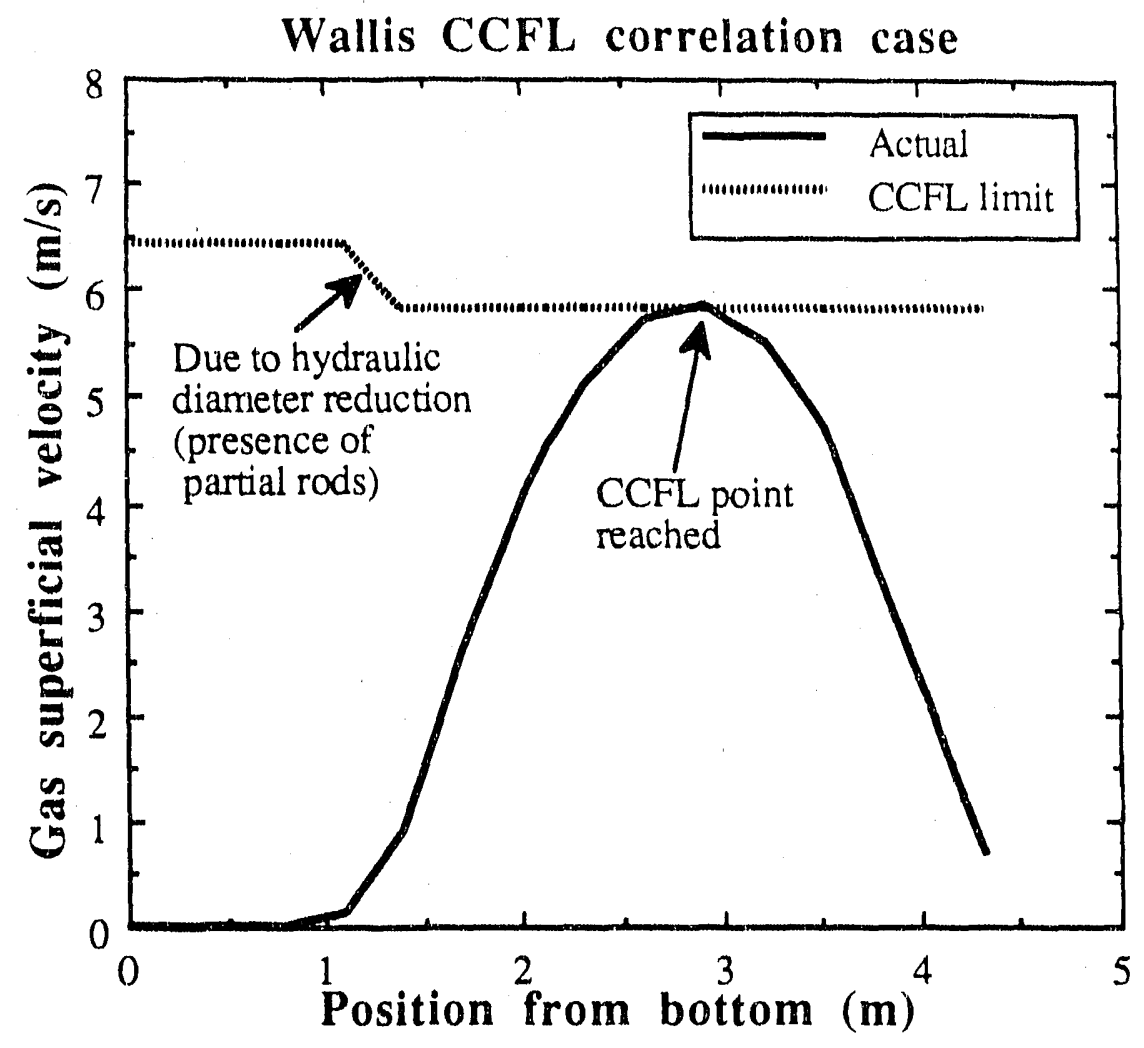

Figure 10 Gas superficial velocities as a function of axial position.

Results based on Osakabe \& Kawasaki CCFL correlation: A lower septifoil power limit is obtained if the Osakabe and Kawasaki correlation for annular flow channels is assumed. Table III indicates the septifoil power limit is $119 \mathrm{~kW}$ which corresponds to a reactor power of $648 \mathrm{MW}$ or $27 \%$ of historical full power. Similar behavior is observed as for the preceding example as illustrated by Figures 11 through 14. A notable difference is that Figure 14 indicates no vapor exits the septifoil housing at the power limit. Therefore there is no net boiling and no power is dissipated through this mechanism.

Table III Computed results for septifoil power limited by the Osakabe and Kawasaki CCFL correlation.

\footnotetext{
-- INPUT INFORMATION - -

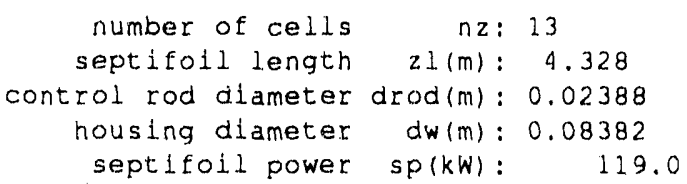




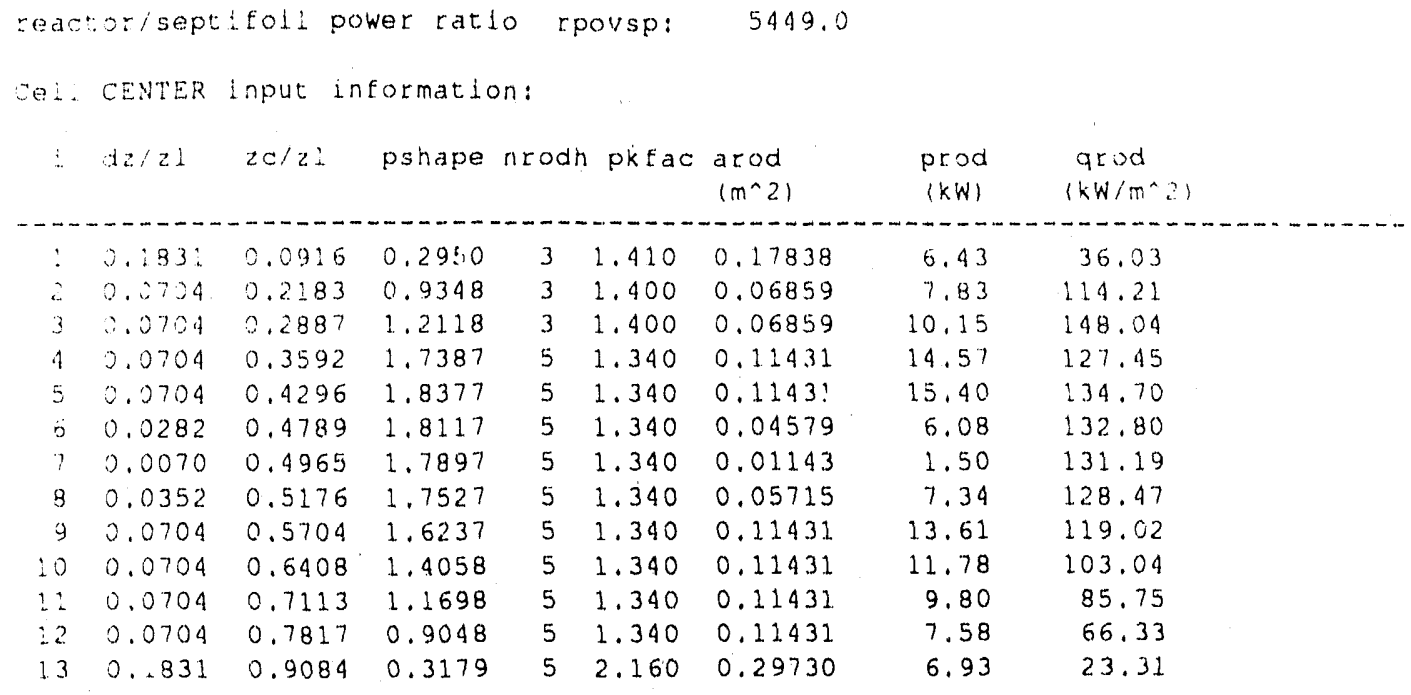

Cel1 EACE (JUNCTION) input information:

\begin{tabular}{|c|c|c|c|c|c|c|c|}
\hline i & $\begin{array}{c}a c \\
\left(m^{\wedge} 2\right)\end{array}$ & $\begin{array}{l}d h \\
(m)\end{array}$ & $\begin{array}{l}d c \\
(m)\end{array}$ & $\operatorname{ccflm}$ & $\operatorname{ccflc}$ & \multicolumn{2}{|l|}{ nrod } \\
\hline \multicolumn{8}{|c|}{ 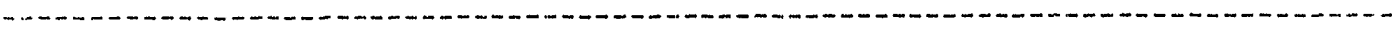 } \\
\hline 0 & 0.003675 & 0.0156 & 0.0850 & 0.80 & 0.38 & 3 & \\
\hline 1 & 0.003675 & 0.0156 & 0.0850 & 0.80 & 0.38 & 3 & \\
\hline 2 & 0.003675 & 0.0156 & 0.0850 & 0.80 & 0.38 & 3 & \\
\hline 3 & 0.002780 & 0.0127 & 0.0850 & 0.80 & 0.38 & 5 & \\
\hline 4 & 0.002780 & 0.0127 & 0.0850 & 0.80 & 0.38 & 5 & \\
\hline 5 & 0.002780 & 0.0127 & 0.0850 & 0.80 & 0.38 & 5 & \\
\hline 6 & 0.002780 & 0.0127 & 0.0850 & 0.80 & 0.38 & 5 & \\
\hline 7 & 0.002780 & 0.0127 & 0.0850 & 0.80 & 0.38 & 5 & \\
\hline 8 & 0.002780 & 0.0127 & 0.0850 & 0.80 & 0.38 & 5 & \\
\hline 9 & 0.002780 & 0.0127 & 0.0850 & 0.80 & 0.38 & 5 & \\
\hline 10 & 0.002780 & 0.0127 & 0.0850 & 0.80 & 0.38 & 5 & \\
\hline 11 & 0.002780 & 0.0127 & 0.0850 & 0.80 & 0.38 & 5 & \\
\hline 12 & 0.002780 & 0.0127 & 0.0850 & 0.80 & 0.38 & 5 & \\
\hline 13 & 0.002780 & 0.0127 & 0.0850 & 0.80 & 0.38 & 5 & \\
\hline s.lot & 0.003960 & & 0.0167 & 1.00 & 0.80 & & \\
\hline \multicolumn{4}{|c|}{$H / X$ cold-side temp } & \multicolumn{2}{|c|}{$t \operatorname{col} d(c):$} & \multicolumn{2}{|l|}{26.2} \\
\hline & \multicolumn{2}{|c|}{ dpres (Pa): } & \multicolumn{2}{|l|}{34475 . } \\
\hline \multirow{2}{*}{\multicolumn{3}{|c|}{ temp. If itmod.not.1 }} & & \multicolumn{2}{|c|}{ 1.tmod: } & \multicolumn{2}{|l|}{1} \\
\hline & & & & \multicolumn{2}{|c|}{$\operatorname{tmod} 3(\mathrm{C}):$} & \multicolumn{2}{|l|}{70.0} \\
\hline \multicolumn{4}{|c|}{ moderator $\mathrm{h}$ flag } & \multicolumn{2}{|c|}{1 mod: } & 1 & \\
\hline \multirow{2}{*}{\multicolumn{3}{|c|}{$\begin{array}{l}\text { mod. } n \text { il imod.not. } 1 \\
\text { iongitudinal velocity }\end{array}$}} & nmod3 & \multirow{2}{*}{\multicolumn{2}{|c|}{$\left(W / m^{n} 2-C\right):$}} & 0.0 & \\
\hline & & & & & (s): & \multicolumn{2}{|l|}{0.900} \\
\hline \multicolumn{3}{|c|}{ cross velocity } & \multicolumn{3}{|c|}{ ucross $(\mathrm{m} / \mathrm{s})$ : } & 0.300 & \\
\hline \multicolumn{3}{|c|}{ internal h flag } & & \multicolumn{2}{|c|}{ Lcond: } & 1 & \\
\hline \multicolumn{3}{|c|}{$\begin{array}{r}\text { Int, } h \text { if icond.not. } 1 \\
\text { u multiplier }\end{array}$} & hcond 3 & \multicolumn{2}{|c|}{$\left(W / m^{\wedge} 2-C\right):$} & 0.0 & \\
\hline \multicolumn{3}{|c|}{ reactor power } & & $\operatorname{rp} 1$ & MW) : & 648.4 & \\
\hline Er & action of & $2400 \mathrm{MW}$ & & & $(8):$ & 27.0 & \\
\hline mode & rator temp & erature & & $t \bmod$ & (C) : & 47.1 & \\
\hline & under-rela & xation w & ejght & $w:$ & 0.50 & & \\
\hline maxim & um number & of itera & tons & itrmax: & 300 & & \\
\hline
\end{tabular}

HEAVY WATER Properties 


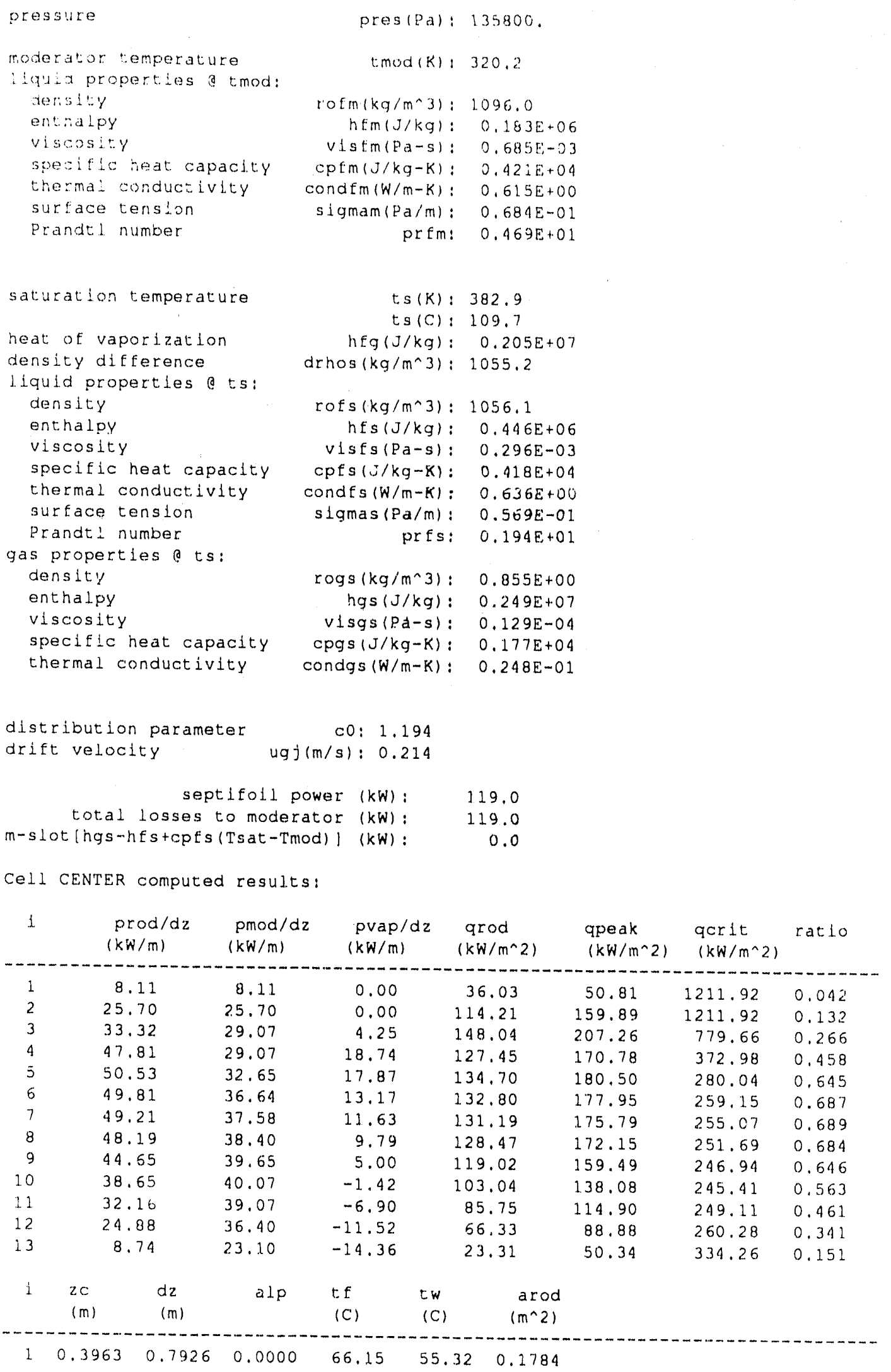




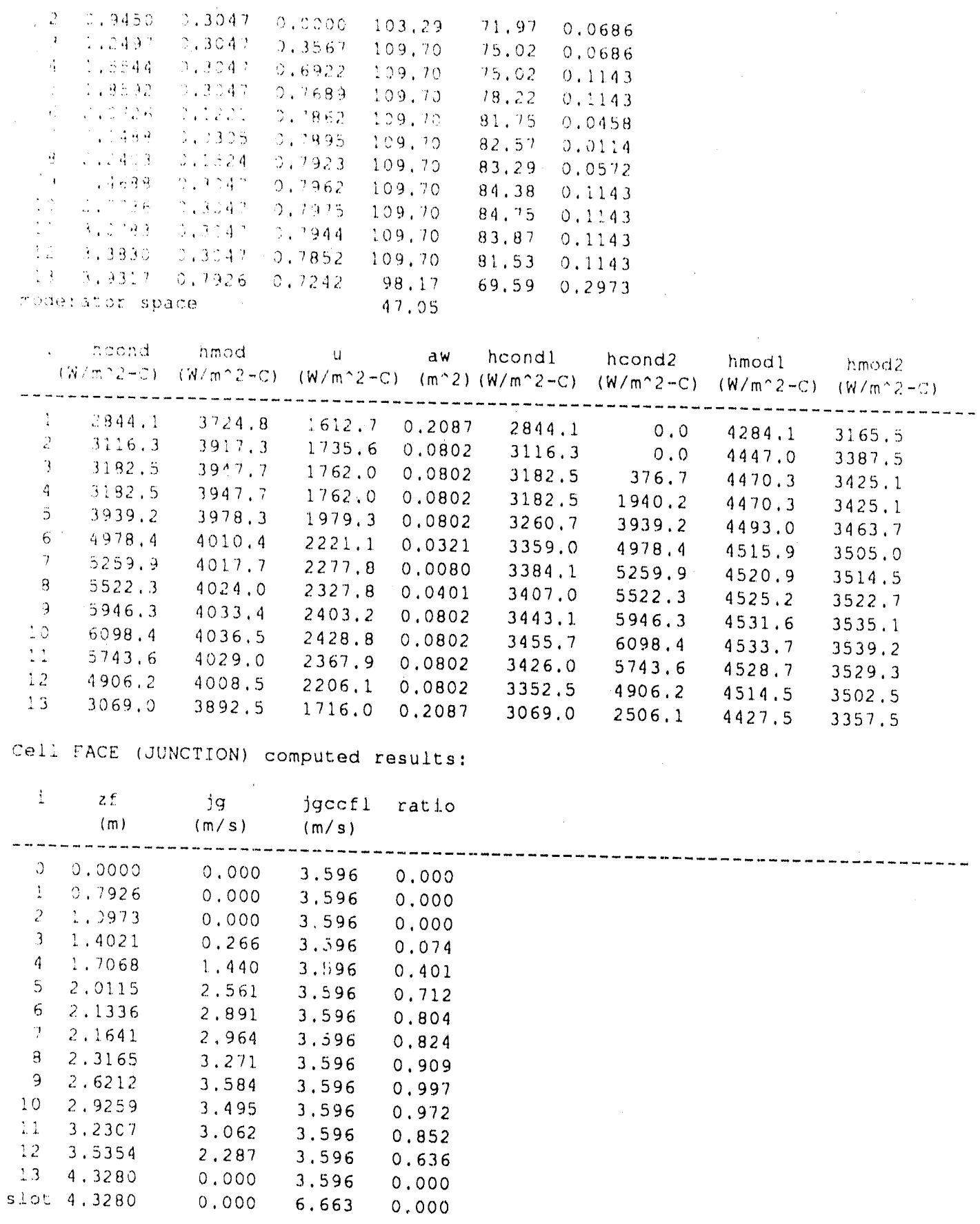




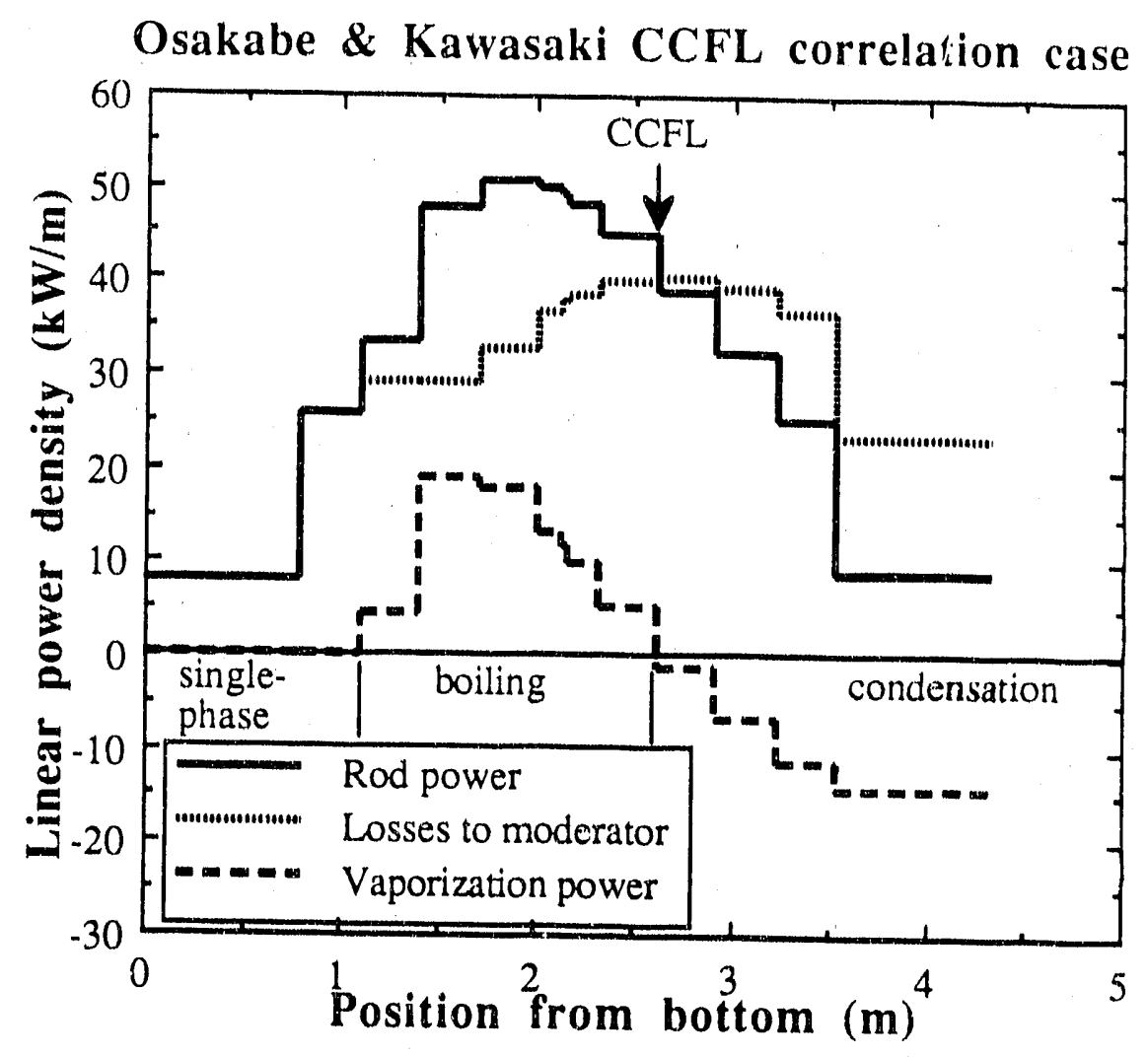

Figure 11 Linear power generation and dissipation as a function of axial position. 


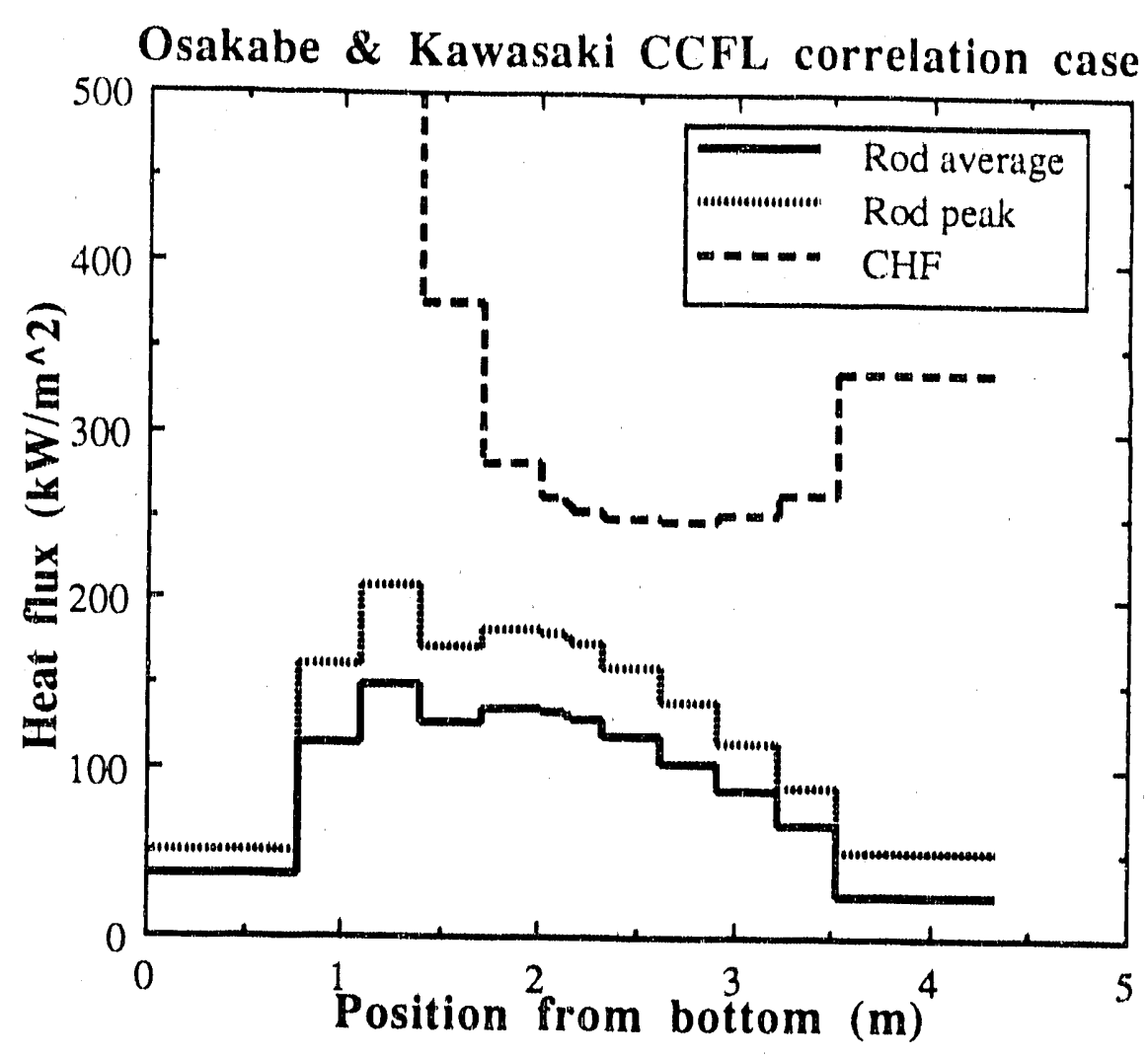

Figure 12 Heat fluxes as a function of axial position. 


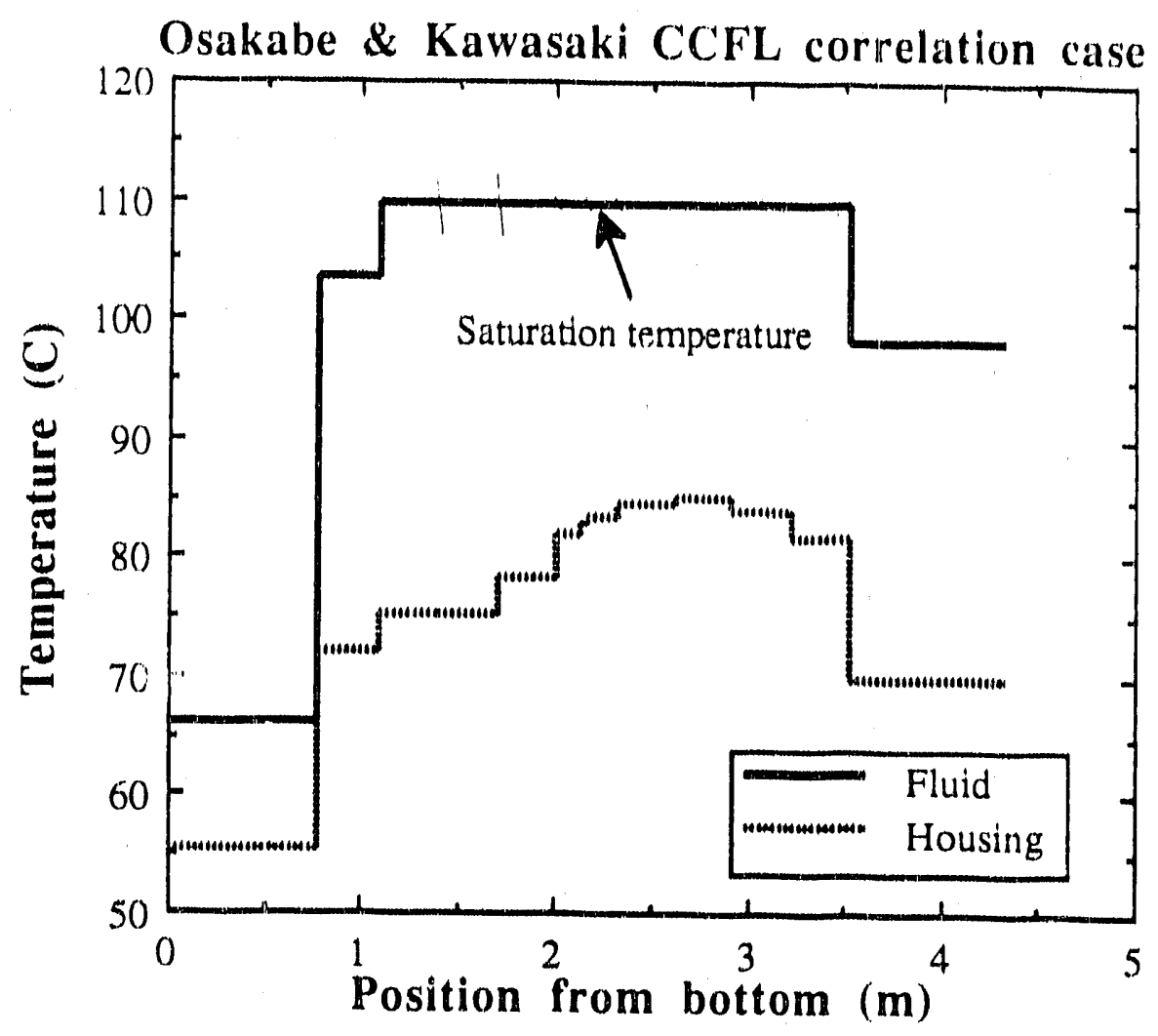

Figure 13 Internal fluid and housing temperature as a function of axial position. 


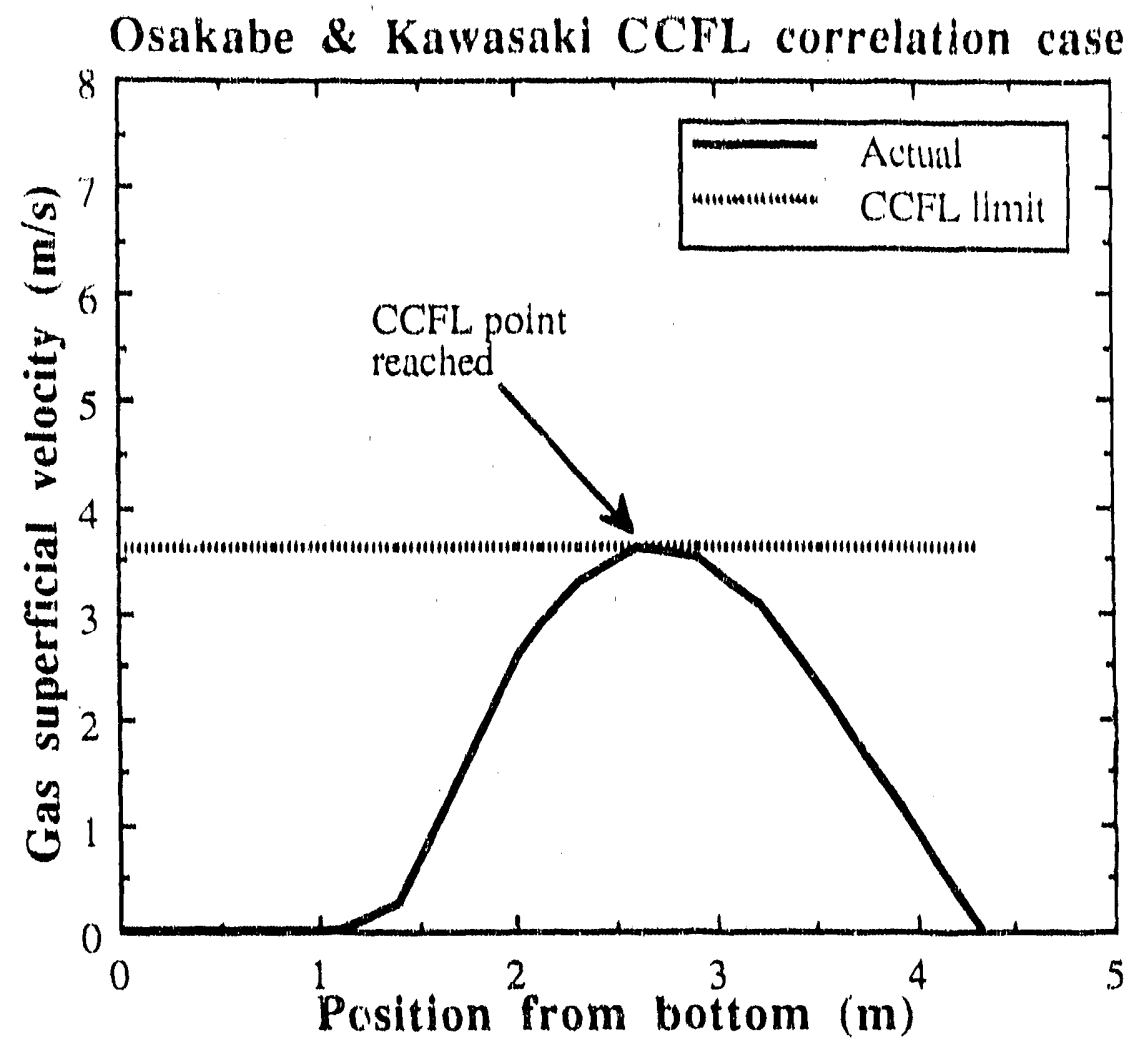

Figure 14 Gas superficial velocities as a function of axial position.

Sensitivity to overall heat transfer coefficient between fluid and moderator: The preceding results indicate the dominant heat removal mechanism is heat transfer through the septifoil housing rather than net boiling. The overall heat transfer coefficient between the internal fluid and the moderator, $U$, controls heat loss to the moderator. The best-estimate model for $\mathrm{U}$ has a significant uncertainty because both $h_{\bmod }$ and $h_{\text {cond }}$ are not well known. To investigate the sensitivity of maximum septifoil heat generation rate to the overall heat transfer coefficient, simulations with $\mathrm{U}$ varied $\pm .50 \%$ were performed. The Wallis correlation was used to test for a CCFL condition. Tables IV and $V$ present the results for $-50 \%$ and $+50 \%$ variations in $U$, respectively. These results are plotted in Figures 15 through 22. With the overall heat transfer coefficient reduced by $50 \%$, the predicted maximum septifoil power is $96 \mathrm{~kW}$ or $32 \%$ lower than the nominal case. For a $50 \%$ increase in $\mathrm{U}$, the power increases $16 \%$ from nominal to $163 \mathrm{~kW}$.

The physical behavior of both sensitivity simulations is somewhat different from that exhibited by the nominal case. For $U$ reduced by $50 \%$, Table IV indicates that the fraction of energy dissipated through net boiling is significant (15\%). Like the nominal case using the Wallis correlation, the maximum heat generation rate is limited by CCFL rather than $\mathrm{CHF}$. For $\mathrm{U}$ increased by $50 \%$, Table $\mathrm{V}$ shows that all of the septifoil power is dissipated through the housing wall because there is no net boiling. More importantly, the limiting phenomenon has changed from CCFL to CHF. The CHF model discussed in the previous 
section uses a conservative value of estimated vold fraction so the maximum seprifiil power predicted for a $50 \%$ increase in $U$ is slightly conservative.

Table IV Computed results for septifoll power limited by the Wallis CCFL correlation and the overall heat transfer coeffictent reduced by $50 \%$ from nominal.

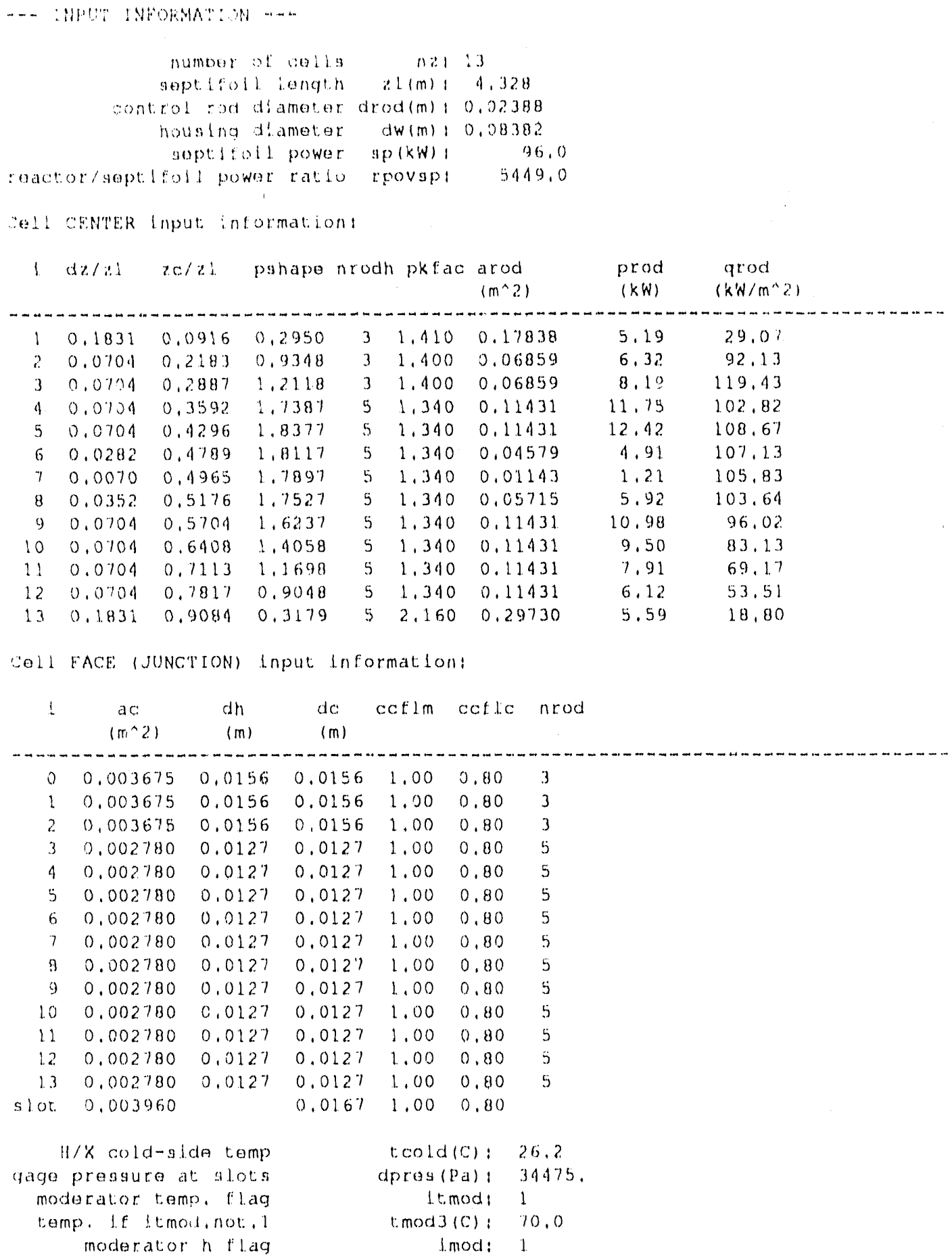




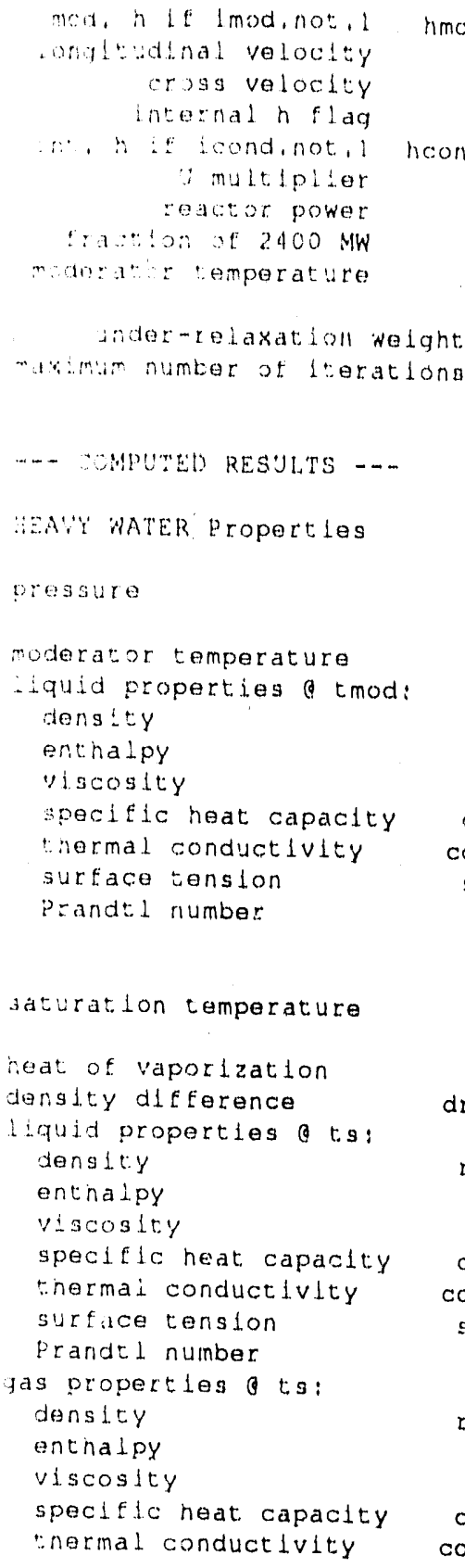

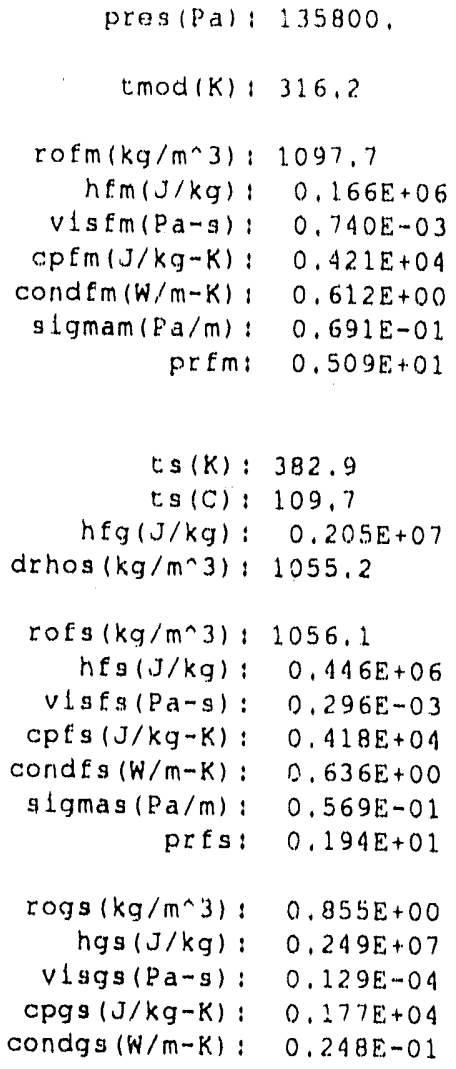

co: 1.194

$\operatorname{ugf}(\mathrm{m} / \mathrm{s}): 0.214$

$$
\begin{array}{rrr}
\text { septlfoll power }(\mathrm{kW}): & 96.0 \\
\text { total losses to moderator }(\mathrm{kW}): & 81.4 \\
\text { m-stot has-hfstcpts (Tsat:-Tmod)l } & (\mathrm{kW}): & 14.6
\end{array}
$$

AELL CENTER computed results:

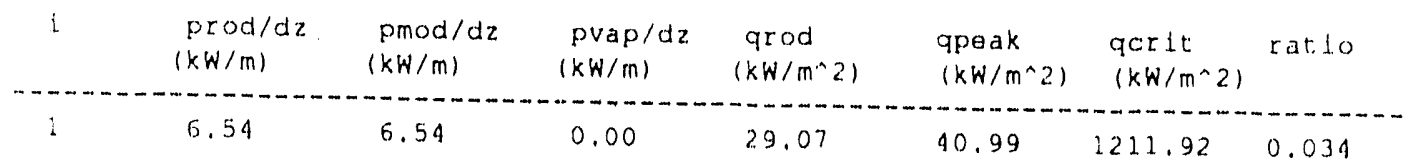




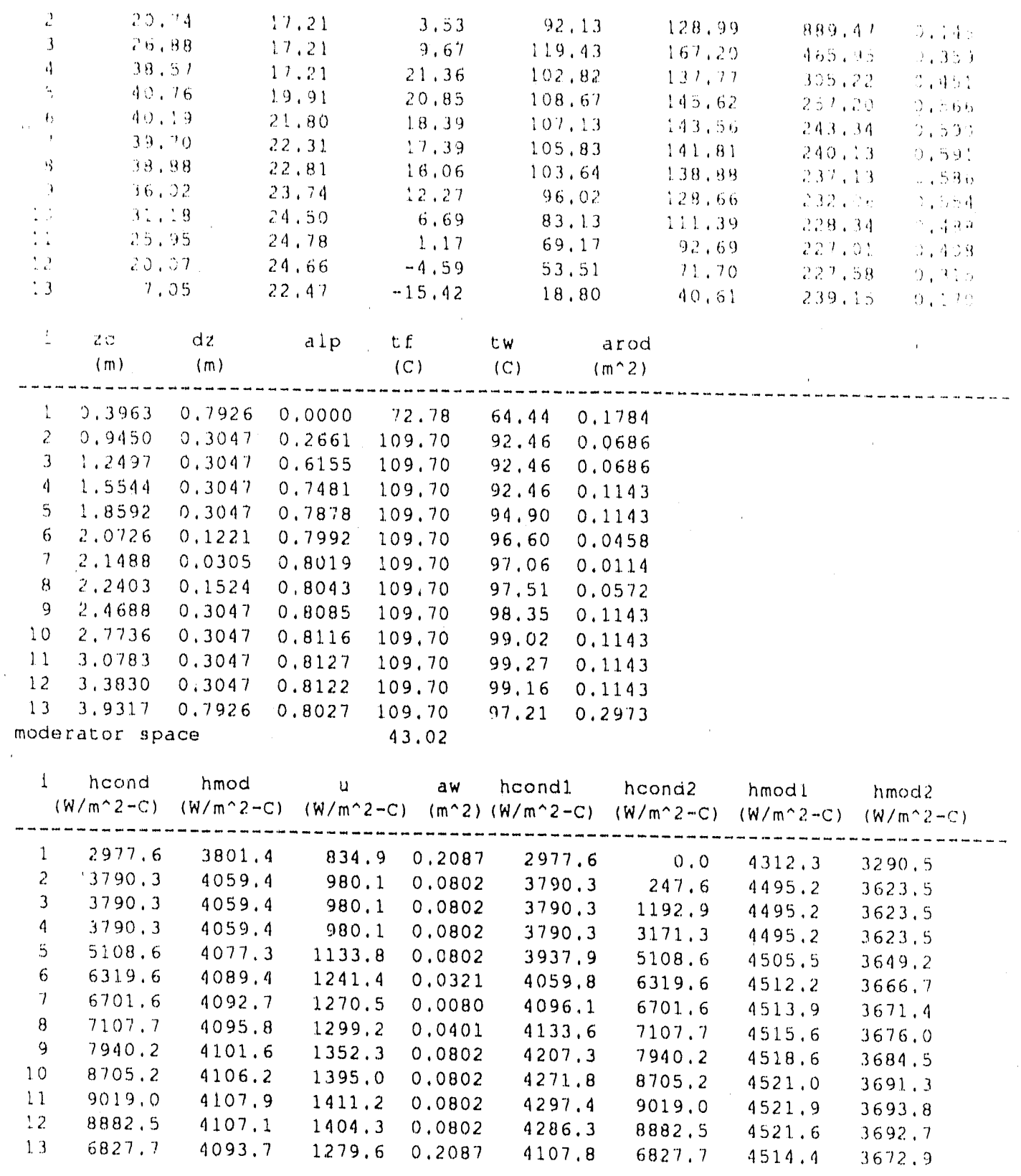

Cell FACE (JUNCTION) computed results:

\begin{tabular}{rcccc}
$L$ & $\begin{array}{c}\text { zf } \\
(\mathrm{m})\end{array}$ & $\begin{array}{c}\mathrm{fg} \\
(\mathrm{m} / \mathrm{s})\end{array}$ & $\begin{array}{c}\text { jgccf } 1 \\
(\mathrm{~m} / \mathrm{s})\end{array}$ & rat 10 \\
\hline 0 & 0.0000 & 0.000 & 6.440 & 0.000 \\
1 & 0.7926 & 0.000 & 6.440 & 0.000 \\
2 & 1.0973 & 0.167 & 6.440 & 0.026 \\
3 & 1.4021 & 0.827 & 5.811 & 0.142 \\
4 & 1.7068 & 2.165 & 5.811 & 0.373 \\
5 & 2.0115 & 3.472 & 5.811 & 0.598 \\
6 & 2.1336 & 3.934 & 5.811 & 0.677 \\
7 & 2.1641 & 4.043 & 5.811 & 0.696 \\
8 & 2.3165 & 4.546 & 5.811 & 0.782 \\
9 & 2.6212 & 5.315 & 5.811 & 0.915 \\
10 & 2.9259 & 5.734 & 5.811 & 0.987
\end{tabular}




$\begin{array}{rrrrr}11 & 3.2307 & 5.807 & 5.811 & 0.999 \\ 12 & 3.5354 & 5.520 & 5.811 & 0.950 \\ 2.3 & 4.3280 & 2.646 & 5.811 & 0.455 \\ 5.2 \% & 4.3280 & 1.858 & 6.663 & 0.279\end{array}$

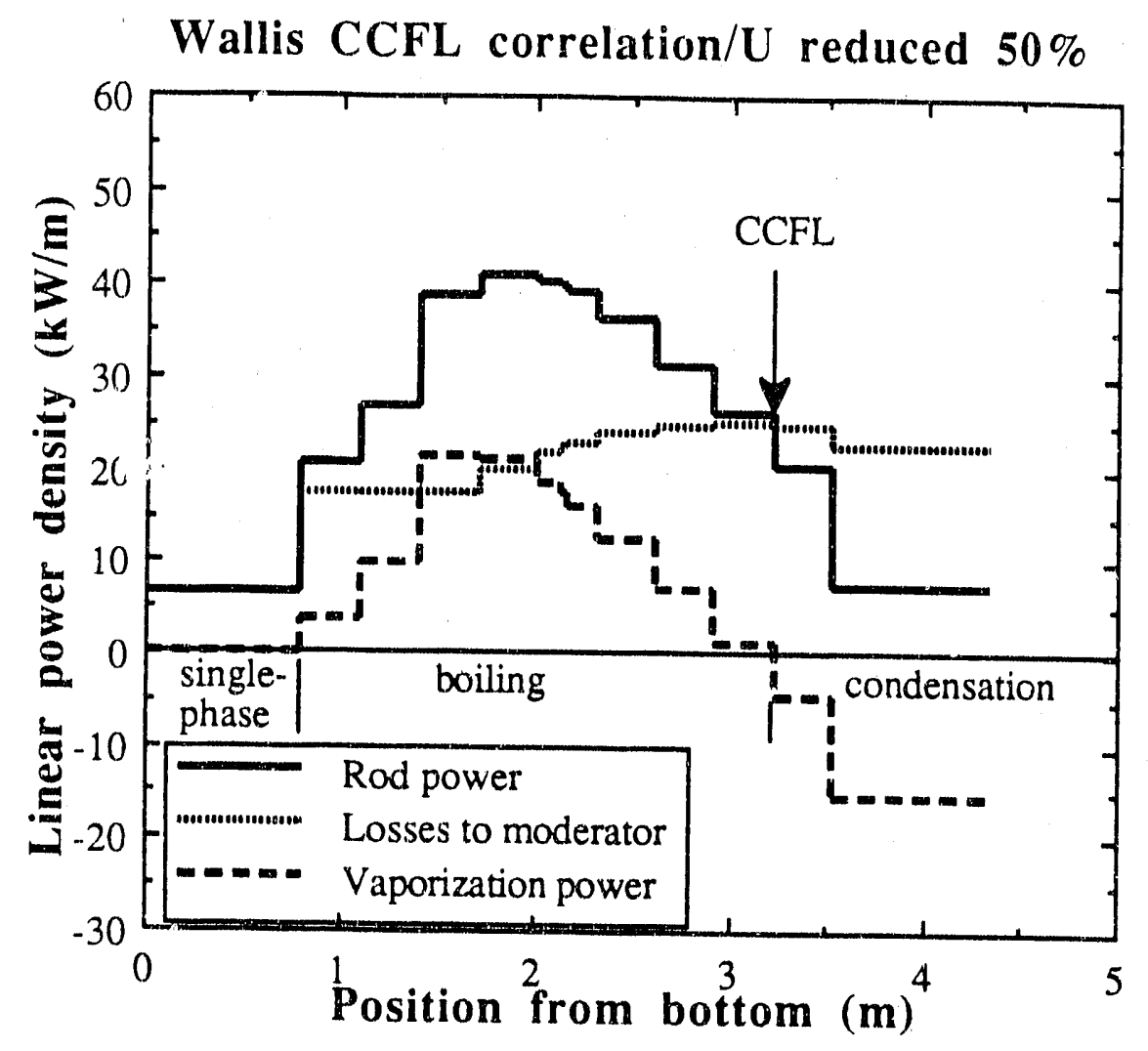

Figure 15 Linear power generation and dissipation as a function of axial position. 


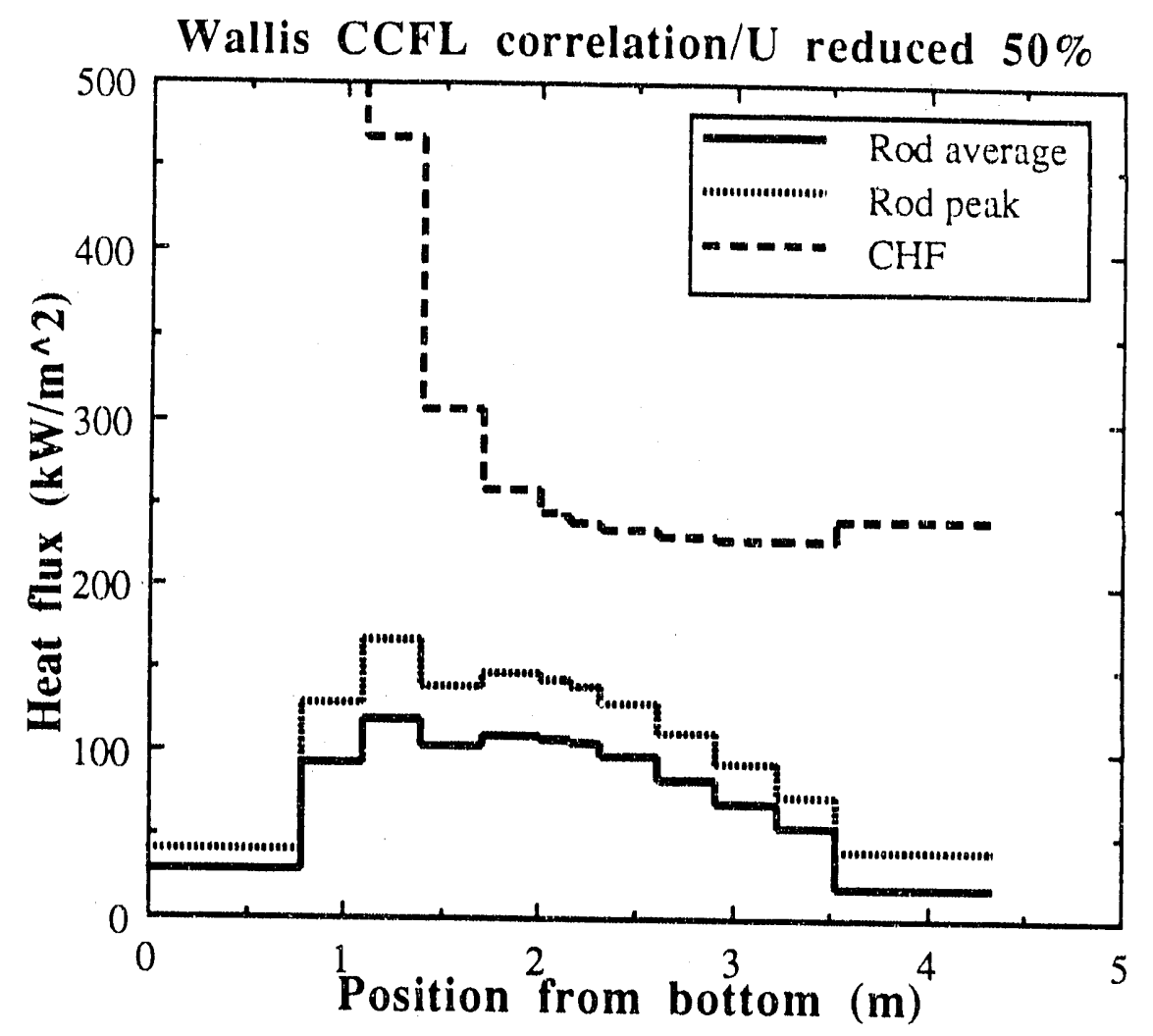

Figure 16 Heat fluxes as a function of axial position. 


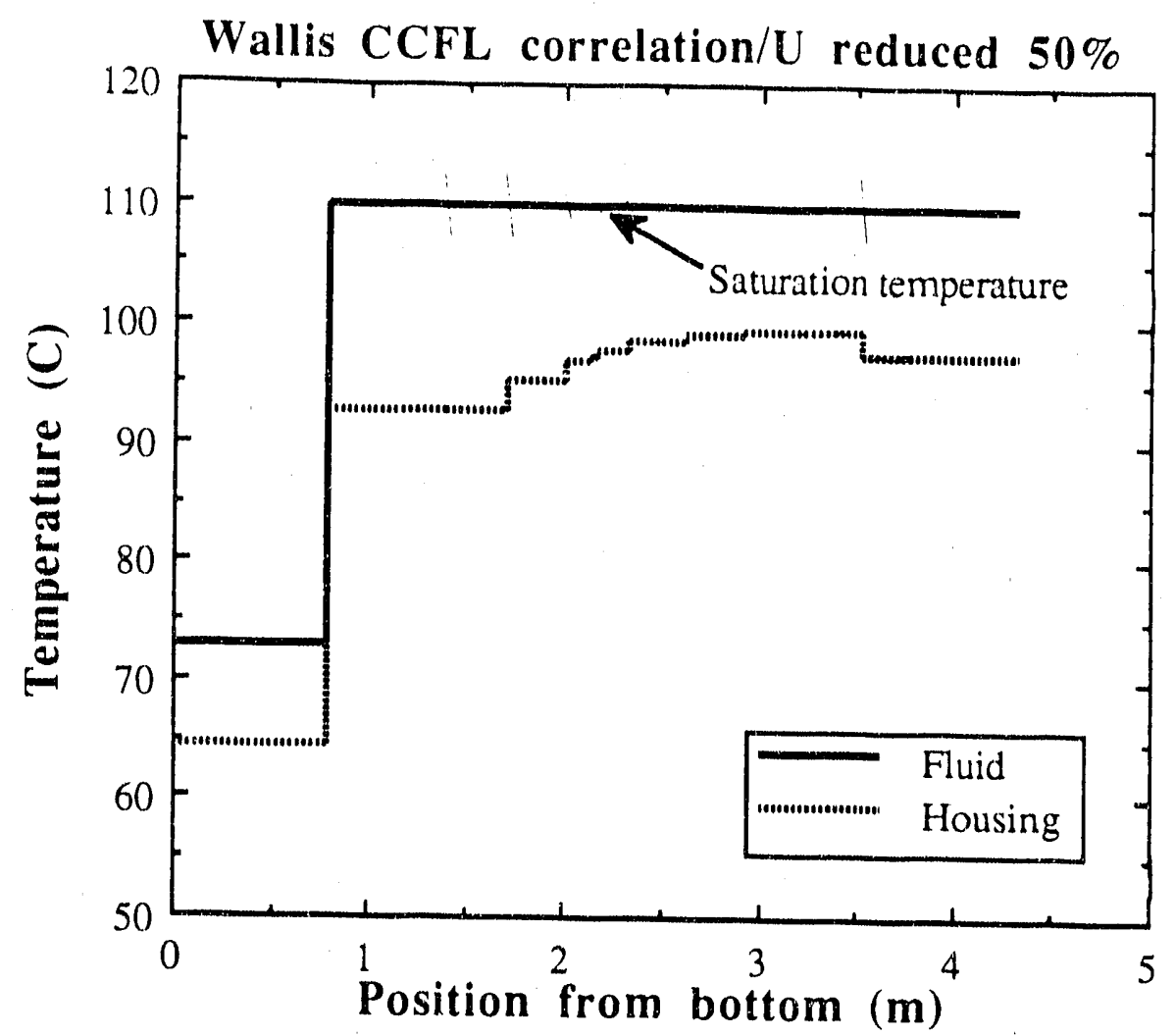

Figure 17 Internal fluid and housing temperature as a function of axial position. 


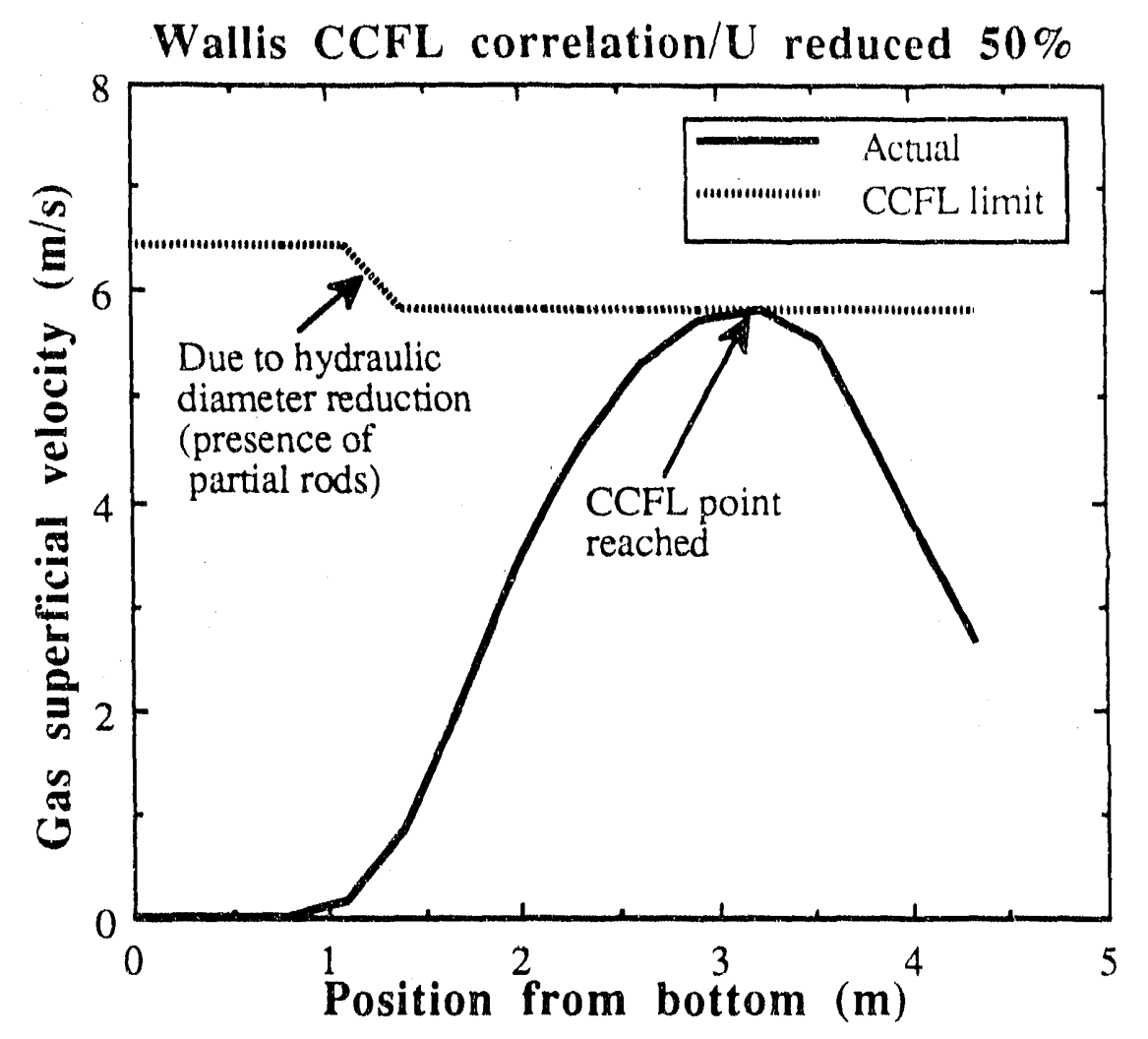

Figure 18 Gas superficial velocities as a function of axial position.

Table V Computed results for septifoil power limited by the Wallis CCFL correlation and the overall heat transfer coefficient increased by $50 \%$ from nominal.

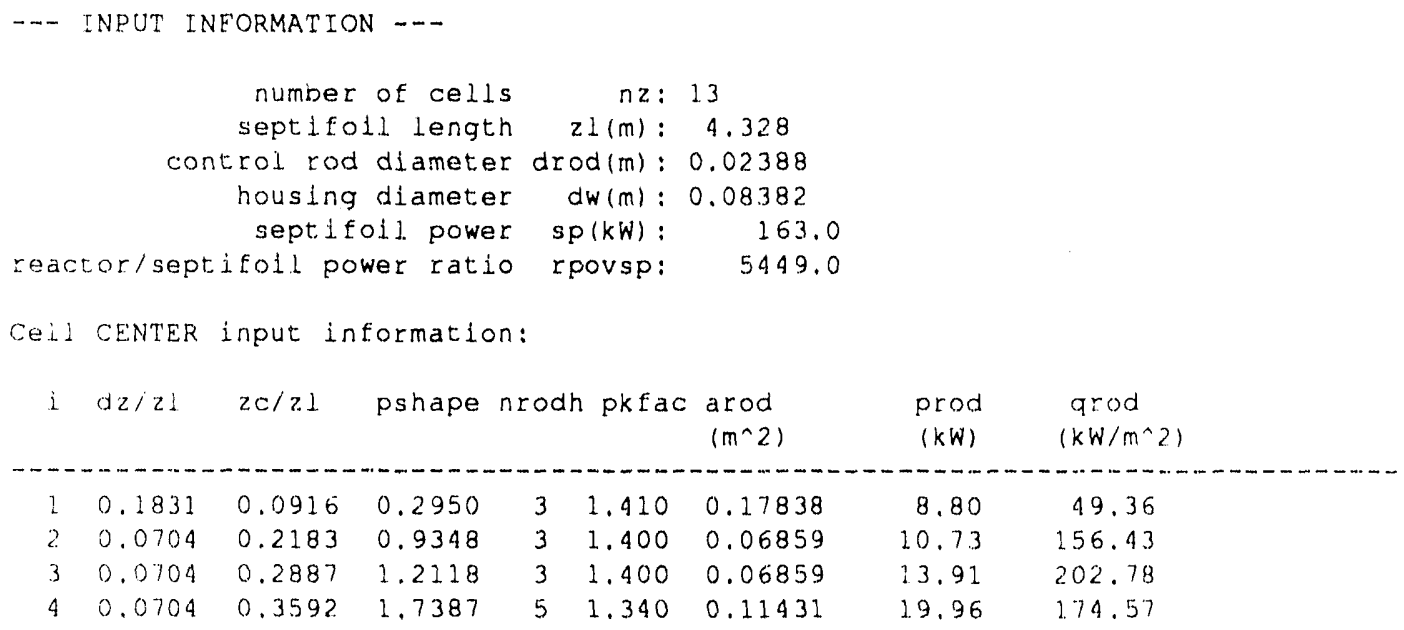




$\begin{array}{rrrrrrrrr}5 & 0.0704 & 0.4296 & 1.8377 & 5 & 1.340 & 0.11431 & 21.09 & 184.51 \\ 6 & 0.0282 & 0.4789 & 1.8117 & 5 & 1.340 & 0.04579 & 8.33 & 181.90 \\ 7 & 0.0070 & 0.4965 & 1.7897 & 5 & 1.340 & 0.01143 & 2.05 & 179.69 \\ 9 & 0.0352 & 0.5176 & 1.7527 & 5 & 1.340 & 0.05715 & 10.06 & 175.98 \\ 9 & 0.0704 & 0.5704 & 1.6237 & 5 & 1.340 & 0.11431 & 18.104 & 163.03 \\ \vdots 0 & 0.0704 & 0.6408 & 1.4058 & 5 & 1.340 & 0.11431 & 16.13 & 141.14 \\ \therefore & 2.0704 & 0.7113 & 1.1698 & 5 & 1.340 & 0.12431 & 13.43 & 117.43 \\ \therefore 3 & 0.0704 & 0.1917 & 0.9048 & 5 & 1.340 & 0.12431 & 10.38 & 90.85 \\ \therefore 3 & 0.2831 & 0.9084 & 0.3179 & 5 & 2.160 & 0.29730 & 9.49 & 31.92\end{array}$

Ce: FACE (JUNCTION) input information:

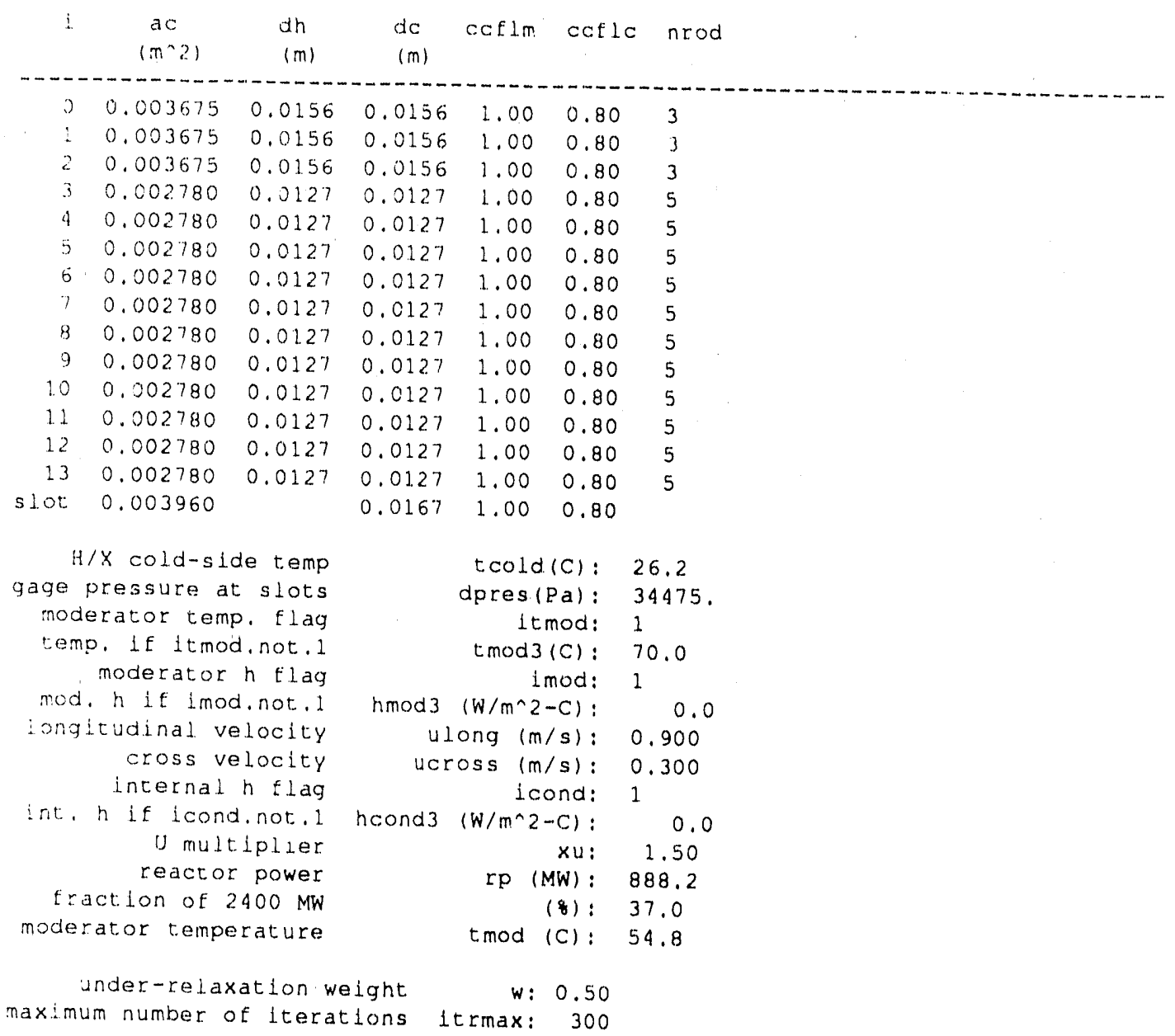

COMPUTED RESULTS -.-

HEAVY WATER Properties

pressure

moderator temperature

liquid properties o tmod: density

enthalpy

viscosity

specific heat capacity

thermal conductivity

surface tension
pres(Pa): 135800 .

$t \bmod (K): 327.9$

$\operatorname{rofm}\left(\mathrm{kg} / \mathrm{m}^{\wedge} 3\right): 1092.4$

$\mathrm{hfm}(\mathrm{J} / \mathrm{kg}): \quad 0.215 \mathrm{E}+06$

visfm(Pa-s): $0.598 \mathrm{E}-03$

$\operatorname{cpfm}(\mathrm{J} / \mathrm{kg}-\mathrm{K}): \quad 0.420 \mathrm{E}+04$

cond $\mathrm{fm}(\mathrm{W} / \mathrm{m}-\mathrm{K}): \quad 0.620 \mathrm{E}+00$

$\operatorname{sigmam}(\mathrm{Pa} / \mathrm{m}): \quad 0.671 \mathrm{E}-01$ 


\begin{tabular}{|c|c|c|c|c|c|c|c|c|}
\hline$\therefore$ & $\begin{array}{l}\text { noond } \\
n \cdot 2-\infty 1\end{array}$ & $\begin{array}{c}\text { nmod } \\
(w / m+2-\infty)\end{array}$ & $\left(w / m^{n} z-c\right)$ & $\Rightarrow \quad \mid \begin{array}{l}a w \\
n a|1|\end{array}$ & $\begin{array}{l}\text { noond } \\
\left(W^{\prime} m^{\wedge} 2-C\right)\end{array}$ & $\begin{array}{l}\text { heond } \\
\left(W / m^{*} 2-c\right)\end{array}$ & $\begin{array}{l}\text { hinod } \\
(W / m \cdot 2-c)\end{array}$ & $\begin{array}{l}\text { hmod: } \\
\left(w: m^{+} i-b\right)\end{array}$ \\
\hline- & , & 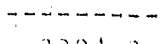 & $-\cdots-\infty$ & . & & - & & ----- \\
\hline & $\therefore 912$ & 3804.2 & 2453,8 & $0.208^{-1}$ & 2870.0 & 0.0 & 4417.0 & 3131.5 \\
\hline$\therefore$ & 2949,3 & $38 \div 2.2$ & $25: 1.2$ & 0.2802 & 2949.3 & 0.0 & 4478.8 & 3255.1 \\
\hline 3 & 2953.4 & $38 \cdot 5.4$ & $\therefore 3: 4 .:$ & 0.0302 & 2953.4 & 745.1 & 4481.6 & 3269. \\
\hline$\therefore$ & $3: 02.5$ & 3886.6 & 2587.9 & 0.0802 & 2968.5 & 3102.5 & 4491.5 & 3291.8 \\
\hline$\because$. & 5299.7 & 4000.8 & 3419.7 & 0.0802 & 3165.2 & 5299.7 & 4587.3 & 3414.3 \\
\hline 6 & 6392.2 & 4036.1 & $3: 11.0$ & 0.0321 & 3250.0 & 6392.2 & 4615.0 & 3457.3 \\
\hline$?$ & 0689.7 & 4044.3 & 3783.7 & 0.0080 & 3271.9 & 6689.7 & 4621.2 & $346^{\circ}$. \\
\hline 8 & 6960.0 & 4051.2 & 3841.0 & 0.0401 & 32.91 .4 & 6960.0 & 4626.5 & $34 / 5.9$ \\
\hline 9 & 7356.3 & 4060.7 & 3924.6 & 0.0802 & 3319.4 & 7356.3 & 4633.6 & $348 \% 8$ \\
\hline$\therefore$ & 7375.9 & 4061.1 & 3928.6 & 0.0802 & 3320.7 & 7375.9 & 4634.0 & 3488.3 \\
\hline$\therefore:$ & 6763.8 & 4046.2 & 3797.6 & 0.0802 & 3277.3 & 6763.8 & 4622.7 & 3469.7 \\
\hline$\therefore$ & 3561.6 & 4010.2 & 3495.1 & 0.0802 & $3 \pm 86.2$ & 5561.6 & 4594.8 & 3425.6 \\
\hline$\therefore 3$ & 2925.3 & 3853.2 & 2494.3 & 0.2087 & 2925.3 & 2802.1 & 4461.8 & $32.44,6$ \\
\hline 12 & FACE & NCTIONI & ed & esults: & & & & \\
\hline$i$ & $\begin{array}{l}2 \mathrm{f} \\
(\mathrm{m})\end{array}$ & $\underset{(\mathrm{m} / \mathrm{s})}{j g}$ & $\begin{array}{l}j g c e f l \\
(\mathrm{~m} / \mathrm{s})\end{array}$ & ratio & & & & \\
\hline-1 & $\cdots-\cdots$ & . & $-\cdots$ & & & & & \\
\hline 0 & 0.0000 & 0.000 & 6.440 & 0.000 & & & & \\
\hline 1 & 0.7926 & 0.000 & 6.440 & 0.000 & & & & \\
\hline 2 & 1.0973 & 0.000 & 6.440 & 0.000 & & & & \\
\hline 3 & 1.4021 & 0.581 & 5.811 & 0.100 & & & & \\
\hline 4 & 1.7068 & 2.338 & 5.811 & 0.402 & & & & \\
\hline 5 & 2.0115 & 3.575 & 5.811 & 0.615 & & & & \\
\hline 6 & 2.1336 & 3.940 & 5.81 .1 & 0.678 & & & & \\
\hline 7 & 2.1641 & 4.01 .9 & 5.811 & 0.692 & & & & \\
\hline 8 & 2.3165 & 4.346 & 5.811 & 0.748 & & & & \\
\hline 9 & 2.6212 & 4.620 & 5.811 & 0.795 & & & & \\
\hline 10 & 2.9259 & 4.376 & 5.811 & 0.753 & & & & \\
\hline 11 & 3.2307 & 3.694 & 5.811 & 0.636 & & & & \\
\hline 12 & 3.5354 & 2.598 & 5.811 & 0.447 & & & & \\
\hline 23 & 4.3280 & 0.000 & 5.811 & 0.000 & & & & \\
\hline slot & 4.3280 & 0.000 & 5.663 & 0.000 & & & & \\
\hline
\end{tabular}




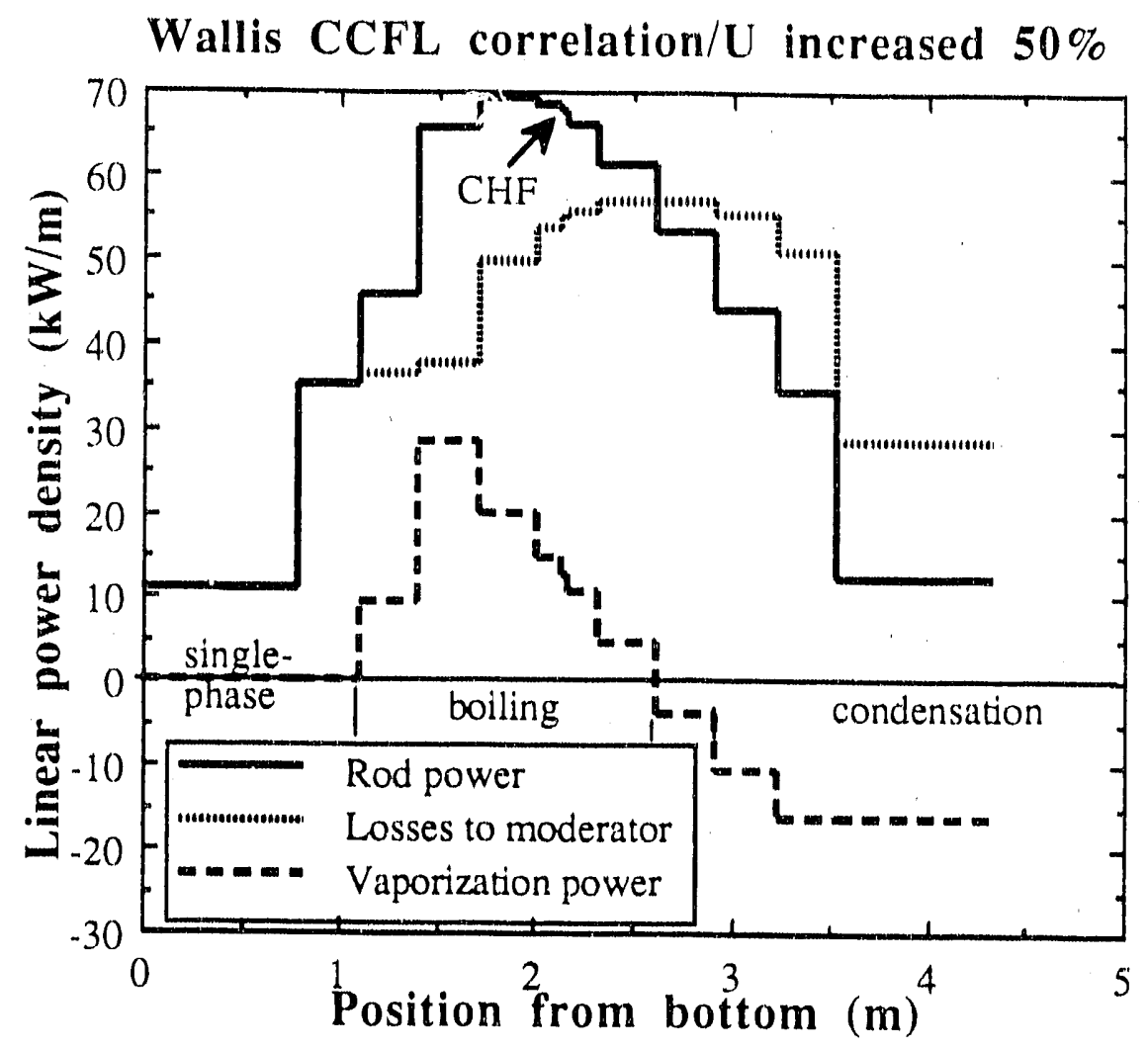

Figure 19 Linear power generation and dissipation as a function of axial position. 


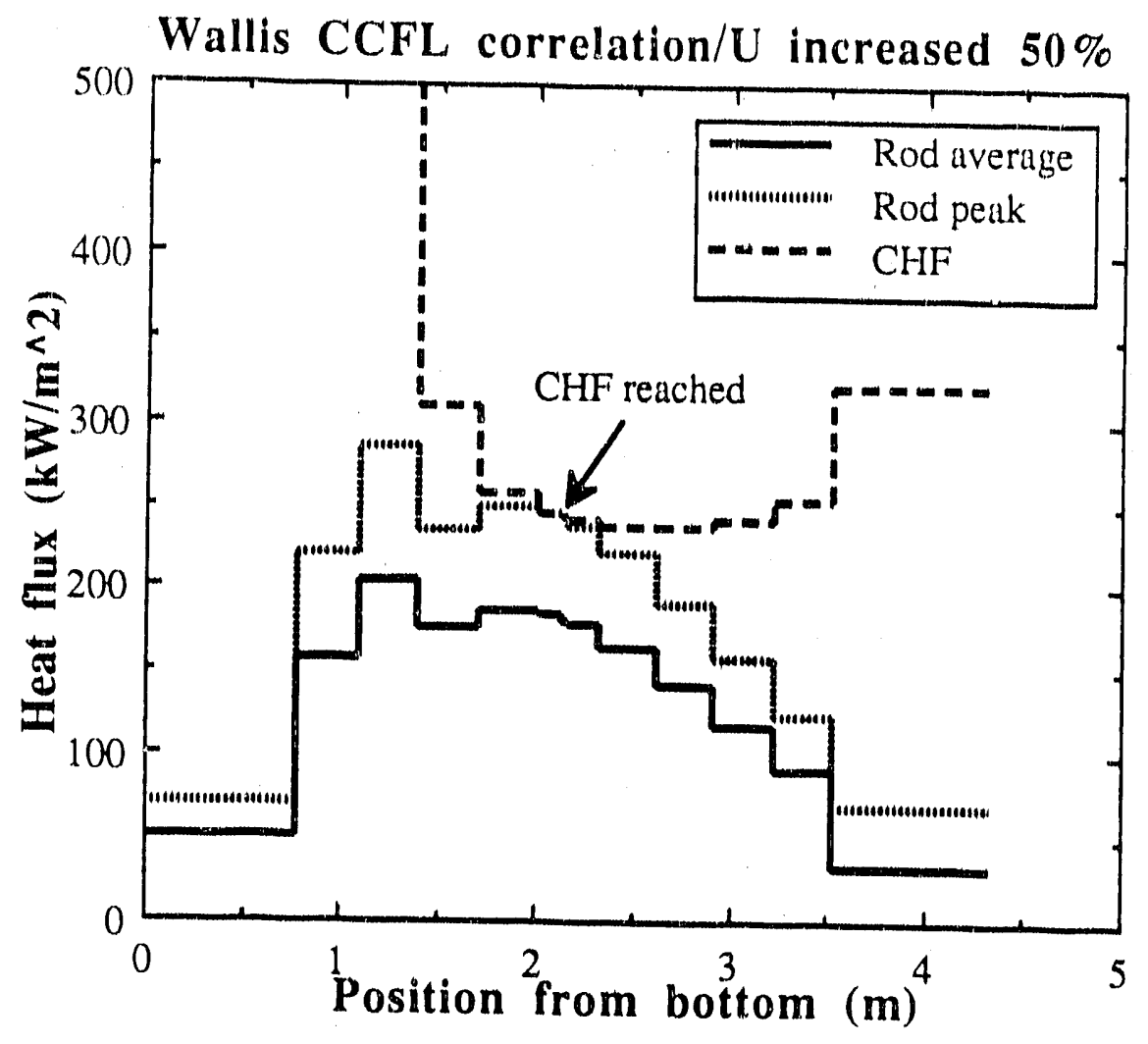

Figure 20 Heat fluxes as a function of axial position. 


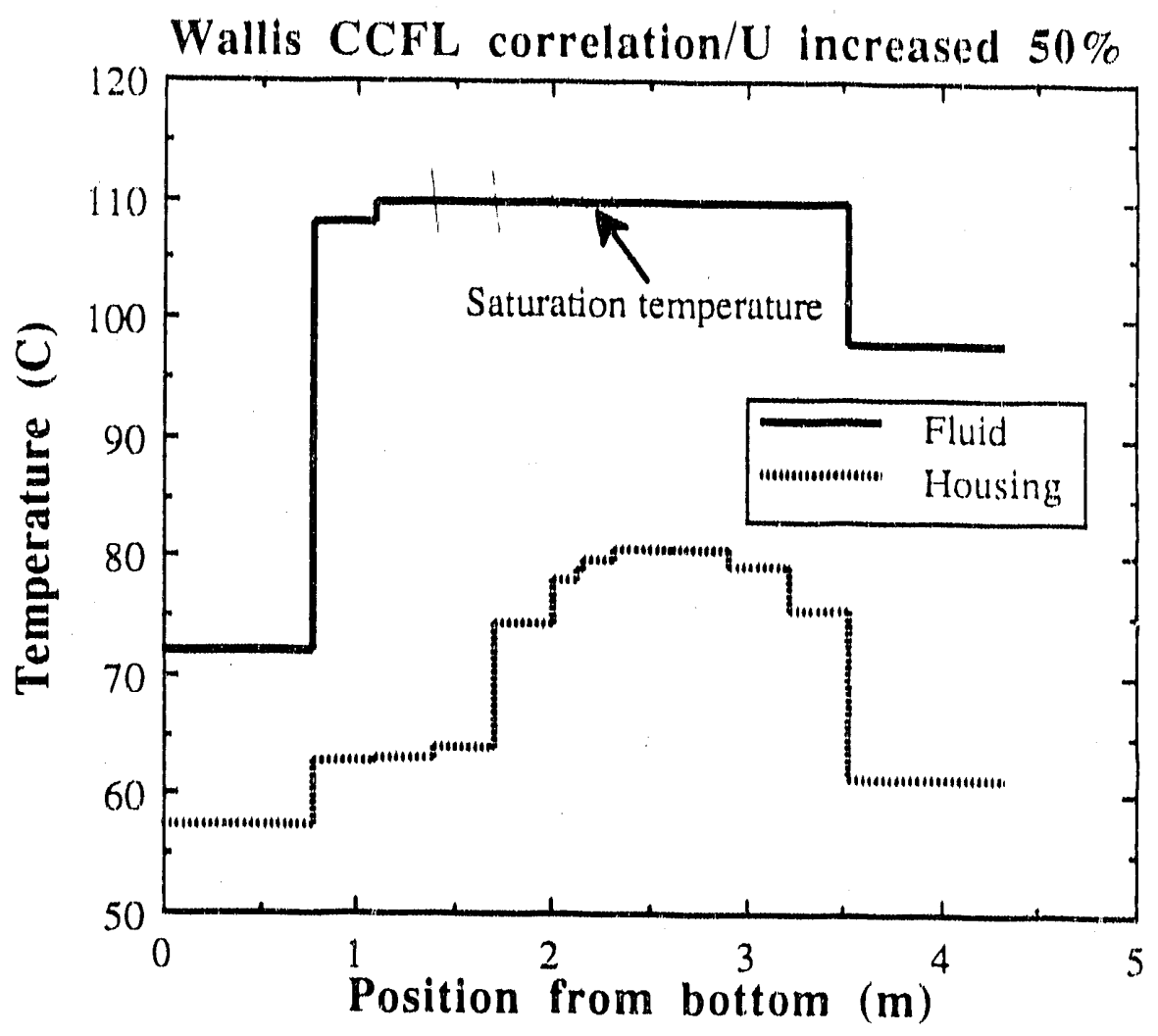

Figure 21 Internal fluid and housing temperature as a function of axial position. 


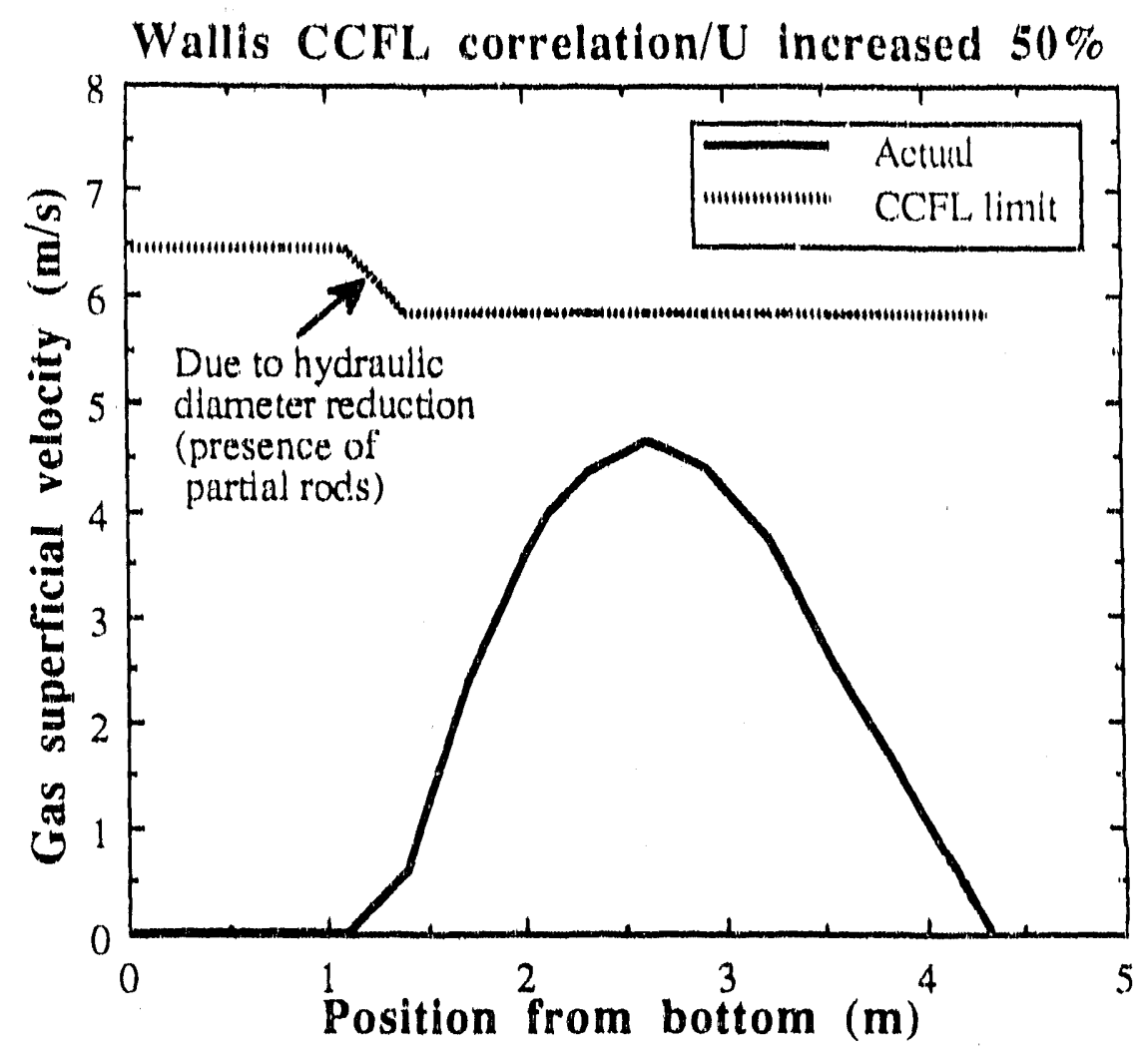

Figure 22 Gas superficial velocities as a function of axial position.

Limitations of the results: The scoping analysis and results just presented have a significant uncertainty because

- dynamic effects have not been considered (steady-state analysis)

- a detailed subchannel analysis was not performed

- the basis for the internal heat transfer coefficient is weak

- the computed external heat transfer coefficient is significantly lower than the value given in Mark 22 hydraulics manual

- a CCFL correlation verified to be applicable to the exact septifoil geometry was not used (not available to my knowledge)

Therefore the results presented in this report should be used with appropriate caution. 


\section{Summary}

The best-estimute maximum septifoil power for a $26,2^{\circ} \mathrm{C}$ cooling water inlet temperature is 119 to $141 \mathrm{~kW}$. The corresponding reactor powers are 648 and $768 \mathrm{MW}$ or 27 and $32 \%$ of $24(0) \mathrm{MW}$. These estimates are based on a simple scoping unalysts and have a large uncertalnty.

\section{References}

Boswell, J. M, 1974, "Hydraulies and Heat Transfer of Mark 22 Fuel Assemblies", DPSTM-22(H), p. IV-13.

- Bornt, F. W., 1991, "Septifoll Cross-sectional Areas and Hydraulic Diameters", Calc-Note SRL-SAG-910120.

- Brown, R., 1991, "Septlfoil Assembly Heat Generation Rates", Calc-Note SRL-SAG-91-9051.

Carteton, J. T., 1959, "Complete Pile Engineering Division Monthly Report - June 1959", DPST-59-13-6, Figure 7.

Colller, J. G., 1972, Convective Boiling and Condensation, McGraw-Hill, London.

Drawing ST-MDX5-10072, "Outer Housing Tube Machining".

Griffith, P., Pearson, J. F., and Lepkowski, R, J., 1977, "Critical Heat Flux During a Loss-of-Coolant Accident", Nuclear Safoty 18, pp. 298-305.

Ishii, M., 1977, "One-Dimensional Drift-Flux Model and Constitutive Equations for Relative Motion Between Phases in Various Two-Phase Flow Regimes", Argonne National Laboratory Report ANL-77-47.

Kakac, S., Shah, R. K., and Aung, W., 1987, Handbook of Single-Phase Convective Heat Transfer, Wiley, New York.

Lahey, R. T., Jr., and Moody, F., J., 1977, The Thermal Hydraulics of a Boiling Water Reactor, American Nuclear Society.

Lienhard, J. H., 1988, "Burnout on Cylinders", J. Heat Transfer 110, pp. 1271-1285.

Lienhard, J. H., and Dhir, V. K., 1972, "Hydrodynamic Prediction of Peak Pool-Boiling Heat Fluxes from Finite Bodies", ASME paper 72-WA/HT-10, American Society of Mechanical Engineers.

Mertz, S, M., 1990, "Cooling Water Inlet Temperature (U)", WSRC-TR-90-42-147.

Osakabe, M., and Kawasaki, Y., 1989, "Top Flooding in Thin Rectangular and Annular Passages", Int. J. Multiphase Flow 15, pp. 747-754. 
Ransom, V. H. Wagner, R, J., Trupp, J, A., Feinumer, L, R, Johnsen, G, W., Kiser, D. M., and Rlemke, R. A., 1985, "RELAP5/MOD2 Code Manual - Volume L: Code Structure, Systems Models, and Solution Methods", NUREG/CR-4.312 \& EGG-2396.

Rolisenow, W, M., Harnetl, J, P., and Ganic, E. N., 1985, Handbook of Heat Transfer Finndamentals, 2nd edition, MoGraw-Hill, New York, ch. 12, p. 38.

Shadday, M. A., Jr., 1989, "The Impact of Cavitation During a DEGB LOCA, With Uncertninties (U)", WSRC-TR-89-1313, Appendix A.

Walkush, J, P., and Griffith, P., 1975, "Counterflow Critical Heut Flux Related to Reactor Trunsient Analysis", EPRI-292-2, Interim Report, Electrical Power Research Institute.

Whalley, P, B., 1987, Boiling, Condensation, and Gas-Liquid Flow, Clarendon Press, Oxford.

Zuber, N., 1959, "Hydrodynamic Aspects of Boiling Heat Transfer", Ph.D. thesis, UCLA, Los Angeles, CA (also available as AECU.4439 Physics and Mathemsatics).

Zuber, N., and Findlay, J. A., 1965, "Average Volumetric Concentration in Two-Phase Flow Systems", J. Heat Transfer 87, pp. 453-468. 


\section{Appendix}

\section{FOIL.FOR}

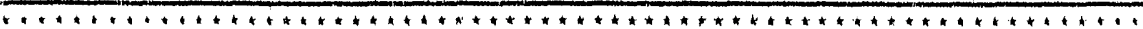

.

- $10 i 2, \because 0 \%$

$11 / 12 / 91$ i. P, Fin:

real ja, fgold, jacotl, jgslot, foflde, fgava

paramoter laero=0,0, g=9,80665, ctok $=273,15$, patm $=101325,0)$

parameter $(n a=100)$

dlmenslon pshape(na), nrodh(na), prod(na), qrod(na), alp(na),

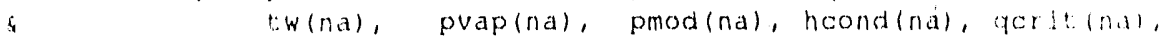

arod(na), aw(na), pkfac(na), $\operatorname{hmod}(11), 4(n a)$,

hoondl(na), hoond? (na), hmodl(na), hmod? (na).

$d z(0: n a), \quad a c(0: n a), \quad t e(n a+1)$

$c$

dimension 2 f $(0: n a), \operatorname{nrod}(0: n a), \quad$ ac $(0: n a)$, jg(0:na),

a dh(0:na), de(0:na), ecfim(0:na), cofle $(0: n a)$,

data $z c(0) / 0.0 \%, d z(0) / 0.0 /, z t(0) / 0.0 /, \operatorname{tgccf} 1(0) / 0.0 /$.

\& eps/0.0001\%, epsalp/0,00001/, eps fg/0,0001/, epstw/0.001/,

C epst: $/ 0.001 /$

$p i=\operatorname{acos}(-1,0)$

do $51=1$, na

$h \bmod 1(1)=0.0$

$\operatorname{hmod} 2(1)=0.0$

heond $1(1)=0.0$

hoond? (1) $=0.0$

cont lnue

READ ITERATION CONTROL PARAMETERS

read $(5, *)$, itrmax

READ CELL CENTER INEORMATION

$\mathrm{suml}=0.0$

sum2 $=0.0$

read $(5, *) n z, z 1$, drod, dw, sp, rpovsp

do $101=1, n z$.

reaci(5,*) Junk, dz(1), pshape(1), nrodh (1), pkfac(1)

$s u m L=s u m l+d z(1)$

sum? s surn? + dz(1) *pshape(1)

(0) continue

RENORMALIZE POWER SHAPE:

pnorm $=54 m 1 / 34 m 2$

do $201=1, n z$

$d z(1)=d z(i) /$ sum 1

pshape(i) * pshape(1) * prorm

$z f(1)=z f(1-1)+d z(L)$

$z c(1)=0,5 *(z t(1-1)+z f(1))$

20 continue

READ CELA FACE INFORMATION 


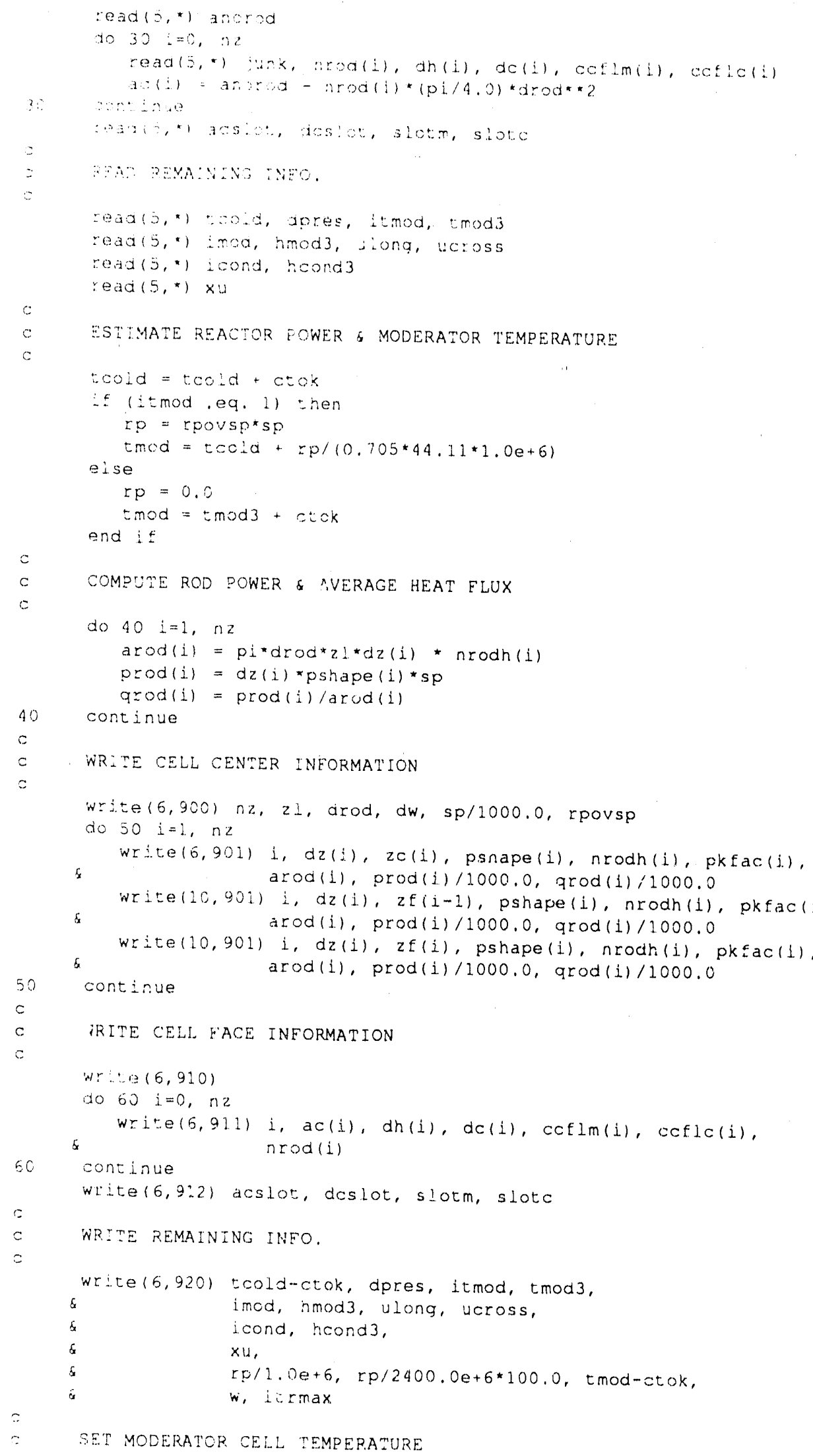




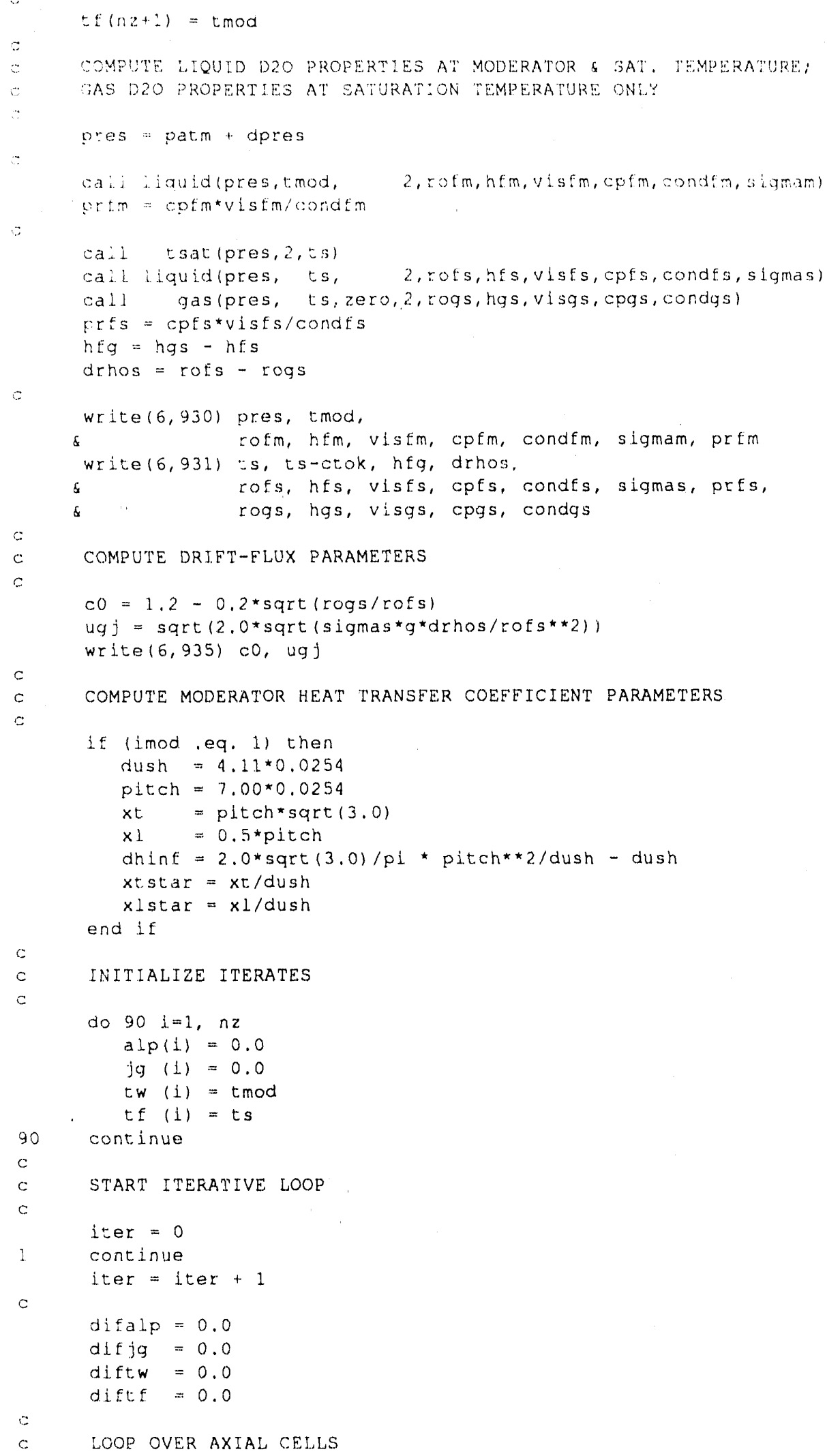




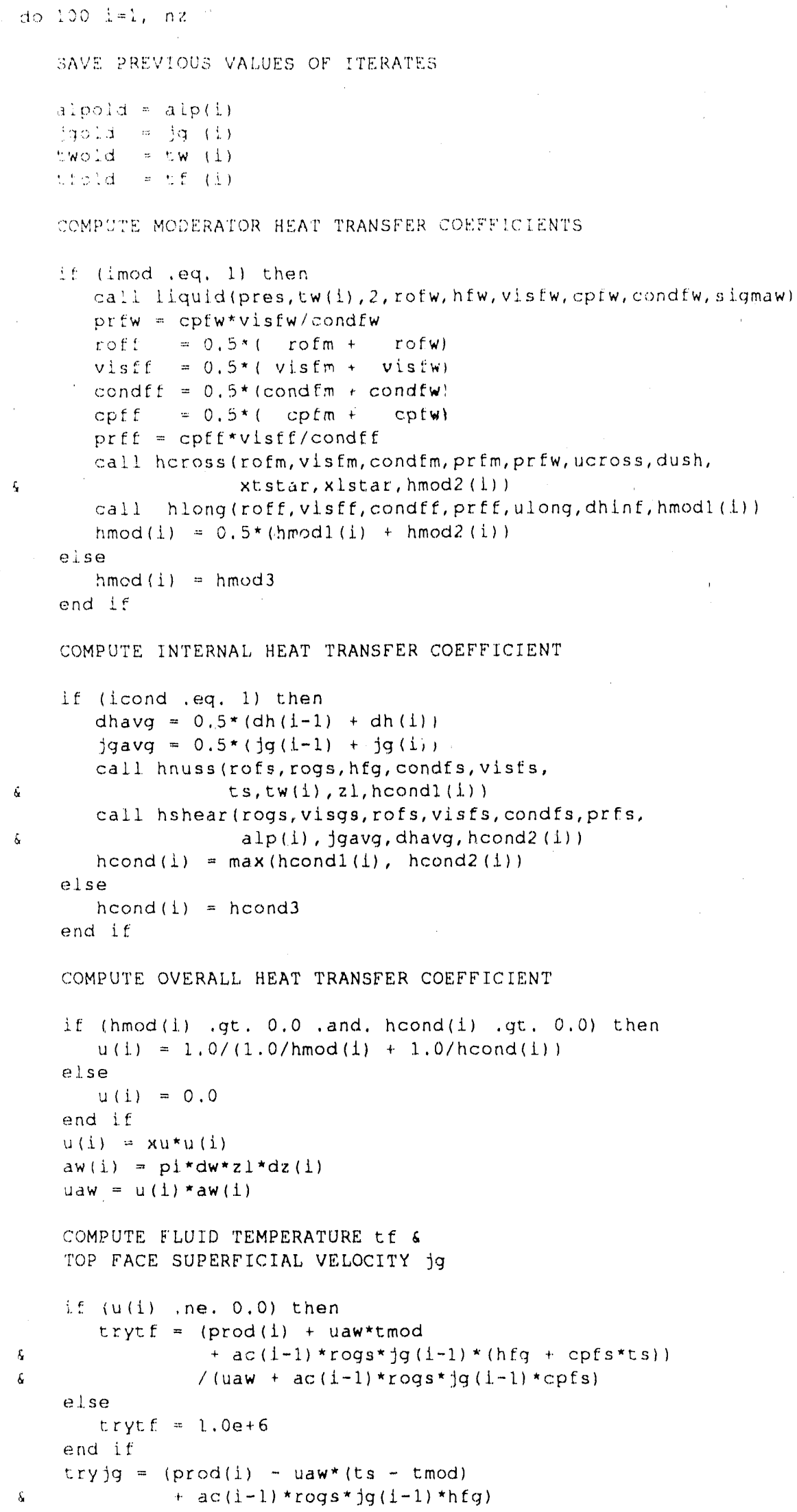




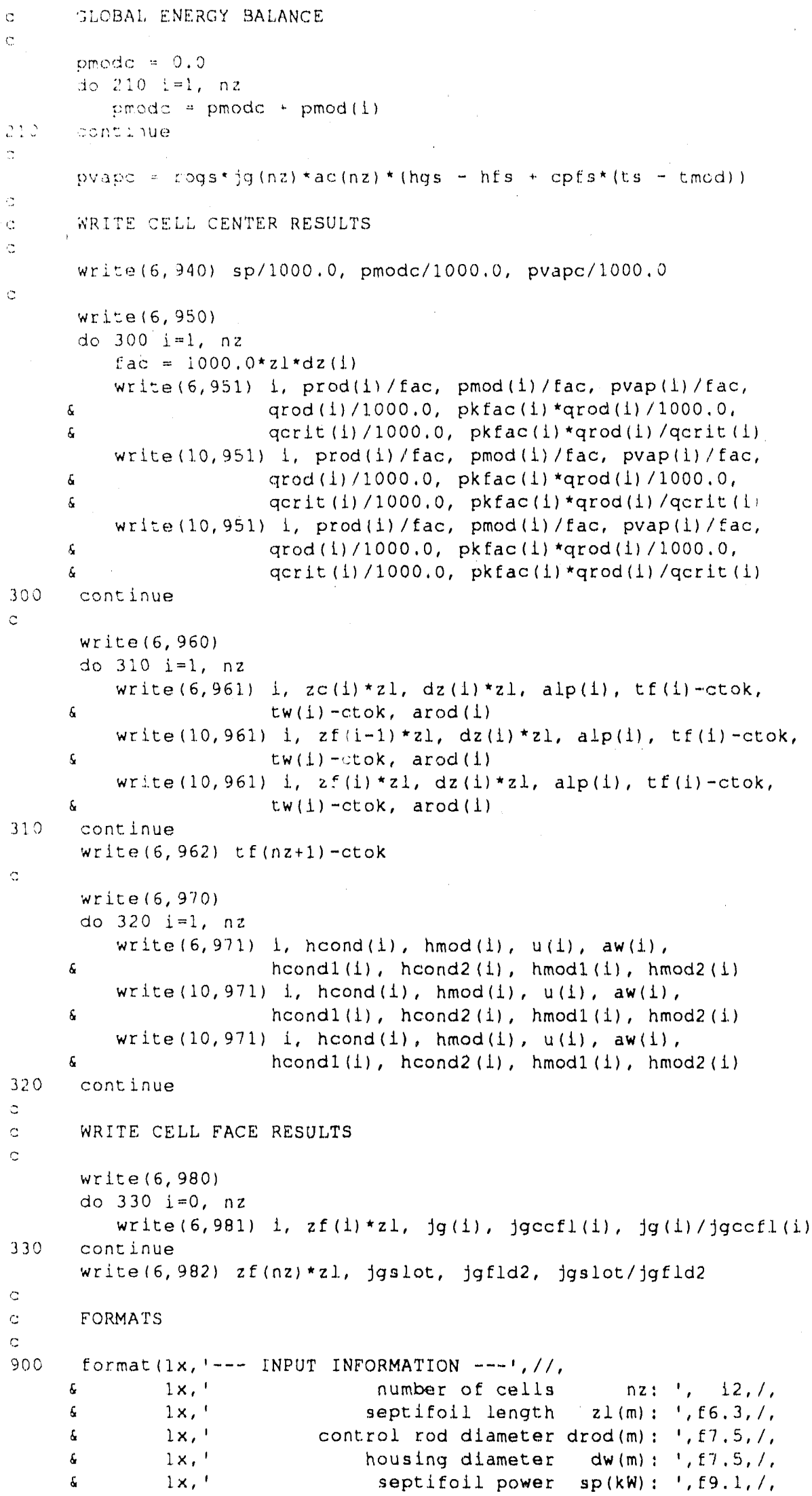




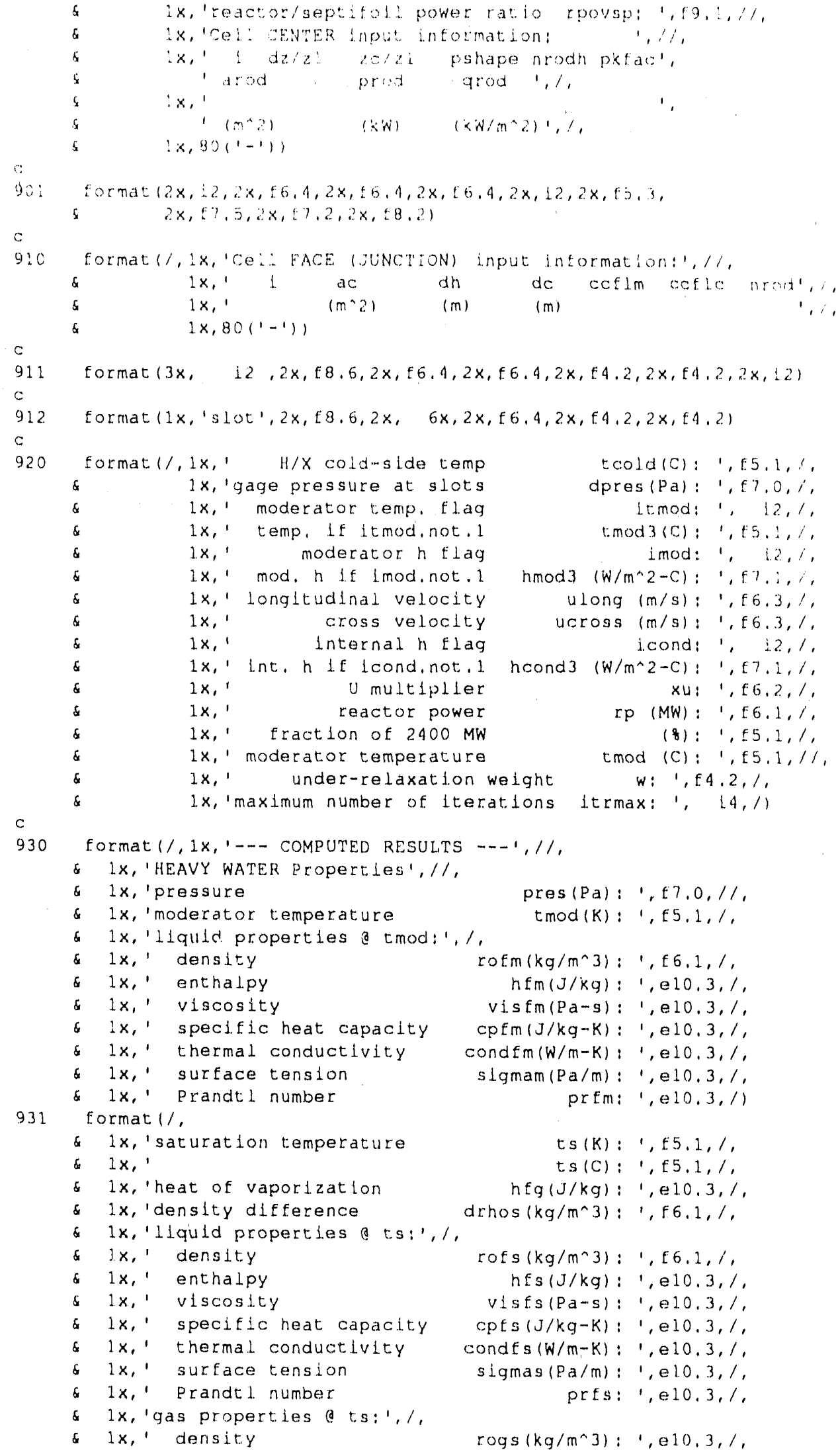




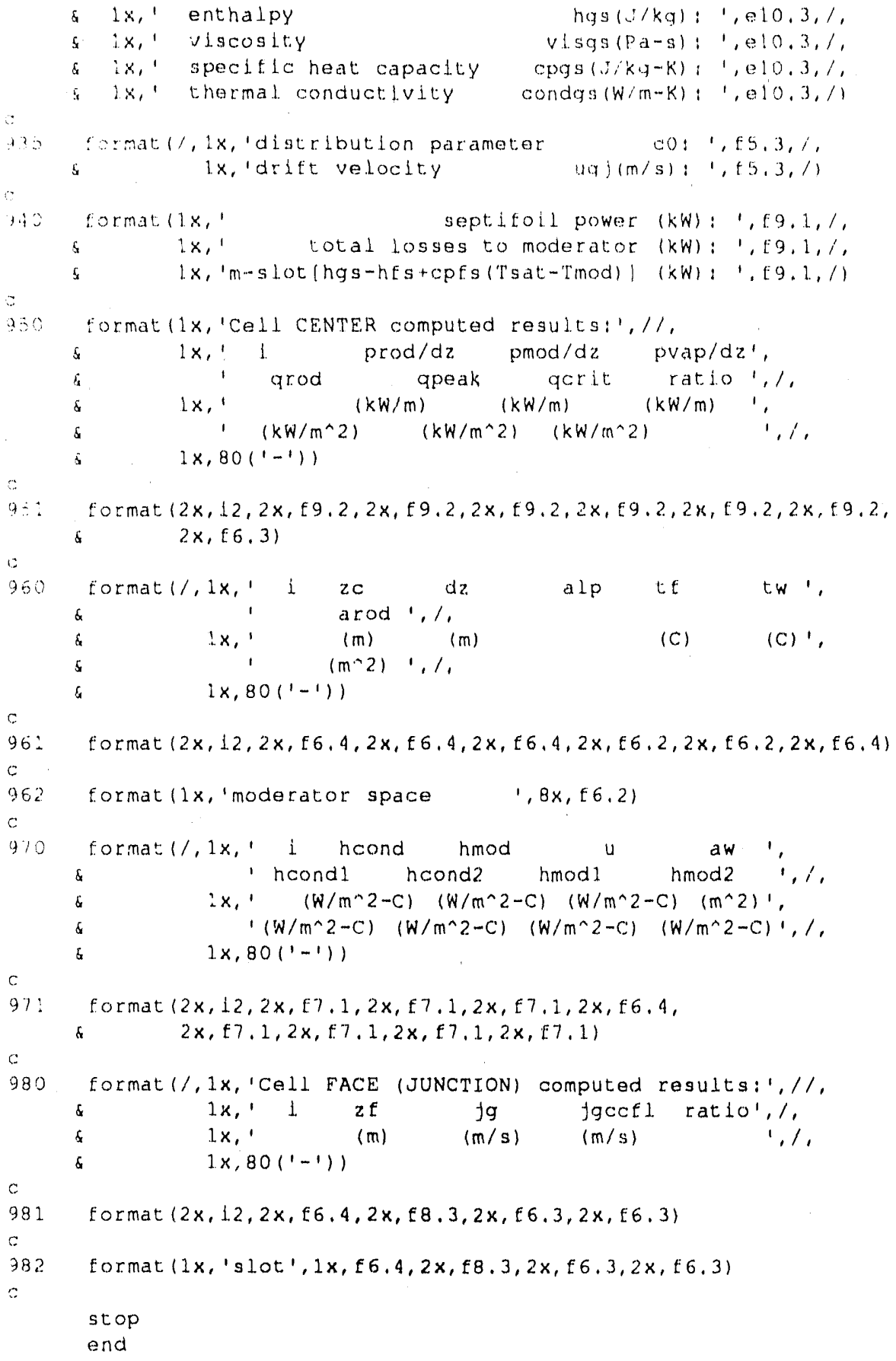

\section{HCROSS.FOR}

subrout ine heross(rho, vis, cond, pr, prw, u, d, xtstar, xlstar.

$\&$

real nu

re $=r h o * u^{*} \mathrm{~d} / \mathrm{vis}$

if (re.1t. 1.0 or. re.gt. 2,0e+6) then

write (*,900) re

stop 


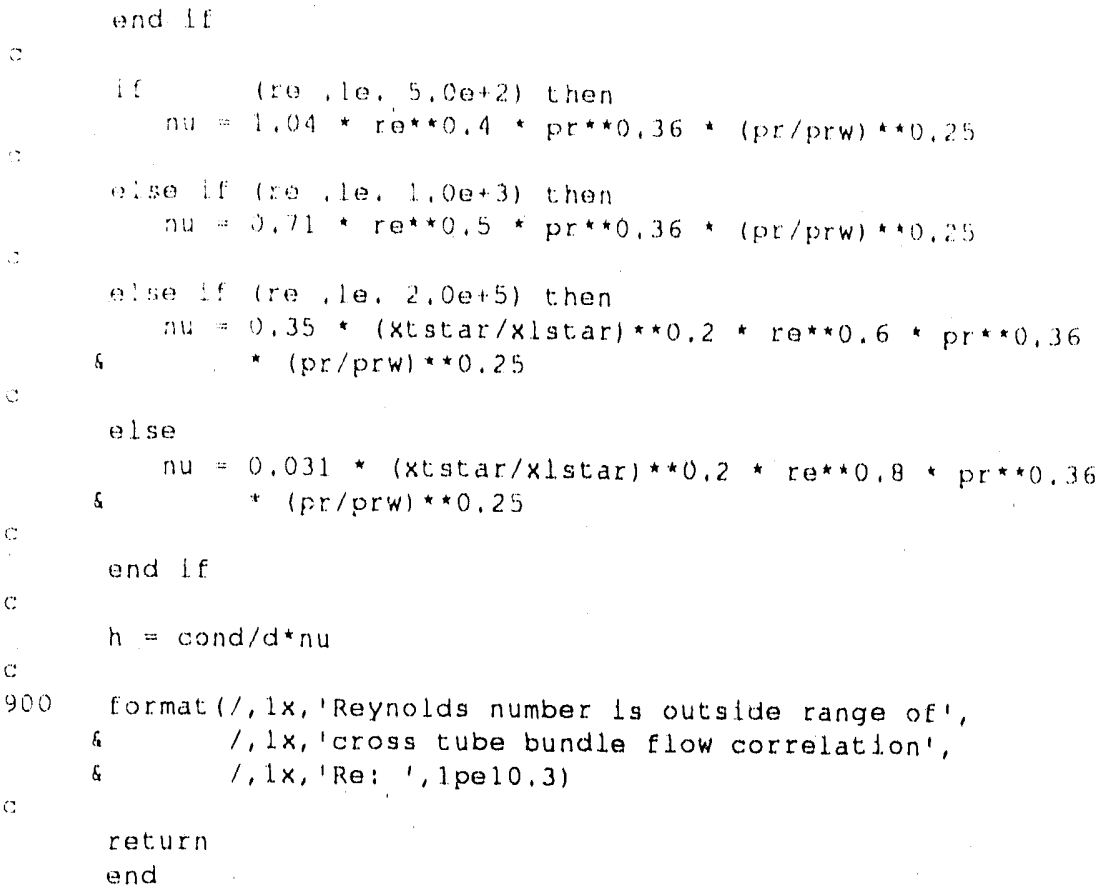

\section{HLONG.FOR}

a

subroutine hlong(rho, vis, cond, pr, $u$, dh,

real nut

$r e=r h o^{*} u^{\star} \mathrm{dh} / \mathrm{v}$ is

Lf (re.1.t. $4.0 e+3$.or. re.gt. 6.0e+5) then write $(*, 900)$ re stop

end if:

$c$

fover2 $=0.5 /(3.64 * \log 10($ re $)-3.28) * 2$

$h_{1}=1.07+900.0 / \mathrm{re}-0.63 /(1.0+10.0 * \mathrm{pr})$

nut $\Rightarrow$ Eover $2 * r e^{\star} \operatorname{pr} /(h 1+1.2 .7 * \operatorname{sqrt}($ fover 2$) \star(\operatorname{pr} \star \star(2.0 / 3.0)-1.0))$

ht $=$ cond $/ d h^{*}$ nut

$h=1.15 * h t$

format $(/, 1 x$, 'Reynolds number is outside range of 1 ,

\& $/, 1 x$, 'longltudinal tube bundle flow correlation'.

\& $\quad(, 1 \times$, Re: 1,1 pe 10,3$)$

return

end

\section{HNUSS.FOR}

subroutine hnuss (rof, rog, hfg, condf, visf, tsat, tw, $x$.

8 h)

$c$

parameter $(g=9.80665)$ 


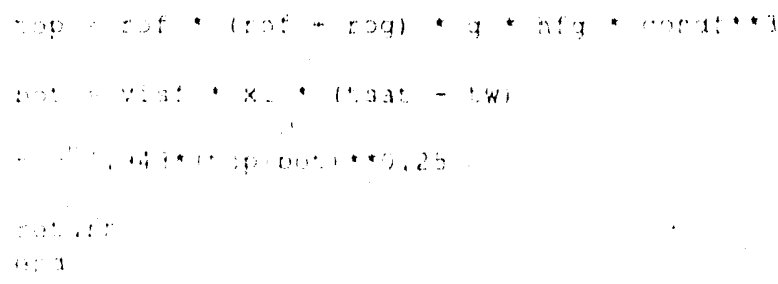

\section{HSHEAR.FOR}

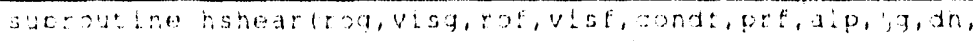
ก)

trian: as

$61: \quad 1$

$\therefore \theta=\operatorname{rog} \cdot z * d h / v i g q$

$\therefore=\tan (e \operatorname{ses}, \operatorname{ros}$

$\therefore=9.079: 0 \times 2.25$

$: \vdots=t g *(2.2+75,0 *(1.0-\max (0.75, a . p) 1)$

$\because a u=f i=10.5 * 20 g * \operatorname{tg} * 21$

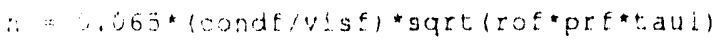

$\because a n+a$

a)

\section{GAS.FOR}

subroutine gas (p, $5 g, x a, m, r o g, i n g, v i s q, c p g, c o n d g)$

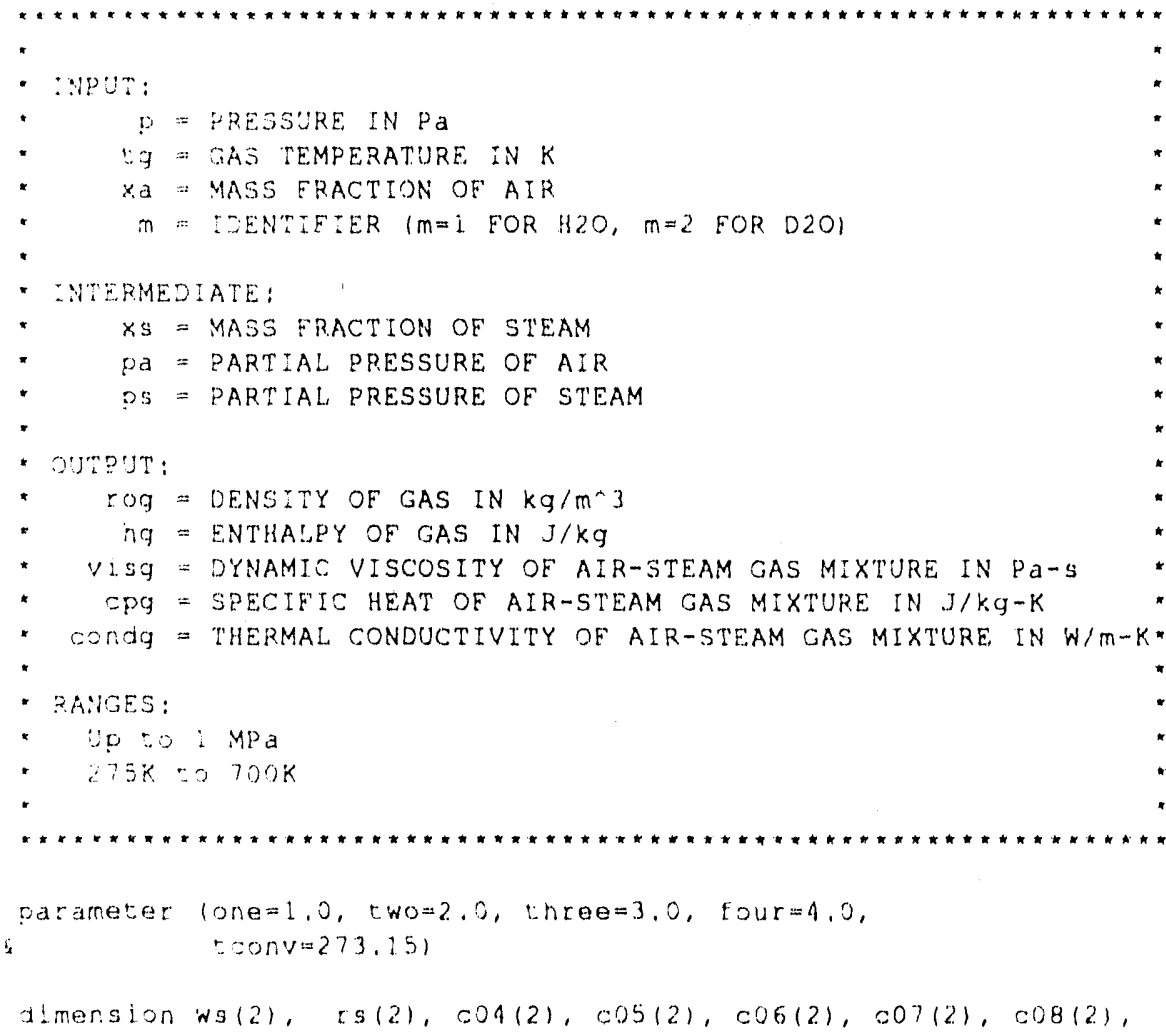




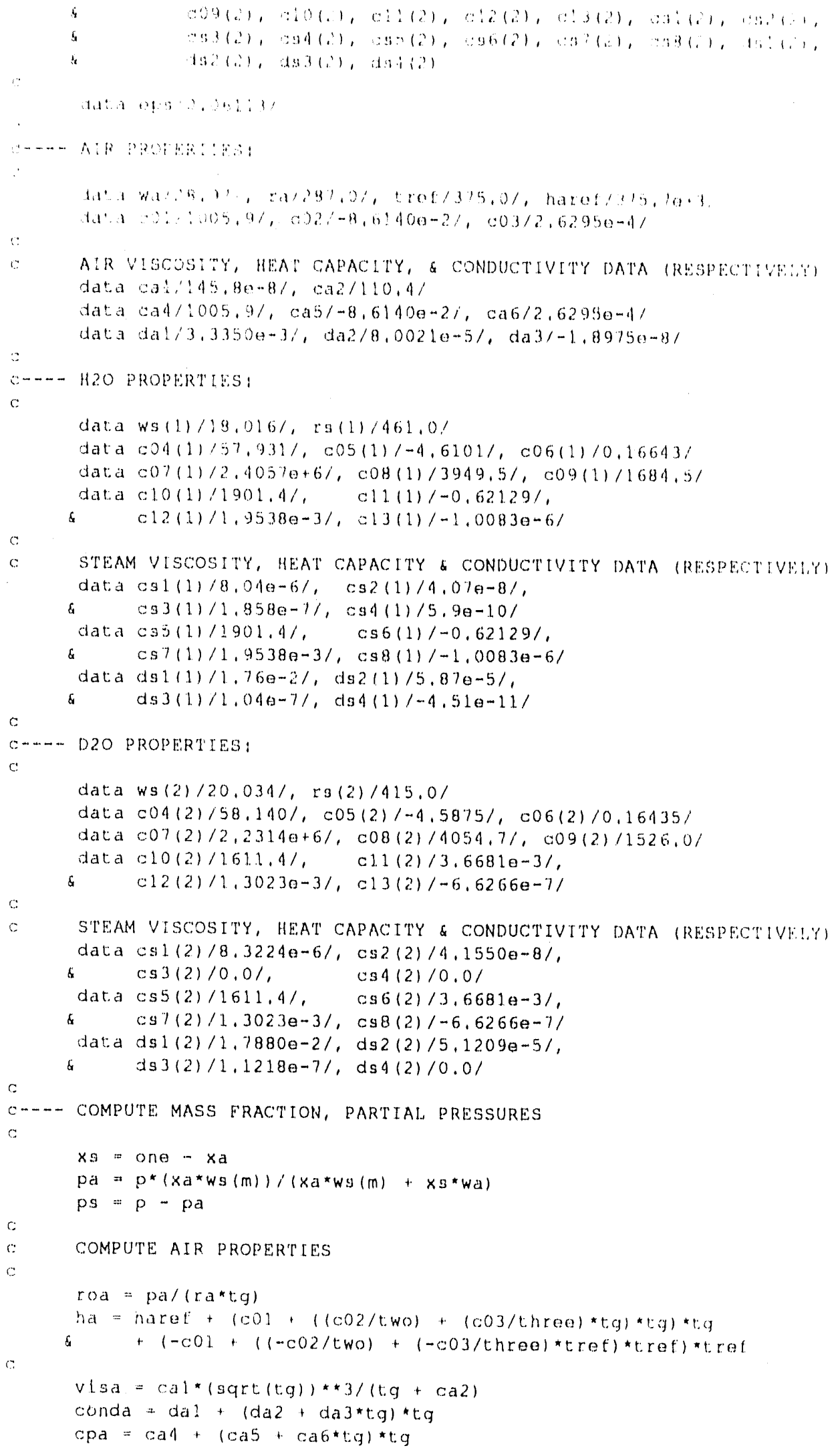




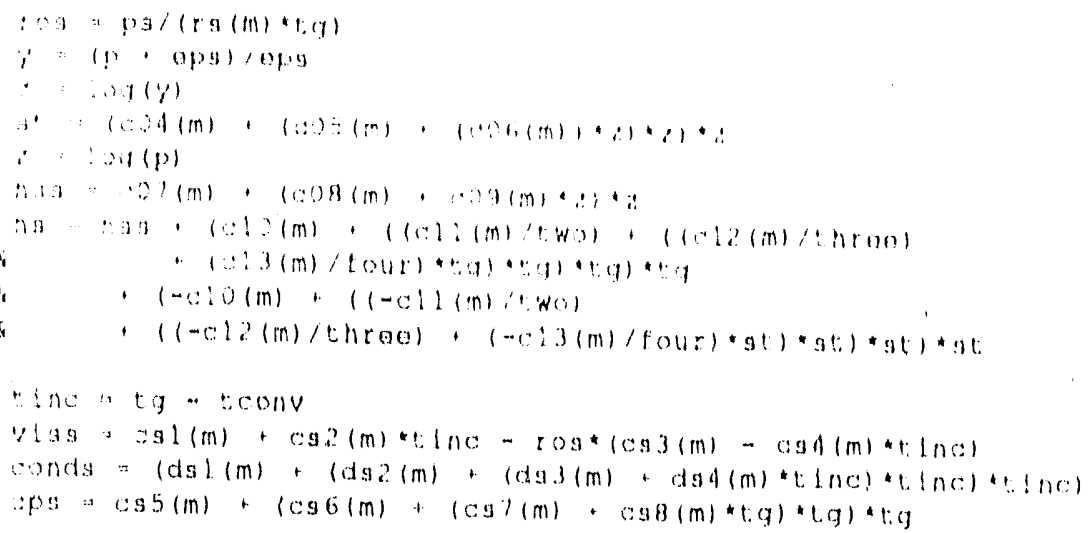

COMPUTE GAS PROPERTLS

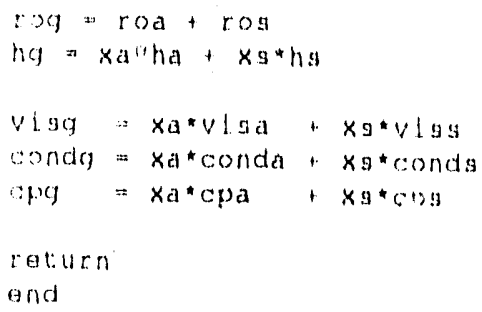

\section{LIQUID.FOR}

subrout lne liquld(p,tt,m, rot, ht, vist, cpf, condt, sloma)

,

- InPuT

- p a pressure in pa

* ti a liquto temperature te k

* in = IDENTIFIER $(m=1$ FOR H2O, mm2 fOR D2O

* outputi

" rot DENSITY OF LIQULD IN kg/m^3

he: = ENTHALPY OF LIQUID IN J/kg

VIEt " DYNAMIC VISCOSITY OF SATURATED LIQUID H2O IN Pa S

CPF SPECIFIC HEAT OF SATURATED LIQUID $1120 \mathrm{IN} \mathrm{J/Kg-K}$

condf a thERMal CONDUCTIVITY OF SATURATED LIOUTD HzO

slgma a SURFACE TENSIDN OF LIQULD H2O iN $\mathrm{N} / \mathrm{m}$

- RANCES

* Up to $1 \mathrm{Mpa}$

* $275 \mathrm{~K}$ to $150 \mathrm{~K}$

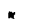

parameter $(t: w o=2.0$, t.conve $=27.3 .15)$

dimenalon drhodp (2), col(2), c02(2), co3(2), con(2), cos(2),

\& $\quad 06(2), \cot (2), \cos (2), \operatorname{cog}(2), \mathrm{c} 10(2), \mathrm{c} 1(2), \mathrm{c} 12(2)$,

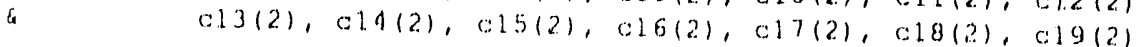

H.NO PROPERTIES

data drhodp (1)/4.580-7) 


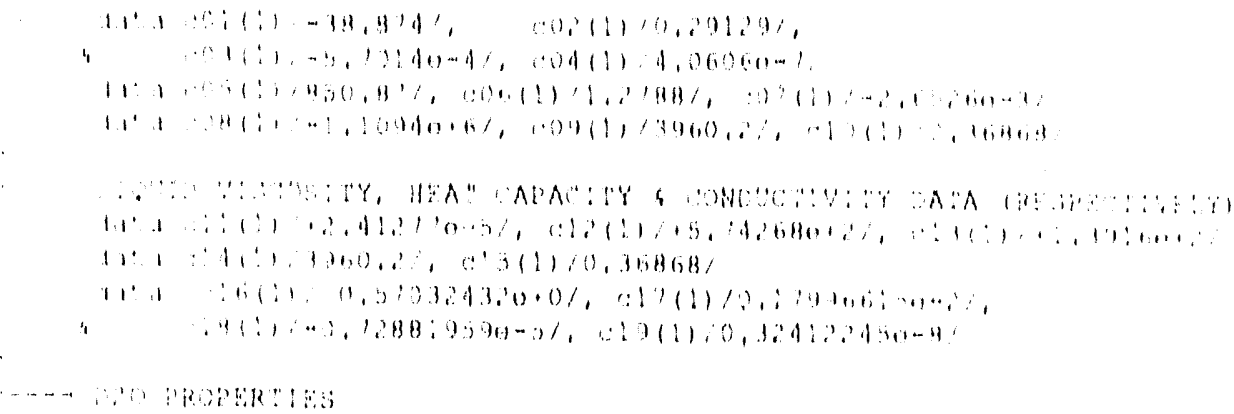

\section{TSAT.FOR}

subrout: the tiat: $(p, m, t s)$

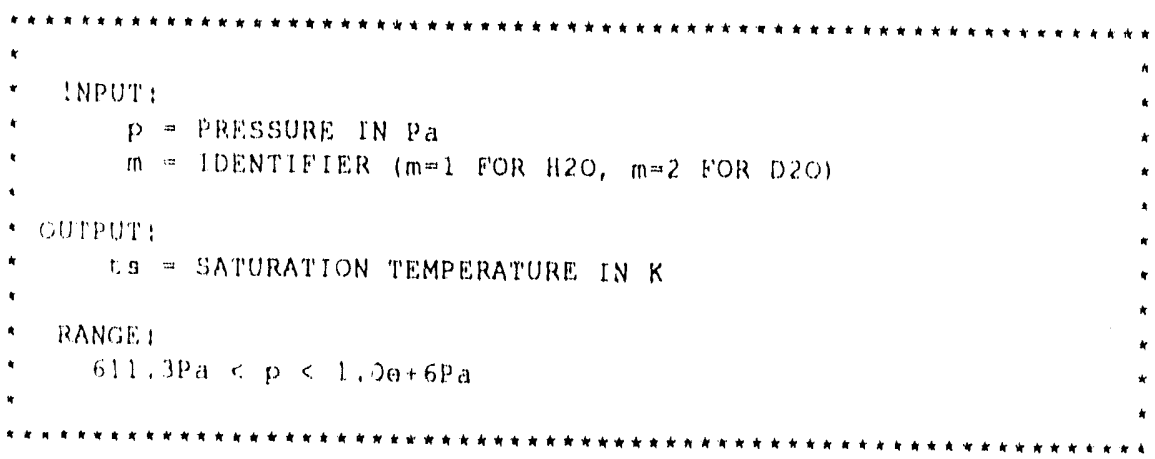




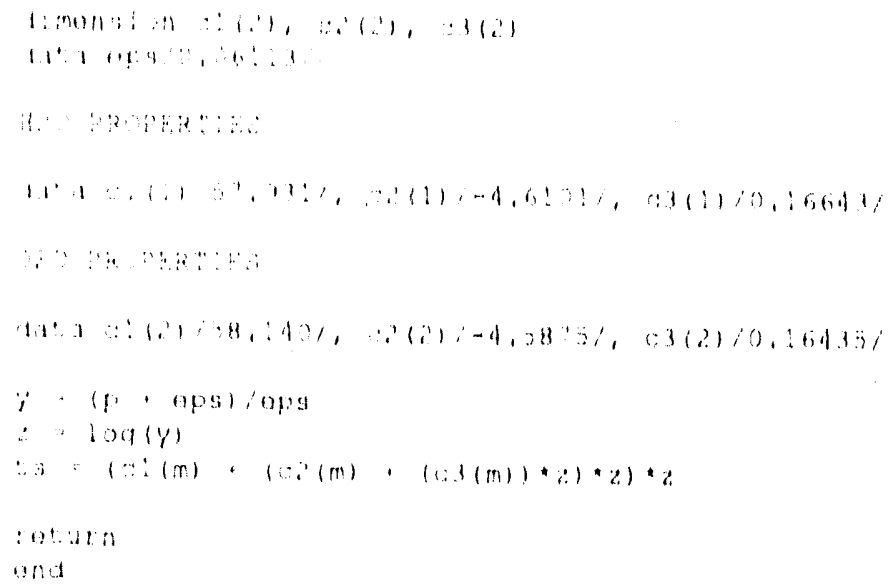



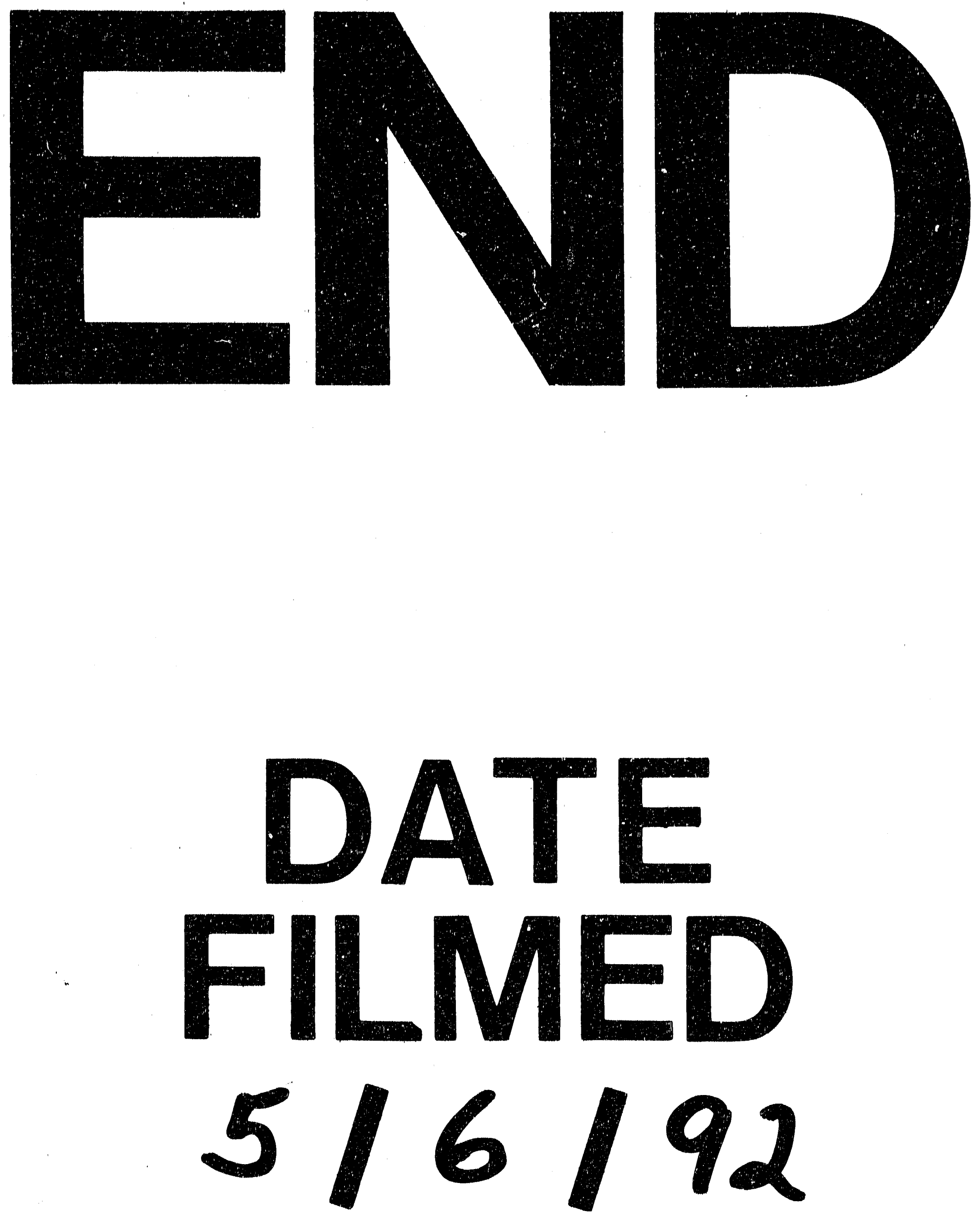

I 